\title{
Global emergency remote education in secondary schools during the COVID-19 pandemic
}

\section{A SYSTEMATIC REVIEW}

Melissa Bond, Nina Bergdahl, Rosa Mendizabal-Espinosa Dylan Kneale, Faye Bolan, Poppy Hull, Fjolla Ramadani

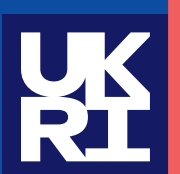

Economic and Social Research Council 


\section{Global emergency remote education in secondary schools during the COVID-19 pandemic: A systematic review}

Authors:

Melissa Bond, Nina Bergdahl, Rosa Mendizabal-Espinosa, Dylan Kneale, Faye Bolan, Poppy Hull, Fjolla Ramadani

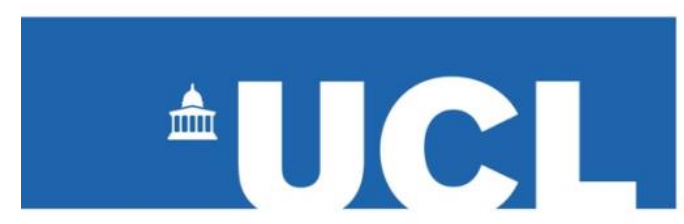

EPPI Centre Evidence for Policy \& Practice 


\section{Author affiliations}

- Melissa Bond, EPPI Centre, UCL Social Research Institute

- Nina Bergdahl, Department of Computer and Systems Sciences, DSV, Stockholm University

- Rosa Mendizabal-Espinosa, EPPI Centre, UCL Social Research Institute

- Dylan Kneale, EPPI Centre, UCL Social Research Institute

- Faye Bolan, EPPI Centre, UCL Social Research Institute

- Poppy Hull, EPPI Centre, UCL Social Research Institute

- Fjolla Ramadani, EPPI Centre, UCL Social Research Institute

\section{Funding \& funder involvement}

This review was undertaken by the EPPI Centre as a partner of the International Public Policy Observatory (IPPO) (https://covidandsociety.com) which is ESRC-funded.

\section{Conflicts of interest}

There were no conflicts of interest in the writing of this report.

\section{Contributions}

The opinions expressed in this publication are not necessarily those of the EPPI Centre or the funders. Responsibility for the views expressed remains solely with the authors.

This report should be cited as: Bond M, Bergdahl N, Mendizabal-Espinosa R, Kneale D, Bolan F, Hull P, \& Ramadani F (2021). Global emergency remote education in secondary schools during the COVID-19 pandemic: A systematic review. London: EPPI Centre, UCL Social Research Institute, University College London.

Design and editorial support by: Lionel Openshaw

ISBN: 978-1-911605-26-3

\section{Copyright 2021}

Authors of the systematic reviews on the EPPI Centre website (http://eppi.ioe.ac.uk/) hold the copyright for the text of their reviews. The EPPI Centre owns the copyright for all material on the website it has developed, including the contents of the databases, manuals, and keywording and data-extraction systems. The centre and authors give permission for users of the site to display and print the contents of the site for their own non-commercial use, providing that the materials are not modified, copyright and other proprietary notices contained in the materials are retained, and the source of the material is cited clearly following the citation details provided. Otherwise, users are not permitted to duplicate, reproduce, re-publish, distribute, or store material from this website without express written permission. 


\section{Foreword}

IPPO is pleased to publish our first systematic review. This work has given us the opportunity to review an area of evidence in depth and explore an issue fully from a number of angles. Our intention is that the review is a resource for those with interest and need in learning more about how online and distance learning occurred during the COVID-19 pandemic, providing insight and guidance for future periods when teaching and learning have to take place online. We also hope it will be a useful input into future decision making. In addition to systematic reviews, IPPO is undertaking Rapid Evidence Reviews and producing a range of other outputs. Please see our website for more information.

\section{Professor Joanna Chataway}

Principle Investigator

International Public Policy Observatory 


\begin{abstract}
The worldwide shift to emergency remote education in 2020 as a result of the COVID-19 pandemic impacted billions of students and teachers. A range of teaching and learning strategies were employed by schools as a result, despite confusing and sometimes contradictory government guidance, with systemic issues such as equity and access impacting heavily on disadvantaged students. In light of the findings of a recent IPPO evidence snapshot and roundtable event, and in order to gain further insight into how emergency remote education was experienced by secondary school students, parents and educators, a systematic review was conducted that collates and synthesises primary empirical studies across five key research questions focusing on student engagement, online assessment, peer collaboration, parent engagement, and future directions for online learning. Studies were searched for in May 2021 using Web of Science, Scopus, ERIC, Microsoft Academic Graph, ResearchGate and the COVID-19 living map, and were included if they focused on teaching and learning using blended or online approaches in secondary schools during the pandemic, that were published in English. Following quality assessment on scope and methodological rigour, 81 studies were included for narrative synthesis. The research studies were conducted in 38 countries, with $37 \%$ of studies from low or lower-middle income countries, and $63 \%$ from upper-middle income or high-income countries. Most of the evidence came from students (64\%), followed by teachers (53\%), with very few studies exploring the perceptions and experiences of parents $(6 \%)$ or school leaders $(5 \%)$. Findings reveal that self-regulation and understanding were the most frequently reported indicators of student engagement, with online assessment tools, learning management systems with collaborative tools, live synchronous lessons with peer and teacher interaction, and teacher-made videos considered particularly engaging. Social isolation was the most frequently reported indicator of disengagement, characterised by poor attendance in live lessons, a lack of opportunities to seek help with challenges and difficulties facilitating peer collaboration. Although many articles reported that assessment online was particularly challenging, 21 different types of online assessments strategies were identified, with online quizzes and formative online feedback the most frequently used. Live marking or recorded feedback and assessment were found to be particularly beneficial, as providing feedback during live lessons was sometimes challenging. Peer collaboration was facilitated through peer assessment, inquiry-based group work and experiments, aided by the use of collaborative software and combining multiple applications. Parental involvement and support contributed to student learning, although issues of equity impacted the extent to which they could engage with their children's learning, alongside gaps in family content knowledge and technological skills. Numerous implications for future policy relating to online and blended learning are provided.
\end{abstract}




\section{Contents}

Executive Summary __ 8

The issue of concern ___ 8

How did we find this research?

Findings and recommendations

Finding 1: Use of technology during the pandemic __ 8

Finding 2a: Student engagement and motivation 29

Finding 2b: Student disengagement and demotivation __ 9

Finding 3: Emerging online assessment practices___ 10

Finding 4: Approaches to peer collaboration _ـ 10

Finding 5: Parent engagement __ 11

Conclusions ___ 12

Background___ 13

Rationale for the review ___ 14

Positionality ___ 14

Objectives__ 15

Method___ 15

Search strategy and selection procedure

Search string _ 16

Inclusion/exclusion criteria __ 17

Data extraction ___ 18

Quality appraisal ___ 18

Data synthesis __ 18

Interactive evidence gap maps __ 19

Web database of included studies ___ 19

Further stakeholder involvement ___ 19

Additional considerations ___ 20

Findings___ 20

Overview of the included studies ___ 20

Study characteristics _ 20

Methodological characteristics _ 22

Technology used for remote teaching and learning ___ 23

Research question 1: In what ways did emergency remote education affect motivation and engagement in secondary school students?

Behavioural engagement 24

Cognitive engagement 24 
Affective engagement

Motivation and learning gains__ 25

Challenges: Disengagement and demotivation __ 26

Gender implications

School status implications___ 28

Engagement, disengagement and technology __ 29

Research question 2: How did research report on emerging online assessment practices in secondary schooling during the pandemic?

Online quizzes

Formative online feedback

Online conversations or speaking assessments _ـ 32

Images___ 33

Online exams__ 33

When assessment did not work _ـ 33

Research question 3: Are new approaches to peer collaboration emerging and what does this suggest? __________________________

Learning activities in an online mode ___ 34

How practical, aesthetic and theoretical subjects combine modalities to support peer collaboration $\_34$

Social presence to support social engagement___ 35

Synchronous interaction emerging norm in distance teaching and learning___ 36

Research question 4: How did online learning in secondary schools affect parent engagement?

Research question 5: What emerging uses of online and blended learning approaches in secondary schools could continue to be implemented going forward?

Equity considerations need to be at the forefront when assessing the potential of online and blended

learning

Engagement and disengagement ___ 38

Assessment methods that combine brief and deep insights should be integrated into students' learning 39

Opportunities for peer collaboration should be integrated into online learning

Parental engagement is key to online learning, which opens new ways for teachers to engage with

parents

Discussion and conclusion

Plans for future unscheduled school closures

Support and social engagement ___ 40

Informing future strategies ___ 41

Limitations of the review _____________ 41

Future research and development ___________ 42

References __ 43

Appendix A - Data extraction coding scheme ___ 53

Appendix B - Studies included in the review __ 69

Appendix C - Educational technology tool typology (based on Bower, 2016)___ 77

Appendix D - Quality assessment tool___ 78

Appendix E - Items by source ___ 79 
Appendix F - Countries where research was undertaken 80

Appendix G - Participant focus 82

Appendix $\mathrm{H}$ - Subjects 83

Appendix I - Number of participants per study 85

Appendix J - Data collection methods 86

Appendix K - Technology used 87 


\section{Executive Summary}

\section{The issue of concern}

Globally, education has been subjected to a varying degree of digitalisation over the last few decades. While online and blended learning are becoming more common in higher education, uptake in compulsory education varies, as there is debate on the extent to which teaching and learning can and should be done online. Due to the complexity of blended learning, particularly in compulsory education, the debate has focused on inequality caused by the digital divide and teacher and student IT skills, discussion about the kind of teaching and learning that can be done online, and the potential impact on student engagement, motivation and learning outcomes. The widespread school closures provoked by the COVID-19 pandemic hastened decision making relating to formal online learning, and the question of if and to what extent education should be digitalised transformed into an expectation that secondary schools would provide not only blended, but fully online learning.

\section{How did we find this research?}

This review identified and synthesised research evidence on blended and online learning in secondary schools during the COVID-19 pandemic. Relevant studies were defined as those that focused on participants from secondary schools (either solely, or where secondary school data could be clearly extracted), were published in English, and had a focus on teaching and learning during the pandemic. Following a search through five databases and platforms, as well as ResearchGate and a previously published rapid review, 81 studies were identified for inclusion.

\section{Findings and recommendations}

The studies included in this review were undertaken in 38 countries. $37 \%$ of studies were from low or lower-middle income countries, and 63\% were from upper-middle income or high-income countries. Most of the evidence came from students ( $64 \%$ of studies), followed by teachers ( $53 \%)$, with very few studies exploring the perceptions and experiences of parents (6\%) or school leaders (5\%). Very few studies focused on vulnerable students, with only five studies including evidence about students with special educational needs and disabilities (SEND), one study about migrants and refugees, seven studies including students from lower socio-economic backgrounds, and one study of students with lower levels of attainment. While the shift to emergency remote teaching has sparked a discussion about whether online teaching suits particular forms of learning, complementing classroom teaching, or whether all learning should be in a physical classroom, this report focuses on what worked well in the online mode.

\section{Finding 1: Use of technology during the pandemic}

The most frequently used technologies were synchronous collaboration tools (e.g., live video lessons), knowledge organisation and sharing tools (e.g., Google Classroom), text-based tools (e.g., WhatsApp, email), and multimodal production tools (e.g., recorded videos). More studies from high-income countries reported using live video lessons compared with those from lower middle-income countries. Conversely, text-based tools such as WhatsApp were more common in lower-middle and low-income countries.

Recommendation 1: On a global level, digital infrastructure, accessibility, quality and usability are still preventing equal access to education. Effective uses of technologies should continue to be embedded into education going forward to prevent perpetuating digital exclusion. Technology choice for online learning should be governed by the student's ability to reliably access and use the tool; which will vary geographically and perhaps even within a class. 
Finding 2a: Student engagement and motivation

Despite the challenges of emergency remote education, the number of studies reporting at least one measure of engagement was equal to the number of studies reporting instances of disengagement. Some teachers reported that some students were more motivated to learn and complete schoolwork than prior to the pandemic, citing an increased ability to study and problem-solve independently, as well as a greater sense of responsibility. Students reported that teachers who checked in with them via email or phone, gave them timely feedback, used collaborative tools and made their expectations clear, were motivating.

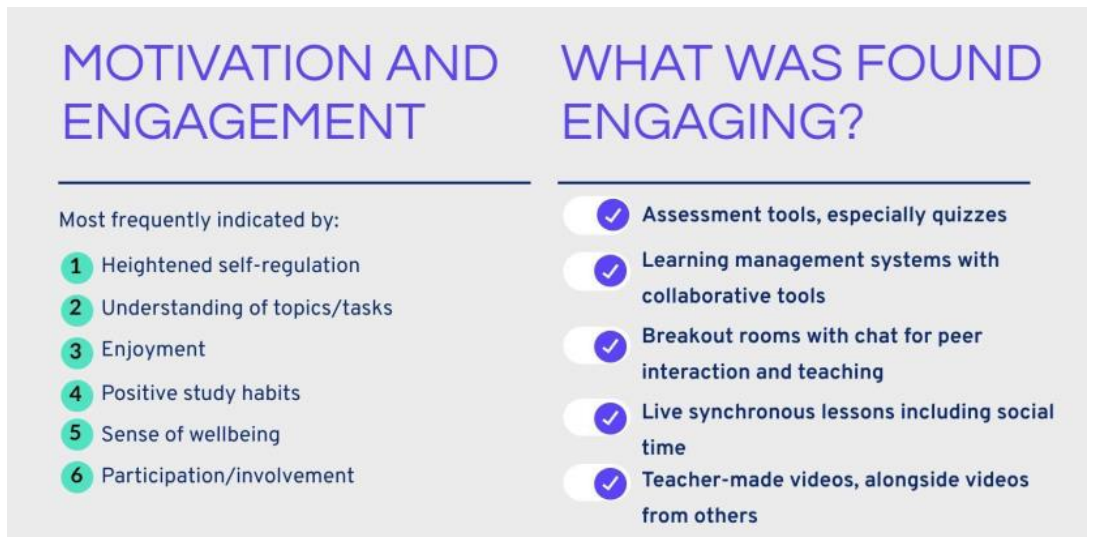

The most commonly reported engagement/motivation domains and the learning approaches that were found to be engaging/motivating for students.

Finding 2b: Student disengagement and demotivation

Absence was the most common form of behavioural disengagement reported, followed by poor conduct and task completion. Some teachers encountered poor attendance at live lessons, as well as students who kept their cameras turned off. Some students attended live lessons, but then did not engage further in the virtual classroom. Given the abrupt shift to remote learning during the pandemic, social disengagement was unsurprisingly a factor, with over a quarter of studies mentioning students' social isolation.

\section{DISENGAGEMENT \& DEMOTIVATION}
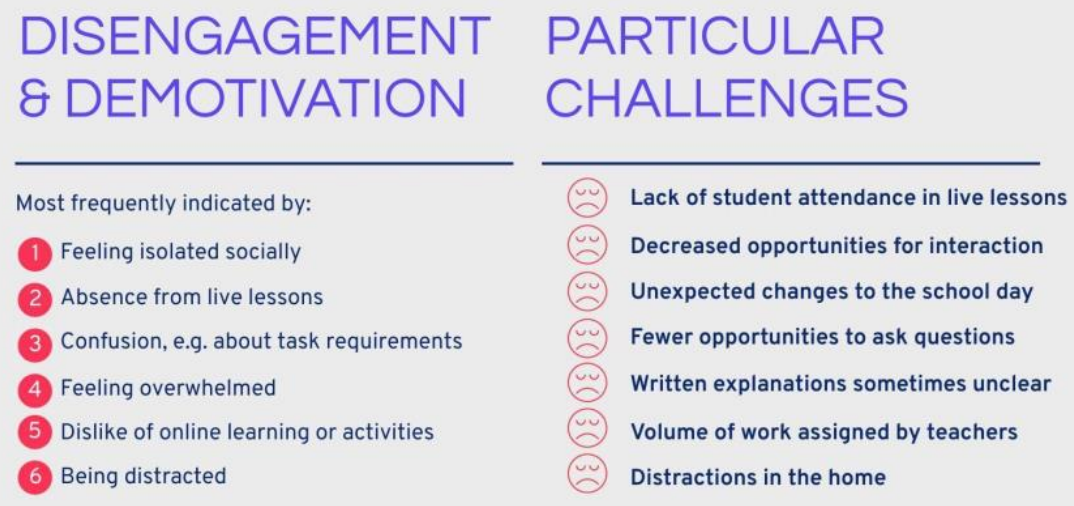

The most commonly reported disengagement/demotivation domains and the challenges leading to disengagement/demotivation among students. 
Recommendation 2: Teachers need to be aware of students' conditions for learning and general wellbeing. Synchronous learning activities with interaction and support was found to keep students engaged, while formal and informal social interaction between peers helped well-being. Traditional school structures can develop to proactively check in with students to learn about their needs in online modes. Scaffolding (i.e., not delivering all learning materials at once), varying learning tasks and giving clear instructions may prevent students from feeling overwhelmed and confused.

\section{Finding 3: Emerging online assessment practices}

Globally, governments responded differently to the online learning switch, with some countries such as South Korea, Senegal, Morocco and the UK halting standardised assessments. Nevertheless, several studies reported creative ways to assess students online during the pandemic, with 21 different online assessment types identified. Several studies reported that online quizzes were beneficial for teachers, as they were easily corrected, can be used to rehearse recommended elements, can help maintain student interest in their learning, and allow teachers to easily check student understanding of concepts.

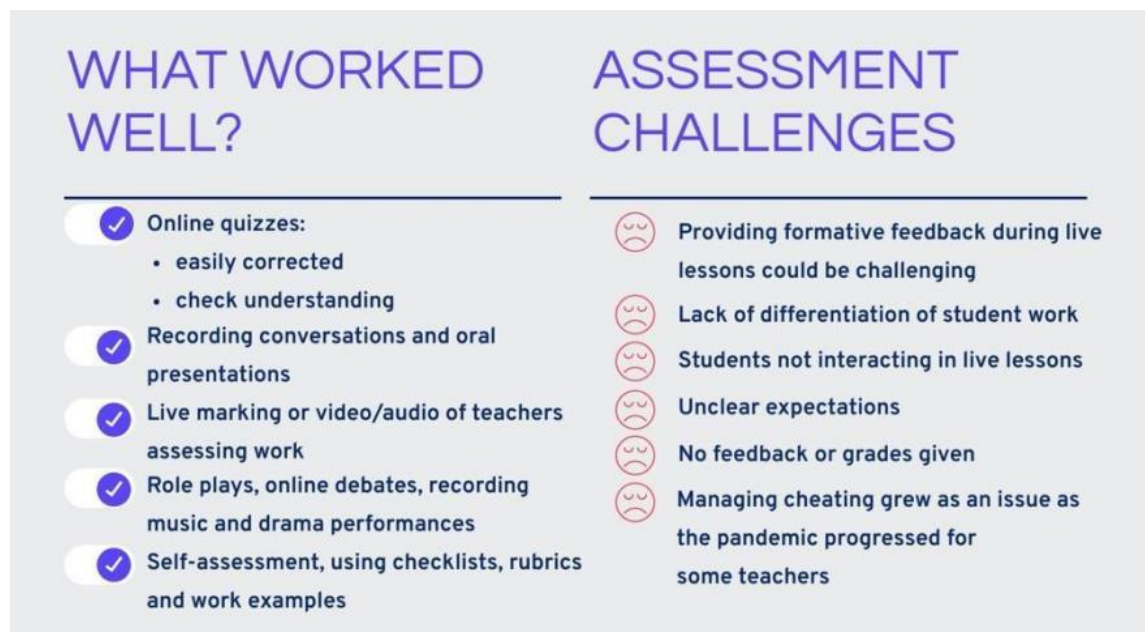

The most commonly used online assessment practices during the pandemic and the main challenges associated with conducting online assessment.

Recommendation 3: Assessment should be used to determine student progress and develop teaching practices. Consideration of student well-being and giving opportunities for students to practise without being assessed are also important. When assessing online, tools should be chosen based on the subject/specific competence being assessed. Dynamic assessment (e.g., spoken) was found to integrate well with synchronous lessons, while digital media were found to effectively complement asynchronous student assignments. Online quizzes should continue to be used as they are an easy and engaging way to assess learning and their use may help to reduce teacher workload. More research is required to determine the best practice for conducting standardised assessments online.

Finding 4: Approaches to peer collaboration

Online learning approaches that facilitated peer collaboration reported largely positive effects. Teachers used live synchronous lessons for inquiry-based group work, experiments, and to allow 
students to revise their work with live feedback from peers. Many studies reported facilitating discussion between students, and it was found that encouraging students to respond to the questions or work of peers alleviated pressure from teachers and encouraged social interaction. Some teachers prioritised social engagement before learning goals due to students' limited social interaction during the pandemic. A common theme emerging from the evidence was that effective peer collaboration was dependent on individual teacher's innovativeness, skills and choice of technologies to implement group work and interactions.

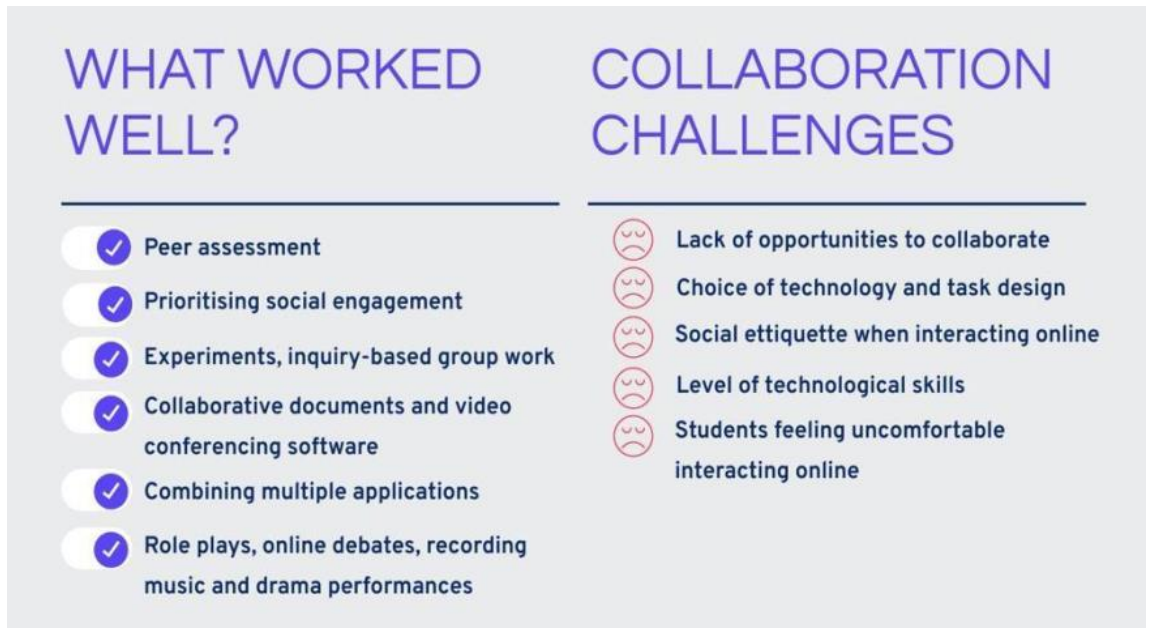

The top collaborative methods that reported positive effects and the main challenges associated with facilitating peer collaboration online.

Recommendation 4: Opportunities for peer collaboration are vitally important when learning online during a pandemic with social distancing. Peer-peer interaction can instil a sense of social presence and inclusion, and is critical for student engagement. Interaction can be synchronous and asynchronous, but synchronous lessons may be more useful for teachers making a shift into emergency remote teaching and for students who did not actively choose asynchronous remote education. However, the choice of technology and tasks must be well designed to facilitate the right type of constructive peer interaction and prevent disengagement through distraction.

\section{Finding 5: Parent engagement}

Teachers communicated with parents through WhatsApp or by email and phone, directly or through the school LMS. In remote areas, lacking infrastructure and facilities to provide remote learning, parents collected lesson materials from schools and delivered their children's assignments. Students welcomed their parents' help with online learning and cited the importance of parents for securing access to online resources, providing a suitable home-learning environment, reducing household chores and providing emotional support. Not surprisingly, the shift to emergency remote learning, coupled with parents working from home, had varying effects on family relations. There are a few reported instances in which parents did not support distance learning and a small number of students felt their parents lacked the knowledge to support them with online learning. 


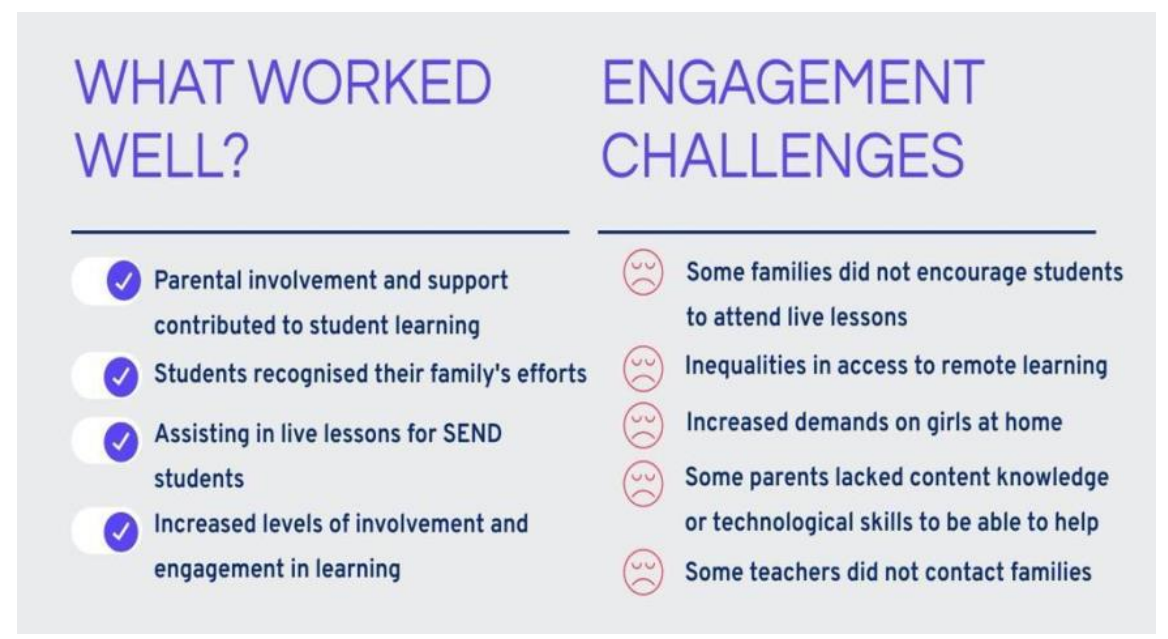

The benefits of parental engagement in online learning and the major challenges associated with poor consideration for parental engagement.

Recommendation 5: Increased parental engagement is seen as a positive outcome of the pandemic. Two-way communication between the school and parents may help to prevent barriers to learning. For example, teachers should be made aware of any issues with access to technology/suitable study space, so learning activities can be designed accordingly. The benefits of online learning should also be communicated to parents. More research into the impact of online learning in vulnerable students is essential to ensure that no students are left behind.

\section{Conclusions}

This review synthesised 81 studies on emergency remote education in secondary schools during the COVID-19 pandemic, focusing in particular on student engagement, online assessment, peer collaboration, and parent engagement. Student engagement was facilitated by varied, interactive and synchronous learning experiences, with well-designed opportunities to collaborate with peers. Online formative assessments, such as quizzes, were useful for rapidly judging understanding and gauging engagement. However, adapting standardised assessment for the online setting was challenging. Parent engagement was critical; however, social inequalities affected the capacity of some parents to provide materials and a suitable study space for their children. Consideration for students' means (availability of technology, devices, internet quota) and capabilities (availability of support at home, digital skills, motivation) and well-being, is therefore vital for online and blended learning. Aside from the varied digital infrastructure available and the quality, accessibility and usability of digital technologies and resources, a noteworthy number of articles reported that teacher confidence and digital skills determined whether they designed online learning activities that enabled peer interaction and collaboration. Thus, in order to support effective online learning, targeted professional development, clear guidelines, accessible high-quality technology and the development of a contingency plan to ensure high-quality education in times of crisis are critical for students, schools and teachers. 


\section{Background}

The COVID-19 pandemic and the resulting restrictions on social contact, triggered a rapid shift to emergency remote education in secondary schools around the world. The Organisation for Economic Co-operation and Development (OECD) estimated that school closures occurred in 188 countries, which impacted the education of over 1.7 billion children and their families (OECD, 2020a). Students, teachers and parents were forced to adapt and innovate to continue teaching and learning remotely, primarily using online learning ${ }^{1}$. While many school systems already had online learning tools in place prior to the pandemic, others had to adopt tools and techniques on an ad hoc basis, with limited training, preparation or infrastructure in place (Li \& Lalani, 2020; Jelińska \& Paradowsk, 2021; ThurabNkhosi et al., 2021).

As a result of the unprecedented emergency situation, systemic issues of equity, access and quality became apparent, in addition to disparities in student digital skills and teacher technological pedagogical knowledge (OECD, 2020b; POST 2021). Existing and emerging evidence of online or blended learning ${ }^{2}$ identifies motivation, engagement and enabling constructive peer collaboration as specific challenges for this learning mode in secondary school students (Bergdahl et al., 2020; Bond, 2020a). Yet, well-designed online learning that supports student motivation, engagement and peer interaction is associated with improved academic outcomes (Education Endowment Foundation, 2020; Ofsted, 2021). The positive impact of parental engagement in their children's learning was already well-established (Education Endowment Foundation, 2019); however, the circumstances arising during the COVID-19 pandemic meant that parents and caregivers became essential for supporting their children's online learning. The loss of in-person teacher and peer support resulted in parent's assuming the role of teacher, which may have caused increased strain on family relationships (Russell et al., 2020). Parents also became responsible for resolving technology issues, despite evidence that many parents may lack the digital skills needed to help (ONS, 2019; Onyema et al., 2020).

Finally, the pivot to remote online learning created significant issues with assessing learning, particularly with adapting standardised assessments for the online setting. In many countries examinations were cancelled, provoking chaos and confusion for older secondary school students. Where attempts were made to carry out assessment online, concerns emerged relating to cheating due to the difficulty in controlling the online environment and invigilating remotely.

Despite these challenges, the extended period of online learning has also highlighted a number of potential benefits of this style of learning. For instance, the forced shift to online learning has driven innovation and led to, what some may call, a long overdue modernisation and digitisation of education systems. Many stakeholders in the education sector believe that the changes to education provoked by the COVID-19 pandemic are likely to have a lasting impact on teaching and learning going forward (Li \& Lalani, 2020; Schwartz et al., 2020). While secondary schools are expected to return to in-person learning as COVID-19 restrictions ease around the world, the sector is unlikely to 'return to normal' and some online learning approaches and technologies are anticipated to be carried forward.

1 Online learning is learning that takes place in an online environment through the use of internet connected devices. This may be in a synchronous 'live' or asynchronous classroom where students can interact with teachers and peers and participation in learning does not depend on physical co-location (Singh \& Thurman, $\underline{2019}$ ).

2 Blended learning is a broad term to describe modes of delivery that combine elements of in-person instruction with online learning activities (QAA, 2020). 
Therefore, it is timely to review the evidence gathered to date to learn what worked well during the extended period of online learning and what could be taken forward.

\section{Rationale for the review}

This systematic review aims to summarise the published research evidence on online learning during the period of school closures during the COVID-19 pandemic. It also aims to gain insights into how the period of emergency remote education was experienced by secondary school students, their parents and teachers globally. In particular, the review focuses on topics of interest that were raised during stakeholder discussions at an IPPO Roundtable event 'Online education: what will we take forward from the pandemic?' namely: how online learning affected student motivation and engagement and were there emerging online assessment practices, approaches to peer collaboration and parent engagement.

The review is the first systematic summary of evidence of an extended period of online and blended learning in secondary schooling, aside from rapid reviews (e.g., Bond, 2020b), as evidence collected prior to the pandemic is typically from short-term periods of online learning. The review also considers the key challenges and opportunities for this mode of learning and describes the variety of approaches taken by countries around the world. The review also seeks to identify which online learning approaches could be taken forward by secondary schools, either in the context of building resilience to future crises or for integration into regular education programmes. It is hoped that this review can help to inform future decisions relating to policy and practice for online and remote learning and identify knowledge gaps where further research is necessary.

\section{Positionality}

This review builds on the experience of the authors in conducting thorough evidence syntheses on online and blended learning both prior to and during the COVID-19 pandemic (Bergdahl et al., 2020; Bond, 2020a; Bond, 2020b; Bond \& Bergdahl, 2021). The work follows on from a previous evidence snapshot summarising the emergency remote education situation in schools during the COVID-19 pandemic (Bond \& Bolan, 2021). It also builds on the findings of a recent UK parliamentary briefing, written in consultation with, and peer-reviewed by key stakeholders in the field of online and distance learning (POST, 2021).

Dr Melissa Bond is a Research Associate at the EPPI Centre, UCL, and will take up a position as a Lecturer in Digital Technology Education at the University of South Australia in December 2021. She was a teacher and leader at a high school in South Australia for ten years, and has experience in teaching using blended and online approaches at both high school and higher education levels.

Dr Nina Bergdahl is a Lecturer in the Department of upper secondary and adult education in Malmoe, Sweden and is affiliated with the Department of Computer and Systems Sciences, DSV, Stockholm University, Sweden. She worked as lead teacher in ICT in secondary education for 15 years before earning her PhD. Her research interests are student engagement and disengagement, learning designs and teacher leadership in blended learning.

Dr Rosa Mendizabal-Espinosa has been a Research Associate at the Social Science Research Unit, UCL since 2018. Her research focuses on children's rights and shared decision-making within healthcare institutions. Prior to her career in academia, she worked with children with special educational needs in early years education settings in Mexico for more than 10 years. 
Dr Dylan Kneale is a Principal Research Fellow based at the EPPI Centre, UCL. His research involves synthesising evidence for social policy and developing methods to enhance the use of evidence in decision-making. Substantively he is interested in demography and ageing, and in a number of public health topics and issues around social exclusion and sexuality.

Faye Bolan is a PhD student at the University of Manchester and former Research Fellow at the UK Parliamentary Office of Science and Technology (POST), where she consulted key stakeholders from academia, the charitable sector and UK Government to write a parliamentary briefing on distance learning.

Poppy Hull is a Masters student at UCL, specialising in Systematic Reviews. She volunteers as a Research Assistant, supporting the EPPI Centre with the creation of evidence products for the International Public Policy Observatory.

Fjolla Ramadani is a Masters student at UCL and volunteering as a Research Assistant at the EPPI Centre.

\section{Objectives}

In order to explore how blended and online learning occurred in secondary schools during the COVID19 pandemic, a systematic review was undertaken using explicit and transparent methods, with studies included for synthesis based on predetermined criteria (Gough et al., 2012; Zawacki-Richter et al., 2020), and following the PRISMA reporting guidelines as closely as possible (Page et al., 2021).

In order to determine the research questions guiding the review, an IPPO roundtable event was held in April 2021 with key stakeholders (teachers, school leaders, education department representatives from the four UK nations, policy makers and researchers). Following a discussion of key issues and experiences during the pandemic, and drawing on an evidence snapshot (Bond \& Bolan, 2021), five key research questions emerged:

1. How did emergency remote education affect motivation and engagement in secondary students?

2. How did research report on emerging online assessment practices in secondary schooling during the pandemic?

3. Are new approaches to peer collaboration emerging and what does this suggest?

4. How did online learning in secondary schools affect parent engagement?

5. What emerging uses of online and blended learning approaches in secondary schools could continue to be implemented going forward?

\section{Method}

\section{Search strategy and selection procedure}

The initial search was conducted on 5 May 2021 and closely followed the strategy of a previous rapid systematic review (Bond, 2020b) undertaken by the first author that identified studies undertaken 
during the pandemic at both primary and secondary school levels. Due to time constraints, a decision was made to focus the scope of the review solely on secondary education (Years 7-13), and to include only English language publications. The platforms and databases searched were Scopus, Web of Science, ERIC, and Microsoft Academic Graph, which are considered well-suited to evidence synthesis (Chen, 2020; Gusenbauer \& Haddaway, 2020), alongside the COVID-19 living systematic map (Shemilt et al., 2021). A smaller number of studies were also found manually (referred to as 'manual searching' in the PRISMA diagram, see Figure 1), within the COVID-19 ResearchGate community ${ }^{3}$, from Web of Science email alerts, through Twitter, or through peer recommendations (see Appendix E). Given the rapidly changing research landscape during the COVID-19 pandemic, as well as the lengthy peer review process, this method of searching grey literature (including pre-print servers) is recommended for COVID-19 reviews (Tricco et al., 2020). All items from the previously undertaken rapid review (Bond, 2020b), as well as from the living version of that review (Bond, 2021), were also included for consideration.

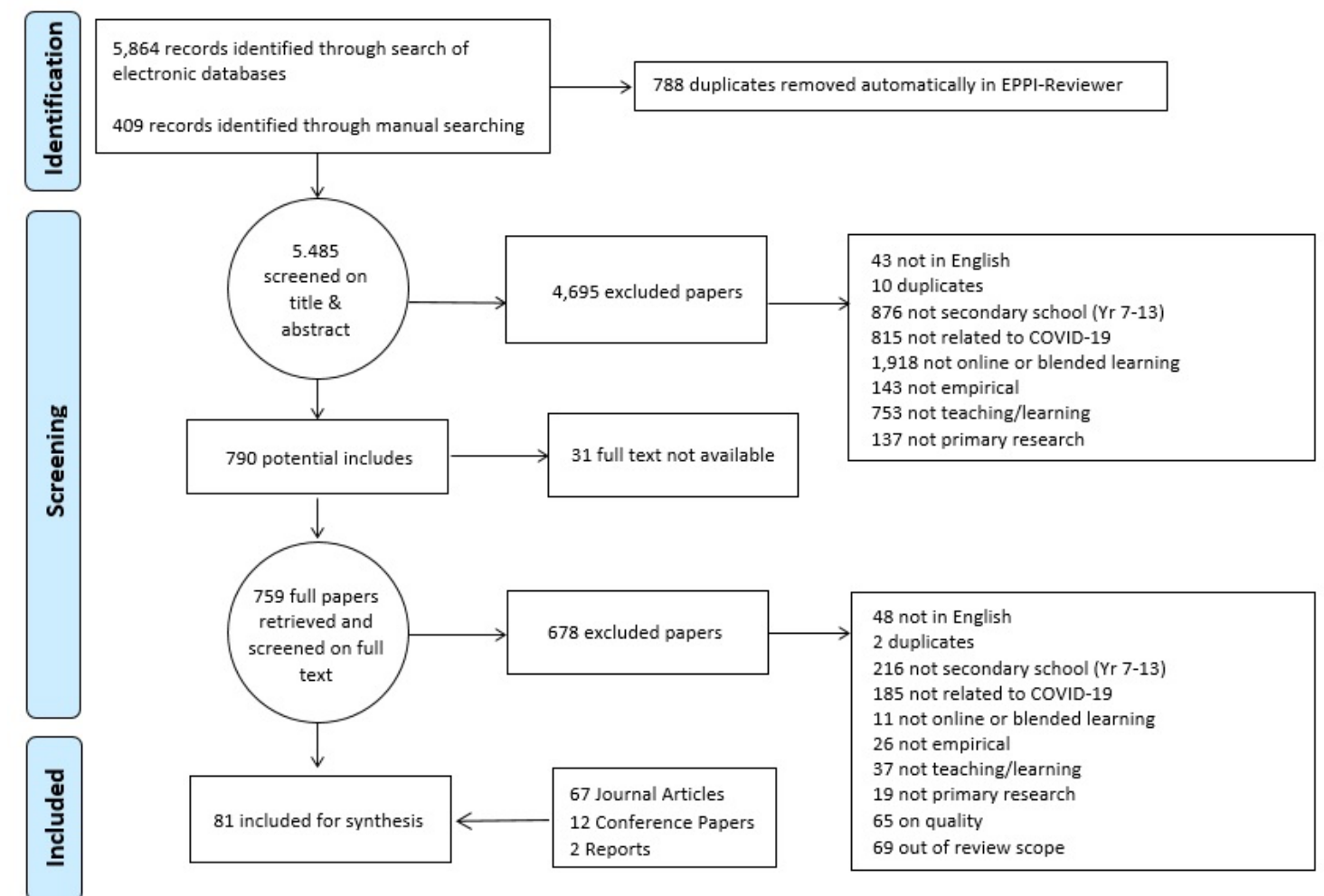

Figure 1. PRISMA diagram

\section{Search string}

The search string (see Table 1) was adapted from Bond (2020b) and focused on formal teaching and learning within secondary schooling (Years 7-13) during the COVID-19 pandemic (after January 2020), using * for truncations. Search terms relating to primary school were included at this stage as some countries offer Year 7 in primary school as opposed to high school. Due to the large number of Coronavirus-related medical studies that have been published during the pandemic (see Shemilt et al., 2021), medical terms such as 'public health' and 'surgery' were added as NOT terms in order to further refine the search results. 
Table 1. Search string

\begin{abstract}
"emergency remote teaching" OR "student-centred remote teaching" OR "emergency remote education" OR "student-centered remote teaching" OR "online pivot" OR "blended learning" OR "online learning" OR "hybrid learning" OR "remote education" OR "remote learning" OR "distance learning" OR "digital learning" OR "eLearning" OR "e-Learning" OR "crisis prompted distance education" OR "home learning" OR "homeschooling" OR "flipped learning" OR "flipped classroom" OR "distance education" OR "online education"

AND

"K-12" OR "primary school" OR "middle school" OR "secondary school" OR school OR "high school" OR "R-12" OR "elementary school" OR "upper primary" OR "senior school"

NOT

"public health" OR non pharmaceutical OR energy OR pharmaceutical OR pharmacy OR clinic* OR pathology OR telemedicine OR inflammation OR patient* OR neurology* OR telehealth OR surgery OR university* OR "higher education" OR postgrad* OR undergrad* OR "tertiary education" OR college
\end{abstract}

\title{
Inclusion/exclusion criteria
}

The combined search strategy yielded 6,274 records (see Fig. 1), which were imported into the evidence synthesis software EPPI-Reviewer (Thomas et al., 2020). Following the automatic removal of 786 duplicated items, 5,488 items were screened on title and abstract by the review team, applying the inclusion/exclusion criteria listed in Table 2. Studies were included if they were empirical, focused on teaching and learning within secondary schools (Years 7-13) using blended or online approaches during the COVID-19 pandemic, and written in English.

Table 2. Review inclusion and exclusion criteria

\begin{tabular}{ll}
\hline \multicolumn{1}{c}{ Inclusion Criteria } & \multicolumn{1}{c}{ Exclusion Criteria } \\
\hline Secondary schooling (Year 7-13) & $\begin{array}{l}\text { Pre-school, primary school, higher education, further } \\
\text { education }\end{array}$ \\
Teaching and learning focus & $\begin{array}{l}\text { No teaching and learning focus (focus on policy, adaptations } \\
\text { in structural support, leader decisions) }\end{array}$ \\
English language & Not in English \\
Empirical study & Not empirical or primary research \\
Studies undertaken during the COVID-19 pandemic & Studies undertaken before the outbreak of COVID-19 \\
Studies published after January 2020 & Published before 2020 \\
Online or blended learning & Solely face-to-face (in-person) learning \\
\hline
\end{tabular}

All authors independently screened 100 items for inclusion or exclusion on title and abstract and subsequently met to clarify ambiguity. All authors then screened an additional 50 items and met to discuss any disagreements and to consolidate the inclusion and exclusion criteria. After the initial screen and author discussions, the interrater reliability for the second round of coding of 50 articles was 0.73 (calculated using Cohen's Kappa, Cohen, 1960), which demonstrates good agreement 
between the seven members of the review team. 790 items were included on title and abstract, however 31 items could not be located despite attempts to contact the study authors via email or ResearchGate. 759 items were then screened on full text, applying the inclusion/exclusion criteria, resulting in 129 studies progressing to the data extraction and quality appraisal phase. A full list of the inclusion/exclusion decisions for all items considered in the review can be found on the review website.

\section{Data extraction}

The coding systems used in Bond (2020a) and Bond (2020b) were adapted for this review, to extract data within EPPI-Reviewer. Data extraction codes included publication type, methodology (e.g., date of data collection, method), setting/context (e.g., country, continent), population (e.g., number of participants, participant focus), intervention (e.g., specific pedagogical approaches), and outcomes (based on the bioecological model of student engagement by Bond \& Bedenlier, 2019; and Bond 2020a). Student engagement in this review was understood as:

"...the energy and effort that students employ within their learning community, observable via any number of behavioural, cognitive or affective indicators across a continuum. It is shaped by a range of structural and internal influences, including the complex interplay of relationships, learning activities and the learning environment. The more students are engaged and empowered within their learning community, the more likely they are to channel that energy back into their learning, leading to a range of short- and long-term outcomes, that can likewise further fuel engagement." (Bond et al., 2020b, p. 3)

Specific examples of student engagement and/or disengagement were coded using multiple indicators of behavioural, cognitive and affective (dis-)engagement (see Bond, 2020a), as well as social disengagement (see Bergdahl et al., 2020). Technology used was also coded at both the individual tool and category levels, as used by Bond (2020b), based on Bower's (2016) typology (see Appendix C). A full list of the coding scheme can be found in Appendix A.

\section{Quality appraisal}

During the screening and data extraction process, the authors considered the quality of the studies. Owing to the difference in maturity and self-regulation of students in secondary as opposed to primary school, any studies that mixed results from the two levels were excluded. Any studies that did not provide a clear and detailed description of the methodology were also excluded. A formal quality assessment was then conducted (see Appendix D), based on the process used by the EPPI-Centre (Moss et al., 2021). The quality assessment was designed to answer two questions:

1. Does this study answer our research questions?

2. Is the evidence trustworthy, given the methods used, results and conclusion?

Studies that were given a decision of 'partly' for either question were reviewed by an additional team member to determine whether the study was suitable for inclusion. At the end of the quality appraisal process 81 studies were included in the evidence synthesis. A full list of the quality appraisal decisions for each item can be found on the review website.

\section{Data synthesis}

A narrative synthesis of the data was undertaken (Petticrew \& Roberts, 2006), including a tabulation of the studies and their characteristics (see Appendix B). Further tables are located throughout the text or included as appendices to clearly summarise the review findings. These are accompanied by a narrative description summarising the results. 


\section{Interactive evidence gap maps}

In order to provide a publicly accessible overview of the studies within this review, interactive evidence gap maps were produced for each research question, using the EPPI-Mapper application (Digital Solution Foundry \& EPPI-Centre, 2020). Following the data extraction in EPPI-Reviewer, a JSON report of all 81 studies was imported into EPPI-Mapper, where filter and display options were chosen ${ }^{4}$. The HTML files of each map were saved and are available to access from the EPPI-Centre website. These maps allow users to explore cross tabulations of data within the review, allowing deeper insights into the data than can be provided in this report. Users can also download the studies as a RIS file (and import it into their own reference management software).

\section{Web database of included studies}

To further assist the education community, an openly accessible database of the included studies and their associated coding was made using the EPPI-Visualiser tool within EPPI-Reviewer ${ }^{5}$. This database allows users to search for specific studies, run frequency and cross-tabulation reports, create bar and pie charts, see publications by year of publication, and see the full coding record of each study (see Fig. 3).

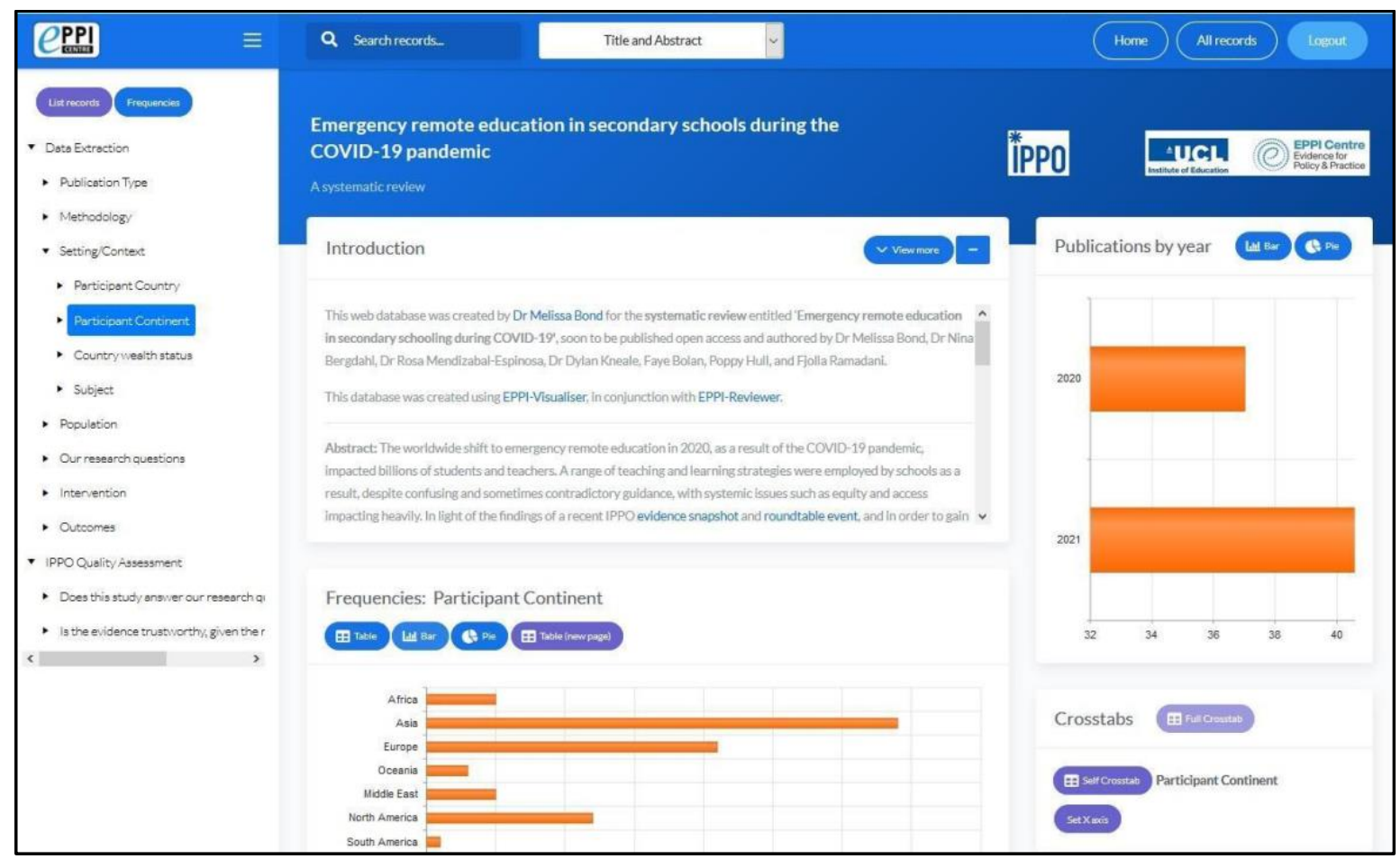

Figure 3. Web database of included studies

\section{Further stakeholder involvement}

Preliminary findings were presented to the participants of a second IPPO stakeholder roundtable event in July 2021. This included an executive summary of the evidence, as well as a summary document. Stakeholders were then given the opportunity to respond to the evidence during the roundtable, helping to refine the final report.

4 For more information about EPPI-Mapper and creating interactive evidence gap maps, see https://eppi.ioe.ac.uk/cms/Default.aspx?tabid=3790

5 See https://youtu.be/bhQuGpeB2Lo for an informal introduction to using EPPI-Visualiser 


\section{Additional considerations}

The studies in the review were coded on indicators of cognitive, affective, behavioural and social (dis-)engagement, alongside (de-)motivation (Appendix A), following the model of student engagement by Bond \& Bedenlier (2019) and the instrument developed by Bergdahl et al. (2020). Research publications often conceptualise engagement differently (as previously noted: Alrashidi, et al. 2016; Henrie, et al 2015). The authors used the indicators of engagement as described in the studies. It should also be noted that the presence of an engagement indicator in a certain percentage of studies does not mean that the rest of the studies reported the opposite; merely that this is the proportion of studies where particular indicators were specifically mentioned (see Bond, 2020a; Bond et al., 2020).

While online ethics, digital privacy and data security are important considerations in online education, Bergdahl and Nouri (2020) found that these aspects were initially neglected when teaching moved online at the beginning of the pandemic. Although they are outside the scope of this review, they have been covered elsewhere (e.g., Stewart \& Lyons, 2021). Another important aspect relates to the difference between perceived and actual learning. The studies included in this review have findings that reflect both learning gains and losses, as well as how experiences of teaching and learning were reported by teachers, students and parents. Here, the review focused on exploring how schools and teachers implemented formal learning and how this was perceived.

\section{Findings}

\section{Overview of the included studies}

The studies in this review were predominantly journal articles ( $n=67,83 \%)$, as well as 12 conference papers and two reports.

\section{Study characteristics}

\section{Geographical characteristics}

The research synthesised in this review was undertaken in 38 different countries (see Appendix $\mathrm{F}$ ), across all continents (Asia 42\% studies, Europe 26\%, North America 15\%, Africa 6\%, Middle East 6\%, Oceania $4 \%$, South and Central America $1 \%)$. Most studies were conducted in Indonesia $(23 \%, n=19)$, followed by the United States $(14 \%, n=11)$, China $(5 \%, n=4)$, and Slovakia, Austria and Hong Kong $(4 \%, n=3$, each). According to the World Bank country wealth status $6,2 \%$ of studies were from lowincome countries, $35 \%$ from lower-middle income countries, $9 \%$ from upper-middle income countries, and 54\% from high-income countries (see Figure 4). 


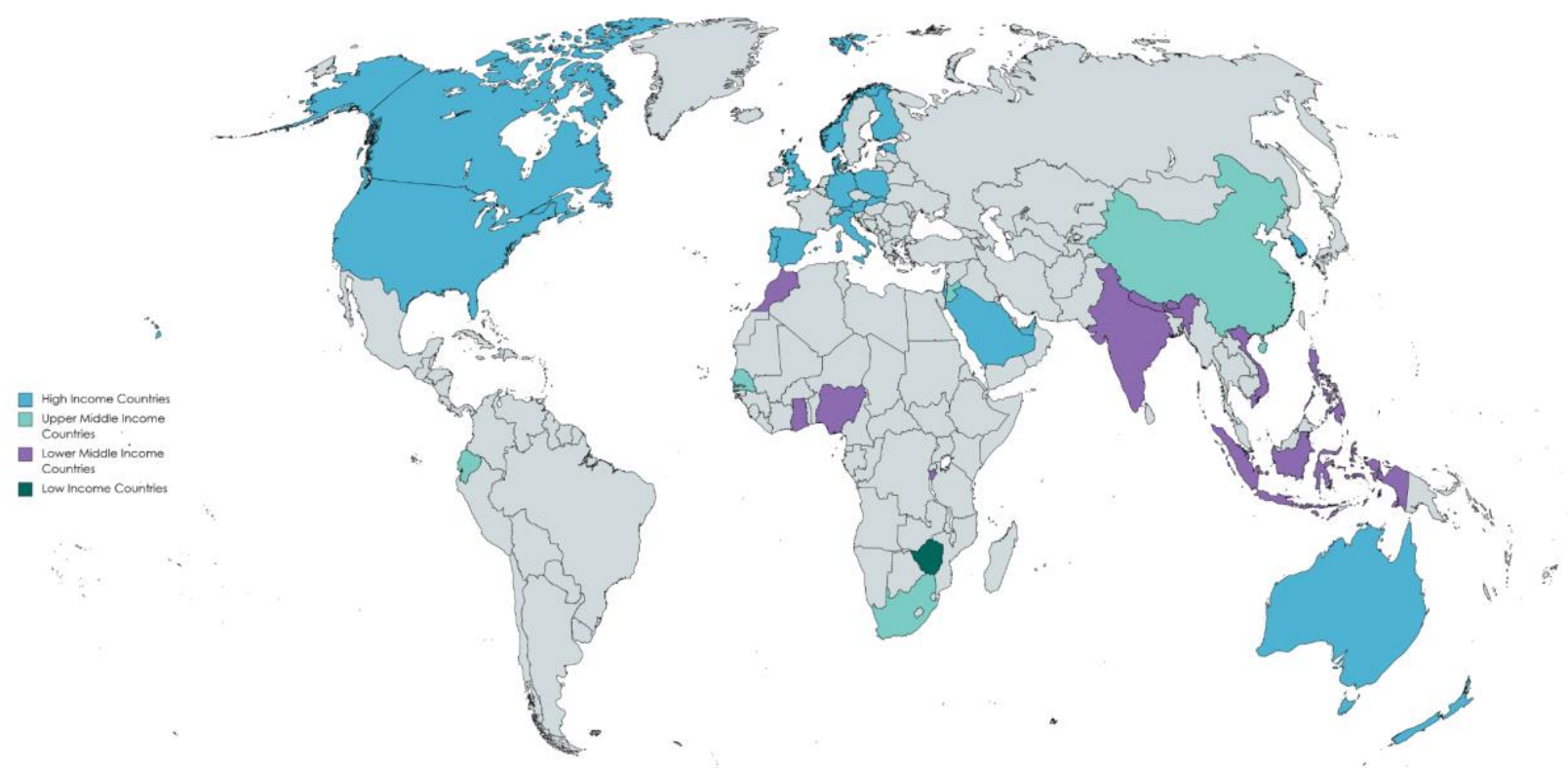

Figure 4. Countries in the review by World Bank wealth status

\section{Sample focus}

Most of the evidence came from students ( $64 \%, n=52$ studies), followed by teachers ( $53 \%$ ), parents (6\%) and school leaders (5\%), although some studies did not specify whether their teacher respondents were also part of the school leadership team (see Appendix G). Very few studies triangulated data from multiple sources; for example, one study interviewed students, parents and teachers on the use of Google Classroom and television lessons (Dorji, 2021); one study explored student, teacher and school leader perceptions (Niemi \& Kousa, 2020); and one study conducted focus groups with teachers, students, parents and school leaders (Education Scotland, 2021). As has been highlighted previously (Bond, 2020b), this is likely due to research manageability and access to participants during the pandemic. However, collecting data from multiple sources has been noted as a priority focus for future research (Kim \& Asbury, 2020; Primdahl et al., 2020).

Few studies focused specifically on vulnerable students, with one study exploring the experiences of migrants and refugees (Primdahl et al., 2020), one study focusing on students with lower levels of Maths attainment (Hodgen et al., 2021), and seven studies specifically reporting on students from lower socio-economic backgrounds. Five studies explicitly included evidence about students with special educational needs and disabilities (SEND). For instance, Becker et al. (2020) explored the experiences of students with Attention-Deficit/Hyperactivity Disorder, and four other studies included students with a range of profiles from Indonesia (Balkist \& Agustiani, 2020), Spain (Álvarez-Guerrero et al., 2021), Scotland (Education Scotland, 2021), and Germany (Nusser, 2021). Of the 52 studies with students as participants, only $40 \%(n=21)$ reported which school year students were in (see Figure 5$)$. This revealed that studies focused predominantly on senior secondary year levels, with participants from years 10 and 11 included most frequently (16\% of studies). This was in contrast to pre-pandemic research into flipped learning (Bond, 2020a), which focused primarily on middle year secondary students. 
15

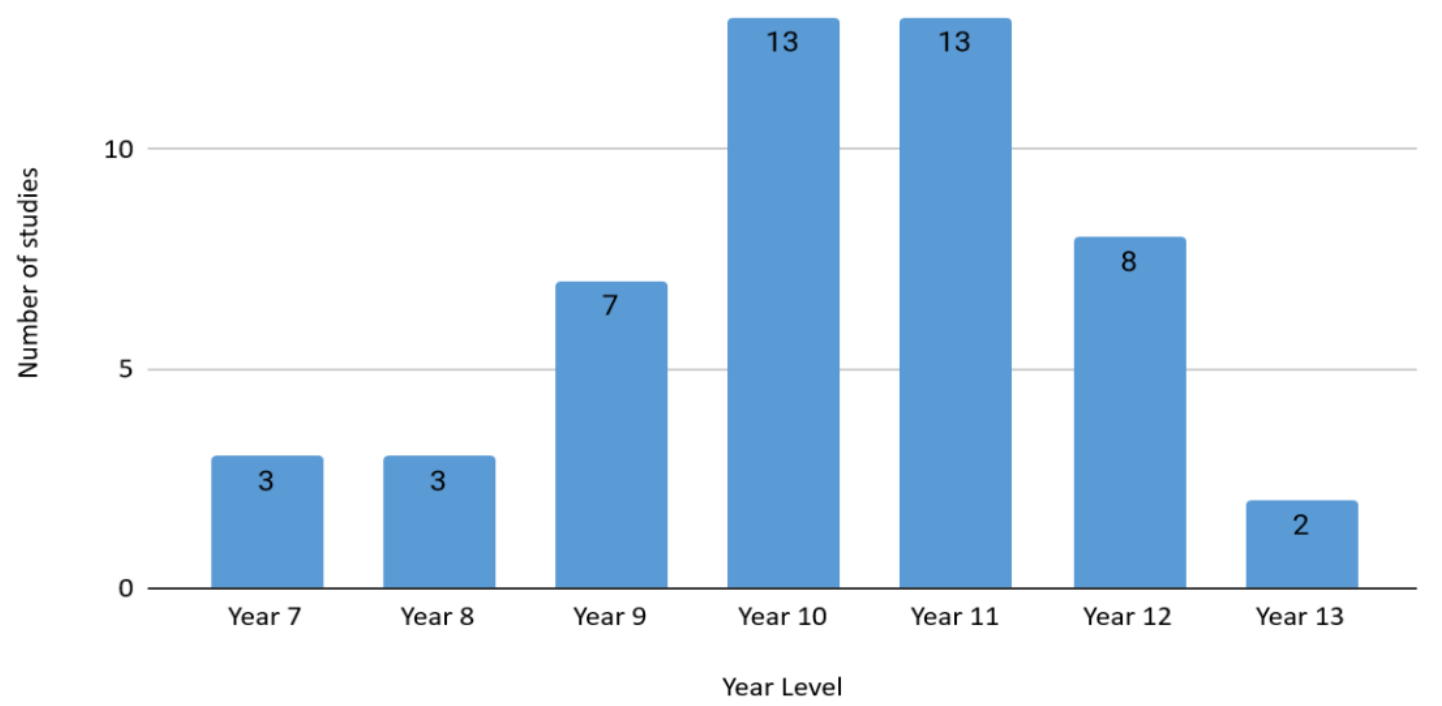

Figure 5. Year levels represented

$40 \%$ of studies ( $n=32$ ) classified their respondents by gender, including three studies with female only respondents (Oraif \& Elyas, 2021; Schaefer et al., 2020; Sibanda \& Mathwasa, 2021). The studies were also categorised according to sample size (see Appendix I). $18.5 \%$ of studies had more than 400 participants, with three European studies having over 2,000, from Slovakia (Velichová et al., 2020), Poland (Korzycka et al., 2021), and Austria (Pelikan et al., 2021). 33\% of studies ( $n=27$ ) had between one and 25 participants, which represents a higher percentage of smaller scale studies than in higher education research (16\%, Bond et al., 2021). Three studies did not report the exact number of participants involved (Education Scotland, 2021; Okebukola et al., 2020; Rusmansyah et al., 2021).

\section{Education setting}

19 studies (23\%) identified the type of school that the research took place in. Nine studies indicated that respondents were from a government funded/public school, eight studies indicated that their respondents attended both government and private schools, and one study reported that respondents attended a private/independent school only. Specific subjects were mentioned in just over half of the studies ( $n=44$, see Appendix $H$ ), where English as a Second or Foreign Language $(n=$ $14,17 \%)$ was the most frequently researched individual subject, followed by Maths $(n=11)$ and Chemistry $(n=8)$. However, in accordance with previous research on online and blended learning in schools, both prior to (Bond, 2020a; Lo et al., 2017; Lundin et al., 2018) and during the pandemic (Bond, 2020b), STEM (science, technology, engineering and medicine) subjects were overall the most researched ( $28 \%$ of studies).

\section{Methodological characteristics}

The majority of studies were qualitative $(47 \%, n=38), 35 \%$ were quantitative $(n=28)$ and $18 \%$ used mixed methods $(n=15)$. Given the emergency circumstances in which the research took place, it is unsurprising that $65 \%$ of studies used an online survey $(n=53)$ for data collection (Appendix J), followed by interviews $(41 \%, n=33)$. Given the varying severity of the COVID-19 pandemic throughout 2020-2021, it is important to consider when data were collected (Figure 6). The majority of studies that reported when data was collected, conducted their data collection in March (16\%), April (25\%), 
May (26\%) and June (16\%) of 2020 (Figure 6), although 45 studies (56\%) did not report when data were collected.

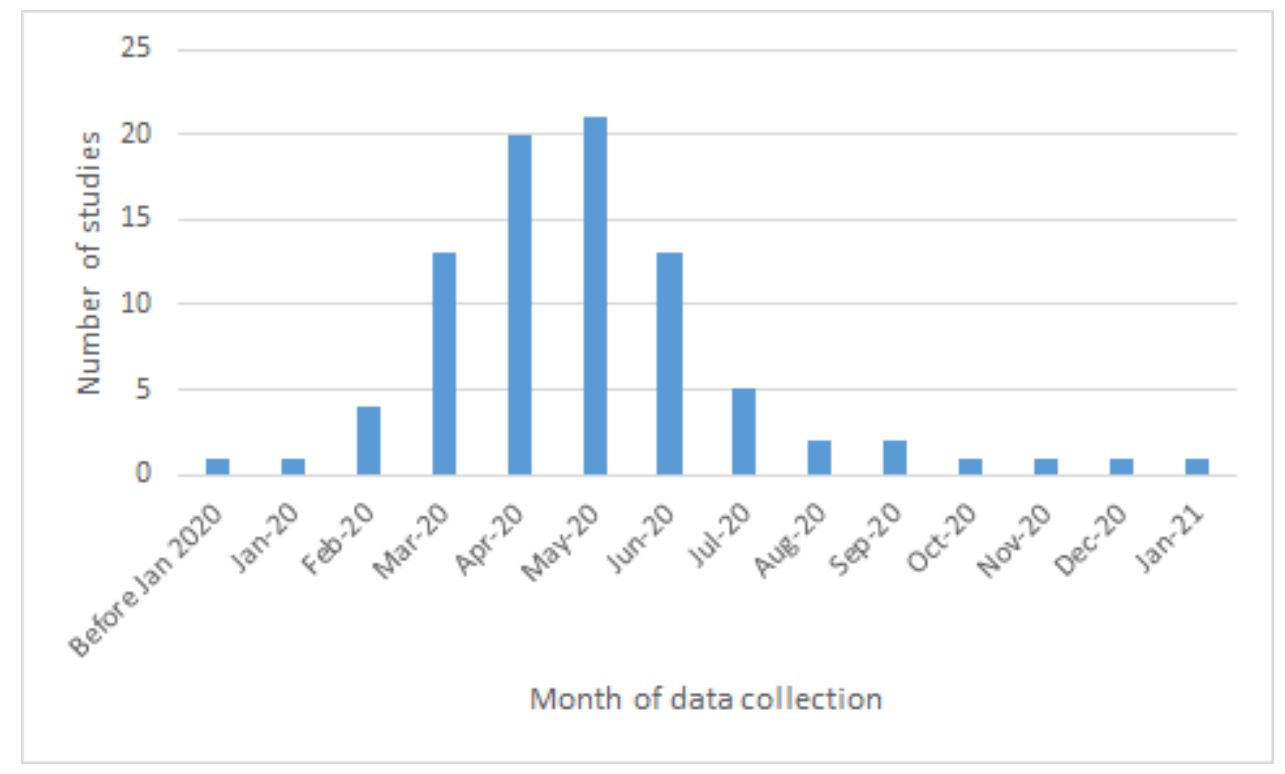

Figure 6. Timeline of data collection

Technology used for remote teaching and learning

The most frequently used technology tools in the studies in this review (Appendix K) were synchronous collaboration tools (58\%, e.g., live video lessons), knowledge organisation \& sharing tools (46\%, e.g., Learning Management Systems such as Google Classroom), text-based tools (43\%, e.g., WhatsApp messages, email), and multimodal production tools (38\%, e.g., recorded videos). Interestingly, the use of synchronous collaboration and multimodal production tools increased by $10 \%$ from a previous review of 89 studies undertaken during the pandemic (Bond, 2020b). This is in accordance with findings from the UK that secondary school students received more live lessons than primary school students (Bond \& Bergdahl, 2021). Also of note was the increased number of studies reporting the use of live video lessons in high-income countries (70\%) as opposed to lower middle-income countries (39\%). Conversely, a higher number of lower middle-income countries (54\%) and low-income countries (100\%, two studies) reported using text-based tools such as WhatsApp, compared to upper middle (43\%) and high-income countries (34\%). A reason for these findings may be related to national differences in digital infrastructure (bandwidth) and accessibility to digital devices.

\section{Research question 1: In what ways did emergency remote education affect motivation and engagement in secondary school students?}

Given the enormity of the shift to emergency remote education and the multiple negative impacts of the pandemic on all aspects of everyday life, it is interesting to find that almost the same number of studies reported incidences of engagement and/or increased motivation $(80 \%, n=65)$ as the number of studies that reported incidences of disengagement and/or demotivation $(81 \%, n=66)$. The most frequently reported dimension of engagement (although arguably the most apparent and therefore easiest to measure) was behavioural engagement ( $56 \%$ studies, $n=45)$, followed by cognitive engagement (53\%) and affective engagement $(48 \%)$. Twenty studies $(25 \%)$ mentioned aspects from all three dimensions of engagement and $20 \%$ of studies $(n=16)$ cited examples of positive or increased 
student motivation. The six most frequently stated indicators of engagement were self-regulation, understanding, positive study habits, enjoyment, sense of wellbeing and participation/involvement (Table 3).

\section{Behavioural engagement}

Twelve indicators of behavioural engagement were identified, with improved study habits the most cited $(17 \%, n=14)$. Some students enjoyed the freedom of being given all their work for the week on Monday and being able to set their own timetable. This was also positively perceived by parents, who were often responsible for supporting multiple children alongside their own work (Education Scotland, 2021). Some students also took the initiative to search for additional learning materials (Shidiq et al., 2021; Weinhandl et al., 2021) or to replay videos or audio files of conversations or feedback (Simanjuntak et al., 2021; Tong \& Wang, 2020). Such behaviours had been noted as a benefit of the flipped learning approach prior to the pandemic (Bond, 2020a).

Active participation/involvement was reported in 13 studies (16\%), with some studies stating that live synchronous lessons were more effective at encouraging participation than providing recorded videos and self-study materials alone (Aldossry, 2021), as students and teachers had a stronger sense of connection (Bruin, 2020). UK school leaders in Mathematics (Hodgen et al., 2020) found that online remote learning was particularly beneficial for students, who were previously reticent to answer questions in the classroom. Teachers in Sweden (Willermark, 2021) also found that there was improved attendance by students who usually did not attend school, as there was no pressure to be physically present. In cases where low participation in online classes was an issue, students still reported feeling more responsible for completing homework tasks (Velichová et al., 2020). Accordingly, $12 \%$ of studies mentioned that online learning helped to boost students' learning independence (e.g., Nawawi et al., 2021).

Table 3. Top five indicators of engagement across the three dimensions

\begin{tabular}{|l|c|c|l|c|c|l|c|c|}
\hline \multicolumn{2}{|c|}{ Behavioural Engagement } & \multicolumn{3}{c|}{ Cognitive Engagement } & \multicolumn{3}{c|}{ Affective Engagement } \\
\hline Indicator & $\%$ & $\mathrm{~N}$ & Indicator & $\%$ & $\mathrm{~N}$ & Indicator & $\%$ & $\mathrm{~N}$ \\
\hline Study habits & $17 \%$ & 14 & Self-regulation & $26 \%$ & 21 & Enjoyment & $16 \%$ & 13 \\
\hline $\begin{array}{l}\text { Participation/ } \\
\text { involvement }\end{array}$ & $16 \%$ & 13 & Understanding & $19 \%$ & 15 & Sense of wellbeing & $15 \%$ & 12 \\
\hline $\begin{array}{l}\text { Assuming } \\
\text { responsibility }\end{array}$ & $12 \%$ & 10 & Critical thinking & $10 \%$ & 8 & $\begin{array}{l}\text { Positive interactions } \\
\text { with peers }\end{array}$ & $15 \%$ & 12 \\
\hline Time on task & $11 \%$ & 9 & Focus/concentration & $10 \%$ & 8 & Interest & $12 \%$ & 10 \\
\hline Confidence & $9 \%$ & 7 & Positive self-perceptions & $7 \%$ & 6 & $\begin{array}{l}\text { Positive attitude } \\
\text { towards learning }\end{array}$ & $11 \%$ & 9 \\
\hline
\end{tabular}

\section{Cognitive engagement}

Linked to study habits and assuming responsibility is students' increased self-regulation, indicated in $26 \%$ of studies $(n=21)$. In a Vietnamese study, Tran et al. (2020) found that students who were intrinsically motivated and believed that "self-learning was necessary because it maintained their learning habits" (p. 12), studied approximately 40 minutes more a day than their classmates. However, Hodgen et al. (2020) found that students who could self-regulate their learning were often highattainers, who already had those skills prior to the pandemic. Yet there were examples of students exhibiting greater ownership of their learning and developing a new sense of independence during 
school closures (e.g., Chiu, 2021; Hira \& Anderson, 2021). One teacher in a US study (Kaden, 2020) speculated that the reason that some students thrived was due to reduced distractions, such as bullying and socialisation issues.

Students' deepened understanding was cited in a number of studies and related to subject content (e.g., Nugraha et al., 2021) and their ability to discuss and communicate topics effectively (e.g., Bruin, 2020). Characteristic approaches of online learning also helped increase understanding (Nurliani et al., 2021; Poláková \& Klímová, 2021), such as the use of videos (e.g., Rusmansyah et al., 2021) and flipped feedback (e.g., Education Scotland, 2021). In a study of Maths students in the United Arab Emirates, Almarashdi and Jarrah (2021) found that students were focused more on developing their understanding of concepts, rather than on memorising answers for tests during remote online learning.

\section{Affective engagement}

Students expressed enjoyment of online learning in $16 \%$ of studies for a variety of reasons. Chemistry students (Babincakova \& Bernard, 2020) enjoyed conducting experiments at home using everyday materials, alongside receiving "interesting videos and interactive homework" (p. 3298). Whereas other students enjoyed making their own videos (Chiu, 2021), learning independently (Pelikan et al., 2021) and at their own pace (Kaden, 2020) and using technology that they normally would not (Amelia et al., 2020). Some students also felt a heightened sense of wellbeing as a result of learning from home (e.g., Babincakova \& Bernard, 2020), as they found it to be more comfortable and less stressful, although this was not the case for all students (see section on disengagement below). Asanov et al. (2021) found that students from wealthier households, with stable internet connection and educated parents, were more likely to report being happy and feeling less anxiety related to completing homework (Ferraro et al., 2020). Interaction with teachers and peers was mentioned frequently as being important for student wellbeing (e.g., Yates et al., 2020), with some studies even reporting improved social skills since the beginning of remote learning (e.g., Álvarez-Guerrero et al., 2021).

\section{Motivation and learning gains}

In a large New Zealand study (Yates et al., 2020), students found that teachers who: checked in with them via email or phone, gave timely feedback, used collaborative tools, made expectations clear and provided differentiated resources, were particularly motivating. Students were also motivated by being allowed to use technology that they normally would not be, for example the use of mobile phones in science lessons to measure sound levels (Baptista et al., 2020) and the use of gamified apps such as Kahoot! (Cheung, 2021). Providing students with opportunities to problem solve, both alone and with peers, also positively affected student motivation (e.g., Weinhandl et al., 2021), with some teachers commenting that a portion of their students appeared to be more motivated during the school closures than usual (e.g., Niemi \& Kousa, 2020). Students in a Vietnamese study (Tran et al., 2020) who were intrinsically motivated to learn were found to study longer than those who were extrinsically motivated (e.g., by parents, teachers, friends).

Learning gains were reported in 18 studies (22\%), although it was widely acknowledged by many teachers that assessing students accurately during the pandemic was difficult (e.g., Niemi \& Kousa, 2021). Kelley (2020) found that students who chose to undertake experiments at home earned comparable grades to average semester lab grades. In addition, Indonesian students found that their anxiety was reduced when undertaking exams from home, as there was less perceived pressure without the exam hall situation (Suliani et al., 2021). Another reported benefit of conducting online learning activities during the pandemic was the development of students' digital competencies (Baptista et al., 2020; Chiu, 2021). However, Hu and Huang's (2021) study of Year 10 students in 
Australia stressed the importance of appropriate curriculum design, including providing materials in multiple ways (e.g., on- and offline resources) and in multiple digital places.

\section{Challenges: Disengagement and demotivation}

\section{Examples and forms of disengagement identified}

Billions of children were at risk of experiencing disengagement from learning during the transition to remote online learning, due to factors such as the (un)suitability of home environments for learning, potential losses in learning and cancelled assessments, experiencing poorer health and well-being at home (e.g., increased anxiety) and lower levels of social interaction with teachers and peers that are conducive to learning. Among the studies included in the review, over three quarters ( $n=66,81 \%)$ reported some form of disengagement in the form of cognitive, affective, behavioural or social disengagement (Table 4). However, many studies also reported positive forms of engagement and over half of studies reported aspects of both positive engagement and disengagement $(n=52,64 \%)$.

Table 4. Top five indicators of disengagement

\begin{tabular}{|l|c|c|l|c|c|l|l|l|l|l|l|l|}
\hline \multicolumn{2}{|c|}{ Behavioural Disengagement } & \multicolumn{2}{l|}{ Cognitive Disengagement } & \multicolumn{2}{|c|}{ Affective Disengagement } & \multicolumn{3}{|c|}{ Social Disengagement } \\
\hline Indicator & $\%$ & $\mathrm{~N}$ & Indicator & $\%$ & $\mathrm{~N}$ & Indicator & $\%$ & $\mathrm{~N}$ & Indicator & $\%$ & $\mathrm{~N}$ \\
\hline Absence & $19 \%$ & 15 & Confusion & $19 \%$ & 15 & Overwhelmed & $14 \%$ & 11 & $\begin{array}{l}\text { Social } \\
\text { isolation }\end{array}$ & $27 \%$ & 22 \\
\hline Poor conduct & $9 \%$ & 7 & Distracted & $11 \%$ & 9 & Dislike & $14 \%$ & 11 & $\begin{array}{l}\text { Reduced } \\
\text { interaction } \\
\text { with teachers }\end{array}$ & $12 \%$ & 10 \\
\hline $\begin{array}{l}\text { Task } \\
\text { incompletion }\end{array}$ & $9 \%$ & 7 & $\begin{array}{l}\text { Unfocused/ } \\
\text { inattentive }\end{array}$ & $9 \%$ & 7 & Dissatisfaction & $11 \%$ & 9 & & & \\
\hline Half-hearted & $7 \%$ & 6 & Unwilling & $6 \%$ & 5 & Worry/anxiety & $11 \%$ & 9 & & & \\
\hline Giving up & $6 \%$ & 5 & $\begin{array}{l}\text { Pressured/ } \\
\text { stressed }\end{array}$ & $6 \%$ & 5 & Boredom & $10 \%$ & 8 & & & \\
\hline
\end{tabular}

\section{Affective disengagement}

Affective disengagement, characterised by a negative emotional response to online learning among students, was reported in almost half of studies ( $n=37,46 \%)$, with students feeling overwhelmed, dissatisfied, worried and anxious, or bored with online learning. The most commonly occurring form of affective disengagement was students feeling overwhelmed (11 studies, 14\%), including feeling overburdened with the volume of online learning and homework. A Slovakian student characterised these feelings of being overwhelmed, saying "At our school, we learn from 8 am to $1 \mathrm{pm}$. It's not that bad, but we also have a lot of homework so I have to learn non-stop. I think it's too much and tiring and stressful" (Babinčáková \& Bernard, 2020, p. 4). In some cases, feelings of being overwhelmed were in turn accompanied by feelings of boredom, anxiety or dislike of school/learning. For example, in one study students reported feeling overwhelmed with the barrage of assignments that felt insurmountable, while being confined to a restrictive home learning environment, which heightened feelings of frustration and boredom (Schaefer et al., 2020).

\section{Behavioural disengagement}

Behavioural disengagement reflects the observable negative actions of students, such as being absent from learning, giving up on tasks, non-participation and being unprepared for learning. Over two-fifths 
of studies reported behavioural disengagement among students $(n=36,44 \%)$, with absence being the most common expression of behavioural disengagement ( $n=15,19 \%)$. In some cases, issues with technology, such as problems with connectivity, were found to impact student attendance (e.g., Okebukola et al., 2020). In some other cases teachers and parents stated that students clicked on links to participate in live lessons but then became distracted with other activities (e.g., Bhattarai, 2020). In some studies teachers also reported low levels of engagement online, i.e., that students were shy about being on camera or being recorded (e.g., Bruin, 2020). Although technology and connection issues are predicted to be a greater barrier to engagement in lower income countries, studies conducted in high-income countries were more likely to report issues with student absence. More broadly, instances of behavioural disengagement were more frequently reported in studies from higher income countries (26/44 studies, 59\%) than those conducted in low- and middle-income countries (10/37 studies, $27 \%$ ). In a small number of studies, behavioural disengagement manifested in more intractable forms, such as the four studies reporting students feeling burnt out and exhausted.

\section{Cognitive disengagement}

Students who are cognitively disengaged are those who are detached from the learning environment, which manifested in the evidence as students becoming distracted, unfocused, feeling stressed or pressured, feeling apathetic or helpless or becoming oppositional or unwilling to learn. Over a third of studies reported students becoming cognitively disengaged ( $n=30$ studies, 37\%), which was most commonly associated with students being 'confused' and having problems understanding or following lesson content ( $n=15,19 \%$ ). In some cases, failing to keep up with lesson content was thought to be particularly challenging for more technical subjects (Dema et al., 2021). In an autoethnographic study, 'confusion' was attributed to a feeling of constant change, where students "felt 'more or less [like] an experiment [in which] things are changing very quickly.' The day is no longer 'set in stone'; rather, class time is fluid: time expands and contracts as needed." (Schaefer et al., 2020, p10). The impact of vague and contradictory directives from government ministries was also forwarded as exacerbating feelings of confusion among students (Weinhandl et al., 2021).

\section{Social disengagement}

Social disengagement - disengagement, isolation and poorer quality interactions and relationships with peers and teachers - was mentioned in a third of studies ( $n=26,32 \%$ ). Over a quarter of all studies indicated social isolation ( $n=22,27 \%)$, and $12 \%$ ( $n=10$ studies) described decreased studentteacher interactions. Among those studies that measured social isolation quantitatively, it reached high levels with $73 \%$ of students expressing feelings of isolation in online learning in a study of students in India (Bhaumik \& Priyadishini, 2020). 96.5\% of students in a Polish secondary school study cited a lack of contact with teachers and peers (Kochan, 2021). A number of studies described the perception of teachers that students were missing out on being part of a school community. For example, they had lost the "rounded classroom atmosphere" (Gordy et al., 2021, p. 4) or were described as missing out on the social connections needed to complete their work (Hira \& Anderson, 2021). Social disengagement was reported more frequently in studies conducted in high-income countries (17/44 studies, 39\%) than those conducted in low- and middle-income countries (9/37 studies, $24 \%$ ).

\section{Lower motivation and learning loss}

A consequence of higher levels of disengagement was that students had lower levels of overall motivation (reported in 16 studies, 20\%) and lower motivation was identified as being particularly problematic among lower achieving students in some studies (Nusser, 2021; Mælan et al., 2021; Pelikan et al., 2021). Although the explanations put forward for lower motivation among students were diffuse, a number of studies attributed issues with technology and internet connection as 
explanatory factors (Al Salman et al., 2021; Dema et al., 2021; Hodgen et al., 2020). Meanwhile, students in another study were observed to have lower levels of motivation as a result of broader uncertainty and concerns about the 'state of the world' (Yates et al., 2020) and a small number of studies also attributed lower levels of motivation to home environments that were not conducive to learning where other roles and duties that children have (e.g., caring for siblings, helping with family businesses) may have taken precedence (Azhari \& Fajri, 2020; Sibanda \& Mathwasa, 2021; Yates et al., 2020).

In a number of studies, the cumulative impacts of low motivation and various forms of disengagement translated into a loss of learning (reported in 18 studies, 22\%). A study by Code et al. (2020) documented the perspectives of teachers who were concerned that an online format only allowed for certain parts of the curriculum to be taught: "For the most part, we are not able to teach the most important parts of the curriculum. We can teach theory, or use online simulations for some subjects, but the hands-on skills are lost" (p. 7). There was also concern that learning loss was not experienced evenly across the student body, and that female learners were particularly susceptible to losses in some contexts because of caring duties (Sibanda \& Mathwasa, 2021). However, while concerns about lost learning were raised in a number of studies, others highlighted the difficulty in accurately assessing students' real learning (e.g., Niemi \& Kousa, 2021; see also section on assessment).

\section{Gender implications}

Five studies found no significant difference in the experience of students based on gender: in Jordan (Al Salman et al., 2021), Italy (Ferraro et al., 2020; Pirrone et al., 2021), Poland (Korzycka et al., 2021), and Vietnam (Tran et al., 2020). Although in Korzycka et al.'s (2021) study, girls were significantly more likely than boys to have an issue with the requirements of home schooling ( $59.6 \%$ vs. $53.2 \% ; p=0.001)$. In an Ecuadorian study, Asanov et al. (2021) found that females were more likely to be responsible for household tasks, but that they were $5 \%$ more likely to have engaged in online learning. In addition, females were more likely than their male counterparts to do school work into the late afternoon. Sibanda and Mathwasa (2021) also found that female learners in Zimbabwe experienced particular difficulties in accessing online learning due to household chores, internet access, issues of abuse and distraction. In their study of 324 students using the Metacognitive Questionnaire on Study Method, Pirrone et al. (2021) explored differences in learning strategies, metacognition and study, and attitudes towards traditional in-person schooling and online learning. They found that females performed significantly better than males in all three areas during in-person learning, but that the differences were eliminated as a result of the pandemic. One study of SEND students in Germany (Nusser, 2021) found that home schooling was more challenging for parents if their child was male.

\section{School status implications}

When school status is considered in relation to engagement and disengagement (see Table 5), instances of behavioural engagement were higher and social disengagement were lower where both private schools and government schools were included in a study, compared to studies including only government schools. However, affective engagement was higher in government schools, and incidences of both affective and behavioural disengagement were higher in studies of both private and government schools. In a study of 420 Vietnamese students, Tran et al. (2020) found that students attending private school spent more time on school work during the pandemic than those in government schools ( 4.0 hours compared to 3.4 hours on average). 
Table 5. School status and student (dis-)engagement

\begin{tabular}{|l|c|c|c|c|}
\hline & \multicolumn{2}{|c|}{ Both government \& private schools } & \multicolumn{2}{c|}{ Government schools only } \\
\hline Cognitive engagement & 5 & $63 \%$ & 5 & $56 \%$ \\
\hline Affective engagement & 3 & $38 \%$ & 5 & $56 \%$ \\
\hline Behavioural engagement & 7 & $88 \%$ & 4 & $44 \%$ \\
\hline Cognitive disengagement & 3 & $38 \%$ & 4 & $44 \%$ \\
\hline Affective disengagement & 5 & $63 \%$ & 3 & $33 \%$ \\
\hline Behavioural disengagement & 6 & $75 \%$ & 5 & $56 \%$ \\
\hline Social disengagement & 2 & $25 \%$ & 4 & $44 \%$ \\
\hline
\end{tabular}

\section{Engagement, disengagement and technology}

In order to understand how the various technology types used during emergency remote learning are linked to engagement, a co-occurrence analysis was undertaken between technology and instances of overall behavioural, cognitive and affective engagement (Table 6). The analysis revealed that the types of technology tools with the highest incidences of reporting engagement were assessment tools (e.g., online quizzes or polling such as Kahoot!), knowledge organisation \& sharing tools (e.g., Learning Management Systems, LMS), social networking tools (e.g., Facebook), social collaborative tools (e.g., live video lessons) and multimodal production tools (e.g., recorded videos).

Overall, few studies that employed video conferencing reported aspects of student disengagement, with (approximately) one-in-ten or fewer of the 46 studies using video conferencing reporting on aspects of student disengagement (behavioural, affective, cognitive or social). In contrast, reports of student disengagement were more common in studies that reported learning taking place through videos produced by teachers, video materials produced by other sources, or Google Classroom. For example, among the 24 studies where learning took place through Google Classroom, between twofifths and half of studies reported instances of behavioural disengagement ( $n=11,46 \%$ ), affective disengagement $(n=9,38 \%)$, cognitive disengagement $(n=12,50 \%)$ or social disengagement $(n=10$, $42 \%)$. Similarly, although only a fifth of studies overall reported low motivation ( $n=16,20 \%)$, this was higher among studies using Google Classroom ( $n=8,33 \%$ ). Similar distinctions were observed in studies using teacher-produced videos and videos from other sources, as well as studies reporting using WhatsApp for online learning. However, such differences should be interpreted with caution, given that reports of disengagement were often also accompanied by reports of positive engagement. Furthermore, the depth of evidence to support these numbers differed across and within studies. Nevertheless, overall, it was observed that studies using YouTube $(n=14)$ reported behavioural engagement most frequently relative to disengagement ( 8 vs 4 studies) and the same was true for affective engagement ( 8 vs 3 studies). Meanwhile, studies using teacher created videos $(n=18)$ reported cognitive engagement vs. disengagement more frequently ( 9 vs 6 studies). Overall, the quality of evidence and the instances of engagement and disengagement occurring within the same study, makes it difficult to identify any one form of technology over another as having a harmful impact in terms of disengagement. While the findings relating to specific tools are interesting and may stimulate further enquiry, their scope is limited to descriptive purposes only. 
The role of online assessment tools on student engagement

Studies that used online assessment tools, such as quizzes or polling software (e.g., Kahoot!), indicated a heightened level of both affective and behavioural engagement $(71 \%, n=10)$. In particular, they were found to assist students' study habits, helping them to assume responsibility for their learning by promoting reflection and confidence (Education Scotland, 2021). Students particularly enjoyed the gamification element of apps such as Kahoot! (e.g., Yates et al., 2020). Online assessment tools will be discussed in greater detail under research question two below.

Table 6. Relative frequency of studies using technology types and student engagement

\begin{tabular}{|c|c|c|c|c|c|c|c|c|c|c|}
\hline & SCT & MPT & SNT & KOS & TBT & AT & LG & WCT & DAT & VW \\
\hline & $n=47$ & $n=31$ & $n=8$ & $n=37$ & $n=35$ & $n=15$ & $n=2$ & $n=1$ & $n=1$ & $n=1$ \\
\hline Cognitive Engagement & $53 \%$ & $55 \%$ & $50 \%$ & $54 \%$ & $43 \%$ & $47 \%$ & $50 \%$ & $100 \%$ & $100 \%$ & $100 \%$ \\
\hline Affective Engagement & $55 \%$ & $55 \%$ & $63 \%$ & $51 \%$ & $46 \%$ & $67 \%$ & $100 \%$ & $100 \%$ & $100 \%$ & $0 \%$ \\
\hline Behavioural Engagement & $62 \%$ & $58 \%$ & $63 \%$ & $62 \%$ & $51 \%$ & $67 \%$ & $100 \%$ & $100 \%$ & $100 \%$ & $100 \%$ \\
\hline
\end{tabular}

Note: SCT = Social collaborative tools, MPT = Multimodal production tools, SNT = Social networking tools, KOS = Knowledge organisation \& sharing tools, AT = Assessment tools, $\mathrm{LG}=$ Learning games, $\mathrm{WCT}=$ Website creation tools, DAT = Data analytics tools, VW = Virtual worlds

\section{The role of Learning Management Systems on student engagement}

Many schools were able to turn to the use of Learning Management Systems (LMS) quickly, given the large number of secondary schools who already had them in place (Bond, 2020b). The effective use of LMS was linked to students developing better study habits and self-regulation skills. Students reported feeling a heightened sense of control over their own learning when activities were self-paced (Chiu, 2021), as well as feeling more motivated and supported by their teachers (Yates et al., 2020). Google Classroom was the most used named platform (30\% studies) and it was found particularly useful due to its accessibility (Atmojo, 2020) and the ability to post assignments, share videos and provide feedback (e.g., Rusmansyah, 2021). LMS that featured collaborative tools, such as Google Classroom, promoted a sense of wellbeing and positive interactions with peers, over those platforms without such tools, which was in agreement with a previous pre-pandemic review (e.g., Bond, 2020a).

\section{The role of social networking tools on student engagement}

Social media was used by teachers as a way to communicate with students and parents, using technology that they generally already had access to and were comfortable with using. For example, one teacher used Snapchat in their class and reported that it was the most successful tool for reaching and engaging learners (Primdahl et al., 2020). A STEM activity from a Portuguese study (Baptista et al., 2020) involved students conducting inquiry-based investigations into the noise level where they lived, and in creating posters and videos for people in their local area about the health effects of noise pollution. The posters and videos were then disseminated on social networks, such as Facebook and the school's website, which raised the interest level and the authenticity of the task for students. Parents also assisted with creating the videos, which enhanced the experience greatly for students. In a study by Langansan (2020), social media helped break down barriers between teachers, students and parents, as the teacher created Facebook groups for each class, creating announcements of work due and had group chats for teachers and parents to keep lines of communication open. However, despite the reported benefits of using Facebook Live for conducting synchronous lessons, adequate 
internet connectivity was an issue in some cases (e.g., Chirinda et al., 2021) and many teachers opted for WhatsApp ${ }^{7}$ instead (Lawrence \& Fakuade, 2021).

\section{The role of live synchronous lessons on student engagement}

Live lessons (e.g., through Teams or Google Meet) were by far the most mentioned learning tool (57\% of studies). In studies where synchronous live video lessons were used, instances of engagement were found in more than double the number of studies than instances of disengagement. The use of breakout rooms for students to work together in groups was particularly engaging (Education Scotland, 2021) and interactive approaches for social online meetings, such as scavenger hunts and trivia were particularly popular (Easterly et al., 2021). Allowing students to use the chat function within live lessons also promoted peer interaction and peer teaching (Hodgen et al., 2020), as did providing social time at the beginning and end of lessons for students to catch up with each other in a more informal setting (Lepp et al., 2021).

\section{The role of recorded videos on student engagement}

Videos made by those other than their teachers resulted in higher levels of behavioural and affective engagement in students ( $83 \%$, as opposed to $50 \%$ for videos made by teachers), including heightened interest (33\%) and enjoyment (17\%). However, videos made by teachers were more likely to be mentioned alongside a sense of wellbeing ( $28 \%$ over $17 \%)$, understanding $(22 \%$ over $17 \%)$ and study habits (33\%).

\section{Research question 2: How did research report on emerging online assessment practices in secondary schooling during the pandemic?}

The shift to online learning meant that traditional forms of assessment, such as controlled pen and paper tests in the classroom, had to be adapted for the remote setting. Of the studies included in this review, the most frequently reported assessment types were online quizzes ( $n=13,16 \%$ ) and formative online feedback $(n=13,16 \%)$, followed by online conversations or speaking assessments ( $n$ $=6,7 \%)$, images $n=5,6 \%)$ and online exams $(n=4,5 \%)$.

Exploring the results further, we found that most studies mentioned one type of assessment; although, a recent report of Scottish schools (Education Scotland, 2021) mentioned at least nine different types of assessment. Overall, we identified 21 types of online assessment tool. Less common types included checklists $(n=3,4 \%)$, self-assessment $(n=6,7 \%)$, peer assessment $(n=3,4 \%)$, ePortfolios $(n=3,4 \%)$, projects ( $n=2,2 \%)$, reflective learning journals $(n=2,2 \%)$, and videos $(n=2$, 2\%). Other assessment types included at home experiments (Babinčáková \& Bernard, 2020), choose your own adventure (students can choose their own learning path) (Lepp et al., 2021), online debates (Yan, 2021), and research projects (Schaefer et al., 2020).

\section{Online quizzes}

Many studies reported using online quizzes, citing that they were easy to correct (Aldossry, 2021), could be used to rehearse recommended elements (Hodgen et al., 2020), "reduce student boredom in online learning" (Suliani et al., 2021, p. 2), allow students to learn at their own pace, reduce stress during testing (Velichová et al., 2020), and allow teachers to gain insight into student learning

7 It should be noted here, however, that WhatsApp was coded under Text-based Tools, and not under Social Networking Tools or Synchronous Collaboration Tools. 
processes. Some teachers chose to use the built-in quiz feature in the school LMS (Aldossry, 2021) or they created their own using Google Forms (Amelia et al., 2020; Atmojo \& Nugroho, 2020; Cheung, 2021; Rahayu \& Wirza, 2020). Several studies conducted online quizzes through Kahoot (e.g., Education Scotland, 2021; Kaden, 2020; Velichová et al., 2020) and commented on the perceived usefulness of the gamification aspects (Yates et al., 2020). For example, "Through their responses in the Kahoot! game, I can see what mistakes they are making and how much they can understand." (Cheung, 2021, p. 9).

\section{Formative online feedback}

To ensure students were provided with timely feedback on their work, several studies reported a use of built-in LMS features to provide written or recorded responses (e.g., Aldossry, 2021; Kaden, 2020), or used communication applications such as WhatsApp (Budianto \& Arifani, 2021; Okebukola et al, 2020). For example, one study used Formative, which was "incorporated into the course's technology portfolio at the start of remote learning for submission of all previously 'hard-copy' assignments (lab packets, quizzes, tests)" (Kelley, 2020, p. 2).

Engaging in synchronous online learning was identified as a means to provide formative feedback in real-time, where regular learning activities such as presentations, writing, debates and role-plays provided opportunities for dynamic assessment (Hu \& Huang, 2021), as well as a place for teachers to directly praise students (Rusmansyah et al., 2021). In addition, the use of "the chat panel during live learning to ask and answer questions" and the "use of emojis and symbol responses" (Education Scotland, 2021, p4) were used for formative assessment, with more informal feedback using the 'thumbs up' or 'hands up' features helping to gain a snapshot of student engagement and progress.

Receiving adequate feedback from teachers was a concern raised by both student and parent participants in several studies. One study suggested that teachers had been advised to be less strict during the pandemic and to provide formative feedback instead of focusing on assessing grades (Lepp et al., 2021). One student lamented:

"Teachers ask for homework, make us send it, I spend all day doing the homework, send it to them, and they don't give me my grade, I think they don't check the homework, they just check if somebody sent them, and if not, they give them a bad mark (' 1 ') with no chance for improvement" (Korzycka et al., 2021, p 6).

A number of studies also found that teachers struggled to provide formative feedback during online learning and in some cases were unsure if their students were learning, which highlights the impact of the loss of immediate feedback and communication in the online environment (e.g., Cheung, 2021). Hodgen et al (2020) noted that " $46 \%$ of schools provided comments on pupils' work less frequently" and that "teachers expressed frustration about providing formative feedback due to lack of live interaction with pupils". Classroom interactions online can be characterised by teacher efforts to help students achieve learning objectives and gauge actual progress, while trying to overcome the hindrances of students' passive participation and tendency to follow "a modelled explanation of how to do something" (Hodgen et al., 2020, p 21). When teachers cannot identify if their students are actively learning, this may impede feedback and be a barrier to effective learning (Cheung, 2021; Hodgen et al., 2020).

\section{Online conversations or speaking assessments}

Some studies commented on the usefulness of conversation as a method of assessment, particularly for modern languages (Education Scotland, 2021; Yan, 2021). Students recorded themselves speaking 
or listened to recordings of their teacher speaking, in order to improve pronunciation (Hu \& Huang, 2021). Similar methods were used for Drama performances and to rehearse dialogues and presentations (Education Scotland, 2021). In other subjects, personal conversations with students were found to be a powerful way for teachers to informally check student understanding (Chirinda et al., 2021; Kaden, 2020).

Images

Lepp et al. (2021) pointed out that teachers often offered a range of ways to submit homework, including using images, submitted through the school LMS or in hard copy. Images could be sent either by emailing photos of their work (Kochan, 2021; Lepp et al., 2021), or using tools such as Flipgrid (Kaden, 2020). Some teachers asked students to prove that they had completed the task by taking photos, such as when carrying out lab experiments and cooking tasks at home (Easterly et al., 2021; Education Scotland, 2021). One example included students taking pictures of food nutrition labels; to ensure that students had actually done the work themselves rather than finding the photos online, teachers asked students to be in the photo as well (Easterly et al., 2021).

\section{Online exams}

Two studies found that most students were examined online during the period of remote learning (e.g., Kochan, 2021). Bhaumik and Priyadishini (2020) found that a slight majority of the students (52.7\%) felt "ease in appearing for online exams after gaining familiarity with online learning" (p. 9) and concluded that as online learning becomes more familiar to students, so will online exams. Other studies (Budianto \& Arifani, 2021; Willermark, 2021) reported that teachers found it hard to manage cheating in the online setting, which demonstrates the limited readiness of many schools for the online shift. Willermark (2021) added that school leaders had become aware of the extent to which teachers relied on examinations for grading in traditional learning and expressed that exams "have received too much focus among teachers" and that "teachers should become better at trusting their own judgment, [particularly, with students they have taught for many years]" (p. 14).

\section{When assessment did not work}

It should be noted that some studies commented that teachers felt they lacked "knowledge on how to conduct tests efficiently and quickly, and with good quality" (Rap et al., 2020) and that some education departments and institutions decided to cancel assessments (e.g., Hodgen et al., 2020) and halt grading (Easterly et al., 2021). Another reason assessments were delayed was because government policies prohibited or restricted such online practice. For example, Rap et al. (2020) reported that at-home chemistry experiments were not permitted for many Israeli teachers due to legal restrictions. Interestingly, in Ghana, online learning was not permitted at all and in Morocco and Senegal all assessments were suspended. Later in the pandemic, the Ghanaian government began to consider using online assessment (Okebukola et al., 2020). In South Korea, The Ministry of Education instructed schools to halt all assessments until they could be done in person in the classroom (Jeong \& So, 2020).

\section{Research question 3: Are new approaches to peer collaboration emerging and what does this suggest?}

This review also focused on peer collaboration which had previously been identified as an aspect of online learning which is challenging for teachers to facilitate (Bergdahl \& Nouri, 2020). The association between constructive, well-designed peer collaboration and improved learning outcomes is wellestablished for secondary school students. The loss of in-person peer support during the remote learning period forced schools to create new methods of online peer collaboration. These new 
methods included redesigning existing learning activities for an online mode, combining digital devices to allow for peer collaboration and an increased focus on the social aspects of engagement. While there were several instances of creative practices, emerging challenges were also identified and are discussed below.

Learning activities in an online mode

As previously discussed, several studies were of live classes using applications that support (synchronous) communication, such as Google Meet, MS Teams and Zoom (e.g., Aldossry, 2021; Baptista et al., 2020; Bhaumik \& Priyadishini, 2020; Kaden, 2020; Turchi et al., 2020). Within these applications breakout rooms were used to undertake inquiry-based group work (Baptista et al., 2020), work on experiments (Kelley, 2020), develop interactive ePortfolios (Weinhandl et al., 2021), conduct online debates (Yan, 2021), assess work with peers (Education Scotland, 2021), or revise and edit work (Turchi et al., 2020). Several studies highlighted a particular focus on student discussions; for example, by building on literature and using 'Dialogic Literary Gatherings' to listen and learn from each other online (Ãlvarez-Guerrero et al., 2020) or by the teacher choosing discussion topics that encouraged social engagement (Chirinda et al., 2021). The increased focus on student social interaction was likely a deliberate effort by teachers to counteract the social isolation students faced during the pandemic.

While online peer collaboration was primarily facilitated through video conferencing systems (Google Meet, MS Teams and Zoom), some alternative methods emerged, such as: involving students in an online group campaign and using social media production, where students co-created digital posters and videos that were distributed on line to the local community (Baptista et al., 2020), using discussion boards to facilitate one-to-one sharing of ideas and conduct school work with peers (Turchi et al., 2020), or developing and testing a new LMS to support teaching/learning and interaction (Aldossry, 2021; Oraif \& Elyas, 2021). One study pointed out that peer interactions were dependent on teacher innovativeness (Chirinda et al., 2021). While new approaches were identified, some approaches remained traditional; for example, the comment feature and/or 'suggesting mode' in Google applications enabled a simple form of peer feedback and collaboration (Yan, 2021). Using Google applications for learning may be considered traditional, as Google documents have been used for peer collaboration in classrooms for more than a decade (e.g., Kittle \& Hicks, 2009; Rienzo \& Han, 2009; Rhine \& Bailey, 2008). However, it may have been perceived as new if students had not used this tool from home before (Chiu, 2021).

Several studies reported that other applications such as Facetime (Weinhandl et al., 2021, Yates et al., 2021) were used to support peer collaboration. The use of WhatsApp as an educational tool yielded mixed results, with some studies citing problems when using the application as the primary education tool (e.g., Agustin Mawarni et al., 2020; Budianto \& Arifani, 2021; Chirinda et al., 2021). Another study referred to WhatsApp as 'the most liked' application (Nawawi et al., 2021). The mixed responses may reflect the variety of ways the tool was implemented for different purposes and the degree to which the technology was aligned with a pedagogical approach.

How practical, aesthetic and theoretical subjects combine modalities to support peer collaboration

Practical and aesthetic subjects may be viewed as subjects that, perhaps more than the theoretical ones, are dependent on non-verbal communication and embodied modelling ${ }^{8}$ (e.g., Hira \& Anderson,

8 The teacher uses body language to communicate and model exercises and actions. 
2021). Among the studies there were examples of teachers who used multiple devices that enabled students to learn choreographed sections from each other in dance classes: "the dance class used Google Meet, which allowed for students to teach each other choreographed sections and work independently in virtual studios. /.../ Moreover, while trying to teach a new dance, both a computer and phone were used to communicate through Google Meet and play music on" (Yan, 2021, p. X). In music classes, it was reported that students would regularly need to combine devices to enable peer interaction; for example, their instrument and at least one application for communication. Music educators noted an improvement in the way students shared their ideas and took part in online ensemble groups compared to traditional learning (Bruin, 2020). In more theoretical classes, examples of peer collaboration included using chat messaging during synchronous classes. One teacher stated: "so pupils will make comments. Other pupils will respond from that and then you will get a series of inter-connected responses, so I'm just sitting back, watching the chat take place whilst they're talking to each other and helping to answer each other's questions" (Hodgen, 2020, p 21).

\section{Social presence to support social engagement}

A significant number of studies mentioned that students longed for social interaction and that their social needs were not met during the pandemic (e.g., Almarashdi \& Jarrah, 2021; Jayathirtha et al., 2020). One study found that support for social engagement was critical (Yates et al., 2021) and suggested that some students might attend online classes just to see their classmates (Easterly et al., 2021). Some teachers reported prioritising social engagement with peers before learning goals (Lepp et al., 2021). In some cases, both teachers and students took the initiative to form groups that could work together (synchronously and asynchronously) (Turchi et al., 2020) and plan mutual activities to take place after the pandemic, which was found to strengthen the social structure (Weinhandl et al., 2021) and respect (Ãlvarez-Guerrero et al., 2020) between the students. A notable number of studies reported that students felt that they were 'together' when meeting online (Ãlvarez-Guerrero et al., 2020; Nawawi et al., 2021; Weinhandl et al., 2021) and that digital technologies in fact supported better peer-peer communication (Nawawi et al., 2021). However, Yates et al. (2020) noted that fewer than $10 \%$ of the students reported that online collaboration was better than in-person interaction.

Importantly, several studies highlight that not all students are comfortable with the social arena that school provides (Lepp et al., 2021). One study commented that students, when they were allowed to, preferred working individually at their own pace (Turchi et al., 2020). However, not all synchronous communication applications were effective at supporting peer collaboration in all situations. While some studies showed that a majority of students reported 'getting ample opportunity' to interact (e.g., Bhaumik \& Priyadishini, 2020), studies more frequently pointed out that peer interactions were dependent on the individual teacher's innovativeness (Agustin Mawarni et al., 2020; Bruin, 2020; Chirinda et al., 2021) and actual skills to implement effective interaction and group work (Primdahl et al., 2020; Niemi \& Kousa, 2020). Therefore, it appears as though the quality of communication and peer interaction depends on teacher insights, skills, available technologies, choice of technologies, and crucially, whether the chosen technology is accessible by all students. However, the idea that remote learning may lead students to want self-paced and individual work, focusing more on individual student progress and task completion (Turchi et al., 2020), may be in opposition to purposeful peer collaboration. Another interpretation may be that not all students were equally comfortable with online interaction (Bhaumik \& Priyadishini 2020; Willermark, 2021; Yan, 2021) or that students were unhappy with how the teacher orchestrated online collaboration (Yates et al., 
2021). Some studies identified teachers who acknowledged students' different preferences and provided opportunities for peer collaboration for those who wanted it (Lepp et al., 2021).

Synchronous interaction emerging norm in distance teaching and learning

Findings reveal emerging practices to enhance peer collaboration in online teaching and learning in secondary schools. Some reports concluded that synchronous learning methods were optimal as they encouraged "participation and interaction with the teacher to a far greater degree than recorded study or online self-study" (Aldossry, 2021, p. 5) and that learners reported benefits from peer interaction (Hodgen et al., 2020) and appreciated synchronous interaction (Education Scotland, 2021). One study reported that when offered both synchronous (e.g., Meet, Teams, Zoom) and asynchronous (e.g., a forum) teaching and learning, students would ignore the asynchronous resource and only attend synchronous classes (Aldossry, 2021). Another study stated that peer collaboration is critical for supporting students from diverse backgrounds, where the time between peer or teacher interaction, if not synchronous, should be minimised (Jayathirtha et al., 2020). The findings reveal that many teachers struggled with enabling peer collaboration in the online setting (e.g., Hodgen et al., 2020; Jayathirtha et al., 2020; Rap et al., 2020). One study stated that nearly half of the teachers in one study did not make any effort to enable students' collaboration (Rap et al., 2020). Another study found that "there were few (if any) opportunities for peers to see each other's work or to learn from and support each other, which was a core pedagogical practice used across many e-textile teachers" (Jayathirtha et al., 2020, p. 7) and that "almost none of the schools facilitated live interactions between pupils, with many citing safeguarding concerns rather than technical issues" (Hodgen et al., 2020, p 21). One study reported that nearly $40 \%$ of the students experienced challenges when seeking to interact with peers (Agustin Mawarni et al., 2020). Several studies reported on hesitancy amongst teachers to facilitate peer-collaboration which may reflect the limited training and the uncertainty surrounding the speed with which many tools were adopted.

\section{Research question 4: How did online learning in secondary schools affect parent engagement?}

Parental engagement with their child's online learning was perceived as highly important in the studies in this review. A large study in Nigeria found that parental involvement improved students' commitment to online learning (Lawrence \& Fakuade, 2021). Another relatively large Indonesian study found that parental involvement in learning was significantly increased during the remote learning period (Zakso \& Agung, 2021) and a group of Portuguese teachers regarded increased parental involvement as one benefit of the pandemic (Baptista et al., 2020).

Students welcomed their parents' help with online learning (Álvarez-Guerrero, 2021; Ang \& Wu, 2021; Kochan, 2021; Trung et al., 2020; Zakso \& Agung, 2021,). They highlighted the importance of their parents for securing access to online resources, providing a suitable home-learning environment, reducing household chores and for supporting them emotionally (Kochan, 2021). Parents also provided guidance and supervision (Álvarez-Guerrero 2021; Ang \& Wu, 2021; Kochan, 2021; Nusser, 2021), which students found helpful for enhancing their understanding of the subject matter (Kochan, 2021). Parental support with online learning was especially important when students were required to produce visual material, such as videos (Baptista et al., 2020). A Vietnamese study found that family support was a key extrinsic motivation factor that influenced students' learning effectiveness (Tran et al., 2020). 
Unfortunately, not all parents had the financial resources to give their children sufficient access to online learning (Sibanda \& Mathwasa, 2021; Okebukola et al., 2020). In addition, students were encouraged to make use of their parents' electronic devices, which may have been used by multiple children or needed by parents for their own work, and guidelines were developed to help parents set up parental controls (Okebukola et al., 2020). In remote areas lacking infrastructure and facilities to provide remote learning, parents collected lesson materials from schools and delivered their children's assignments in-person (Azhari \& Fajri, 2021).

Teachers communicated with parents through WhatsApp (Okebukola et al., 2021), by phone and text messages (Azhari \& Fajri, 2021), or by email and phone (Clausen et al., 2020) both directly and using the school LMS (Clausen et al., 2020; Okebukola et al., 2021). Teachers sometimes contacted parents to explain the rules of online sessions (Okebukola et al., 2020), to follow up on student progress (Azhari \& Fajri, 2021) and to check on students who were absent (Bhattarai, 2020).

This review found that parent-teacher communication was most affected in lower middle-income areas. Several Indonesian schools contacted parents through a "teacher-on-duty" in school. In some African countries, literate parents were encouraged to open email accounts for themselves and their children to maintain communication with teachers and submit assignments (Okebukola et al., 2020). Yet even in wealthier regions, teachers and schools encountered difficulties trying to reach families; Clausen et al. (2020) found that teachers failed to contact more than half of students (59\%) resulting in parents being unaware of their children's assignments.

Two of the 14 studies that analysed different dimensions of parental engagement, looked at the experiences of students with special educational needs and disabilities (SEND). A Spanish study found that parental support during synchronous sessions was crucial for mediating communication between teachers and students in discussions of literary texts in the context of Dialogic Literary Gatherings (DLG) (Álvarez-Guerrero, 2021). Another study found a substantial discrepancy between the time that parents of students with and without SEND spent supporting their children, with parents of students with SEND spending more than twice the amount of time than parents of students without SEND; however, the parents of SEND students rated their perceived ability to support their children more highly (Nusser, 2021).

\section{Examples of little or no support}

There are a few reported instances in which parents did not support their children's online learning. For example, some families failed to see the benefits of remote teaching and therefore did not encourage children to join online sessions (Bhattarai, 2020). In other cases, inequalities in access to remote learning were aggravated by increased demands on girls to complete household chores or parents fears that they could misuse newly found internet access (Sibanda \& Mathwasa, 2021). A small number of students felt their parents lacked the knowledge to support them with their learning (Kochan, 2021). Unsurprisingly, the shift to emergency remote learning, coupled with parents working from home, had varying effects on family relations, both positively and negatively. A study reported that a conservative amount (10.5\%) of surveyed students $(n=114)$ did not perceive large alterations in their family dynamics (Kochan, 2021). 


\section{Research question 5: What emerging uses of online and blended learning approaches in secondary schools could continue to be implemented going forward?}

Equity considerations need to be at the forefront when assessing the potential of online and blended learning

Teaching practices during the pandemic were immensely varied, particularly between high- and lowincome countries. Online teaching and learning require a basic level of infrastructure, digital accessibility, usability and digital competence from students, parents and teachers alike. As such, recommending one way forward for online learning globally is problematic and beyond the scope of this review. Nevertheless, many common themes emerged from the diverse literature included in this review, which could help to build a general guide for raising the minimum standards of online learning in the future, helping to identify a set of principles that should be implemented or retained going forward.

Despite assurances that we are 'all in this together', the pandemic has not impacted all members of society equally but has in fact exacerbated existing inequalities (Bambra et al 2020). While the unequal impacts of the pandemic have been a focus of a number of studies on health and mental health (although there is still considerable work to be done in these area), systematic study of educational inequalities are only just beginning to be explored. In this review, we observed that the transition to online learning has disproportionately impacted some groups. In particular, students of lower ability were identified as being more susceptible to some of the negative impacts of online learning, such as low motivation. Similarly, girls' education was more likely to be disrupted because of caring duties and other pressures, in some contexts. Meanwhile, large numbers of students globally have been disadvantaged by having limited availability to technological equipment, internet connection and a lack of an appropriate working space for online learning. Some authors of studies in this review attributed these challenges as a barrier to students' motivation. These challenges were foreseeable, although few of the studies described measures taken to ensure equity in access to online learning. In future, it may be advisable to harness teachers detailed and personal insights in order to differentiate and individualise content and assessment strategies, to ensure a more equitable approach to online learning for all students.

\section{Engagement and disengagement}

New online teaching materials developed during the pandemic should be regarded as a sustainable resource that can be reused and developed further going forward. Several studies reporting instances of positive student engagement where those where online learning took place in the form of teachergenerated videos. Teacher-generated videos enable students to re-watch content, which may represent an opportunity for teachers to reuse the videos and reduce the workload associated with remaking resources each academic year. Teacher-generated videos and online quizzes could be integrated within normal in-person schooling, to consolidate understanding and ensure students have a sustainable workload. However, findings also indicated that some teachers struggled with digital innovation and that the level of teachers' digital literacy impacted the quality and variety of online learning experiences offered to students. Some studies have pointed out that students experience sore or strained eyes from excessive screen-time. To avoid monotonous teaching practices, ongoing teacher professional development is key. Such professional development should be integrated throughout a teacher's career, should be updated in line with new technologies and pedagogical 
advances and should educate teachers on effective online learning design methods that supports student engagement.

Assessment methods that combine brief and deep insights should be integrated into students' learning

Online quizzes can enhance student understanding, as well as provide teachers with a quick idea of student progress. In contrast, recorded teacher or peer feedback and assessment tasks provide students with opportunities for deeper reflection and improvement. A blend of both types of assessment can help to maintain student engagement and the development of creative and innovative assessments can drive teacher creativity and professional development. However, the evidence in this review also indicated that over-assessment risked overwhelming students and potentially also staff responsible for marking assessments, leading to demotivation. Therefore, the development of new assessments should be planned in tandem with guidelines on how to balance considerations of student wellbeing, tracking students' educational progress and teacher workload and skills.

Opportunities for peer collaboration should be integrated into online learning

Online learning should be designed in a way that supports peer collaboration and robust guidelines need to be developed so some students do not miss out on this important aspect of learning. The variety of examples cited in this review could be used to inform local best practices on peer collaboration, to support schools looking to develop policy to support student social needs outside the classroom and to guide the choice of useful technologies for enabling such policies.

Parental engagement is key to online learning, which opens new ways for teachers to engage with parents

Parental engagement was found to be a key facilitator of successful online learning. Despite secondary school students being on a pathway to becoming independent learners, they still valued parental input in their learning and parents were involved in facilitating online learning in a number of ways from sharing equipment to helping with practical tasks and assignments. The transition to online learning allowed many parents to become involved in their children's education in a much more regular way than prior to the pandemic, which has provided greater opportunity for parents and teachers to communicate and work together to improve students' learning. However, not all parents could or would engage to the same extent, which may deepen inequalities and widen the attainment gap, and some studies noted difficulties in contacting parents. Therefore, schools may need to use alternative forms of communication to reach some parents and families, particularly those who lack access to online technology, and schools may need to create bespoke plans for parents to engage with their children's learning. In addition to communicating the benefits of remote learning to families, teachers and schools may also need to gain a better understanding of home learning environments and the support available at home. This again reflects a need to develop individualised strategies for supporting parents, and in particular parents of students with SEND or students with low attainment, to ensure online learning does not exacerbate educational inequalities. 


\section{Discussion and conclusion}

Plans for future unscheduled school closures

As a result of the shift towards online teaching and learning, some established and perhaps traditional views of education have been challenged. For instance, the question of how, when, if and to what extent assessments should be conducted, and also how effective communication and socialisation can take place online (i.e., student-student/teacher; student/parent - school/teacher communication). Apart from the varied digital infrastructure and the quality, accessibility and usability of digital technologies and resources, we identified a noteworthy number of articles indicating that teacher digital insecurities determined how well teachers designed online learning activities that enable peer interaction and collaboration. Formative assessment continues to be a reliable way to inform teachers on student progress and develop their (online) practices. While 21 different strategies to assess students online were identified, most teacher, school and even national governments displayed reactiveness rather than proactiveness to shift to online schooling. Thus, ongoing, integrated and targeted teacher digital professional development, clear school, local authority and government guidelines, accessible high-quality technologies and the development of contingency plans will help build resilience and ensure continuity of high-quality education during times of crisis, and are critical going forward.

\section{Support and social engagement}

Student social engagement covers the need to feel supported by teachers and parents, and a feeling of having one's social needs met through collaboration and interaction with peers. As has been presented in this review, much of the research conducted during the period of rapid educational change explored student engagement and related aspects, such as peer collaboration, parent support and assessment. The results show the foci of exploration across studies globally (often expressed in percentages). Informed by previous understanding, these percentages reflect that student engagement in general and social engagement, in particular, are critical. The social restrictions due to school closures and lockdowns have amplified a longing for social inclusion, but despite a handful of positive examples, this review found that students' social needs were often not met. After the first year of the pandemic, innovative approaches are not merely using Google Meet, MS Teams or Zoom for learning, but rather adapting learning designs, combining digital devices (e.g., Yan, 2021) or finding creative ways of using these applications (e.g., Baptista et al, 2020) while striving to create a sense of a social community between teachers and students (e.g., Weinhandl et al, 2021) and creative ways for assessment (Easterly et al., 2021; Education Scotland, 2021). Opportunities for peer collaboration are vitally important when learning online during a pandemic with social distancing. Peer-peer interaction can instil a sense of social presence and inclusion, and is critical for student engagement.

While this report identified increased parental engagement during the pandemic, parental involvement and support with online learning was not common for all. This finding should inform directed interventions to increase parental engagement in case of future pandemics. Results reveal that parents would provide high levels of support, but that social inequalities affected the capacity of some parents to provide materials and a suitable study space for their children. Teachers should be made aware of any issues with access to technology/suitable study space, so learning activities can be designed accordingly. Dietrich et al. (2020) found that receiving support is critical for online learning, as students who do not receive support invest considerably less time and effort than students who receive daily support. In the case of future lockdowns or school closures, schools should prioritise supporting students' social needs, while acknowledging that these may vary between students. 
Informing future strategies

In terms of the future of teaching and learning after the pandemic, synchronous in-person instruction seems to be here to stay. Results indicate that the teachers with good technological knowledge and skills pre-pandemic seemed to embrace the online learning switch more seamlessly to facilitate effective learning, collaboration and assessment. Mindful of the changing conditions of today's global society, with pandemics and extreme weather events becoming more common and the emergence of ever more advanced digital capabilities, schools must adapt to digital technologies and develop the digital skills of teachers and students in readiness for the future. In addition, there is a need for parents to be provided with additional support during periods of remote learning. An increased provision of training in using technology for teaching and learning, for both teachers and parents, is highly recommended. Even with such standardised professional development, it is unlikely that we will see balanced progression across all schools. Rather, as is the case currently, some schools will take a lead in their development, which is why best practice guidance within school districts may be beneficial for schools who lack the means or the initiative to innovate. Such guidance should endeavour to address a range of issues including student and teacher workload, tailored advice on planning and teaching online, carrying out online assessment and student and teacher well-being. This should include consideration for teaching and learning activities away from screen, one-to-one time with teachers, alternative routes for teacher-parent communication, progression monitoring and social activities between lessons and after school. The pandemic has exposed a risk of increased discrepancies across teachers and schools. There is more appetite and motivation in some regions for schools and teachers to embrace the changes and capture the momentum to provide effective, sustainable teaching and learning online. More research is needed to inform stakeholders of the implications of reduced social presence with online teaching and learning and the effect on young students' social-emotional development.

\section{Limitations of the review}

This systematic review was limited to English-language research, indexed in four databases or found through manual searching. Whilst the databases used have been found to be comprehensive and appropriate for evidence synthesis (Chen, 2020; Gusenbauer \& Haddaway, 2020), valuable research published elsewhere or in languages other than English might have been missed. After the initial search, several studies were identified that involved both primary and secondary level education. Given the inherent differences in maturity and self-regulation, and therefore capacity for independent learning between primary and secondary school-aged students, it was determined that primary level findings (particularly in the context of the pandemic) would not be translatable to secondary-level education. Therefore, several studies that pooled data from primary and secondary levels were not included in this review. Studies in this review vary in the rigour with which they were conducted, however quality appraisal was undertaken to help mitigate this issue.

While this review has synthesised a range of emerging practices, there is a need for further research and local policy development, particularly in relation to online assessment, to develop guidelines for emerging assessment practices. Specific consideration of how to manage cheating, support student well-being and the impacts new tools will have on teacher workload should be a priority. Stakeholders who evaluate digital technologies and resources should consider the practical hindrances to implementing online assessment practices effectively. Developers and buyers of digital tools and resources for assessment need to recognise the wide variety of assessment practices (as described in 
this review) that can be undertaken online and assessment tools should be designed based on subject or skill specific needs. The authors acknowledge that there are other important aspects of online learning to consider such as the potential for discrimination and cyber-bullying, issues around safeguarding and ethical concerns, and matters of data privacy and data security. Although these were not a focus of this review this should not be interpreted as their being less important.

\section{Future research and development}

Future systematic literature reviews could examine additional aspects of online learning. On a student/school level, systematic reviews exploring discrimination, specific learning design for students with SEND and school refusers, or interventions to support re-entry to school for students who have dropped out during the pandemic are needed. Stakeholders should focus on the development of contingency plans, addressing the challenges reported in this review and include specific policy relating to safeguarding, data privacy and ethical concerns, to build resilience to future crises. During the pandemic, the accessibility and usability of digital technologies and resources enabled or hindered successful education. One report (Education, 2021) suggested that software developers could 'consider ways of facilitating interactions and personalised feedback'. The findings of this review reiterate this need and emphasise that as several studies banned assessments and cited teacher insecurities implementing equal and fair online assessment, that research into online assessment is needed alongside development of local policies in this area. 


\section{References}

Agustin Mawarni, I. T., Ratnasari, N., Handayani, A. N., Muladi, M., Aji Wibowo, E. P. \& Sri Untari, R. (2020). Effectiveness of whatsapp in improving student learning interests during the COVID-19 pandemic. 4th International Conference on Vocational Education and Training (ICOVET) (pp. 248-252). Institute of Electrical and Electronics Engineers Inc. https://doi.org/10.1109/ICOVET50258.2020.9230031

Al Salman, S., Alkathiri, M., \& Bawaneh, A. (2021). School off, learning on: identification of preference and challenges among school students towards distance learning during COVID19 outbreak. International Journal of Lifelong Education, 1-19. https://doi.org/10.1080/02601370.2021.1874554

Aldossry, B. (2021). Evaluating the Madrasati Platform for the virtual classroom in Saudi Arabian education during the time of COVID-19 pandemic. European Journal of Open Education and E-Learning Studies, 6(1), 8999. https://www.oapub.org/edu/index.php/ejoe/article/view/3620M4

Almarashdi, H. \& Jarrah, M. (2021). Mathematics Distance Learning amid the COVID-19 Pandemic in the UAE: High School Students' Perspectives. International Journal of Learning, Teaching and Educational Research, 20(1), 292-307. https://doi.org/10.26803/IJLTER.20.1.16

Alrashidi, O., Phan, H. P., \& Ngu, B. H. (2016). Academic Engagement: An Overview of Its Definitions, Dimensions, and Major Conceptualisations. International Education Studies, 9(12), 41. https://doi.org/10.5539/ies.v9n12p41

Álvarez-Guerrero, G., Lopez de Aguileta, A., Racionero-Plaza, S. \& Flores-Moncada, L. G. (2021). Beyond the School Walls: Keeping Interactive Learning Environments Alive in Confinement for Students in Special Education. Frontiers in Psychology, 12. https://doi.org/10.3389/fpsyg.2021.662646

Amelia, R., Kadarisma, G., Fitriani, N., \& Ahmadi, Y. (2020). The effect of online mathematics learning on junior high school mathematic resilience during covid-19 pandemic. Journal of Physics: Conference Series, 1657, 12011. https://doi.org/10.1088/1742-6596/1657/1/012011

Ang, J. \& Wu, C. (2021). Research and Thinking on Online Teaching and Learning in Secondary Schools in China Based on the Background of Epidemic Prevention and Control. International Conference On Educational And Information Technology. https://doi.org/10.1109/ICEIT51700.2021.9375602

Asanov, I., Flores, F., McKenzie, D., Mensmann, M., \& Schulte, M. (2021). Remote-learning, time-use, and mental health of Ecuadorian high-school students during the COVID-19 quarantine. World Development, 138, 105225. https://doi.org/10.1016/j.worlddev.2020.105225

Atmojo, A. E. P. \& Nugroho, A. (2020). EFL Classes Must Go Online! Teaching Activities and Challenges during COVID-19 Pandemic in Indonesia. Register Journal, 13(1), 49-76. https://doi.org/10.18326/rgt.v13i1.49-76

Azhari, B. \& Fajri, I. (2021). Distance learning during the COVID-19 pandemic: School closure in Indonesia. International Journal of Mathematical Education in Science and Technology, 1-21. https://doi.org/10.1080/0020739X.2021.1875072

Babinčáková, M. \& Bernard, P. (2020). Online Experimentation during COVID-19 Secondary School Closures: Teaching Methods and Student Perceptions. Journal of Chemical Education, 97(9), 3295-3300.

https://doi.org/10.1021/acs.jchemed.0c00748 
Balkist, P. S. \& Agustiani, N. (2020). Responses of students with special needs to online mathematics learning during pandemic. Journal of Physics: Conference Series, 1657. https://doi.org/10.1088/1742$\underline{6596 / 1657 / 1 / 012031}$

Bambra, C., Riordan, R., Ford, J., \& Matthews, F. (2020). The COVID-19 pandemic and health inequalities. Journal of Epidemiology and Community Health, 74(11), 964-968. https://doi.org/10.1136/jech2020-214401

Baptista, M., Costa, E. \& Martins, I. (2020). STEM education during the COVID-19: Teachers' perspectives about strategies, challenges and effects on students' learning. Journal of Baltic Science Education, 19(6A), 1043-1054. https://doi.org/10.33225/jbse/20.19.1043

Becker, S. O., Breaux, R., Cusick, C. N., Dvorsky, M. R., Marsh, N. P., Scilberras, E. \& Langberg, J. M. (2020). Remote Learning During COVID-19: Examining School Practices, Service Continuation, and Difficulties for Adolescents With and Without Attention-Deficit/Hyperactivity Disorder. Journal of Adolescent Health, 14. https://dx.doi.org/10.1016/j.jadohealth.2020.09.002

Bergdahl, N., \& Nouri, J. (2020). Covid-19 and Crisis-Prompted Distance Education in Sweden. Technology, Knowledge and Learning. https://doi.org/10.1007/s10758-020-09470-6

Bergdahl, N., Nouri, J., Fors, U., \& Knutsson, O. (2020). Engagement, disengagement and performance when learning with technologies in upper secondary school. Computers and Education, 149(August 2019), 103783. https://doi.org/10.1016/j.compedu.2019.103783

Bhamani, S., Makhdoom, A. Z., Bharuchi, V., Ali, N., Kaleem, S. \& Ahmed, D. (2020). Home Learning in Times of COVID: Experiences of Parents. Journal of Education and Educational Development, 7(1).

https://doi.org/10.22555/joeed.v7i1.3260

Bhattarai, P. (2020). English Language Teachers' Experience on Online Teaching amidst COVID-19. Linguistic Forum, 2(3), 24-30. https://linguisticforum.com/index.php/ling/article/view/55

Bhaumik, R. \& Priyadishini, A. (2020). E-readiness of senior secondary school learners to online learning transition amid COVID-19 lockdown. Asian Journal of Distance Education, 15(1), 244-256. https://doi.org/10.5281/zenodo.3891822

Bond, M. (2020a). Facilitating student engagement through the flipped learning approach in K-12: A systematic review. Computers \& Education (151), 1-36. https://doi.org/10.1016/j.compedu.2020.103819

Bond, M. (2020b). Schools and emergency remote education during the covid-19 pandemic: A living rapid systematic review. Asian Journal of Distance Education, 15(2), 191-247.

http://www.asianjde.com/ojs/index.php/AsianJDE/article/view/517

Bond, M. (2021). Schools and emergency remote education during the covid-19 pandemic - living review. EPPICentre. https://eppi.ioe.ac.uk/EPPI-Vis/Login/Open?WebDBid=5

Bond, M., \& Bedenlier, S. (2019). Facilitating student engagement through educational technology: Towards a conceptual framework. Journal of Interactive Media in Education, 2019(1), 1-14.

https://doi.org/10.5334/jime.528

Bond, M., \& Bergdahl, N. (2021). UK parents' perceptions of engagement through digital technology during the covid-19 pandemic: A preliminary analysis. In L. Gómez Chova, A. López Martínez, \& I. Candel Torres (Eds.), Proceedings of EDULEARN21 conference (pp. 11646-11653). IATED Academy.

https://doi.org/10.21125/edulearn.2021.2438 
Bond, M., \& Bolan, F. (2021). What have we learned about online learning? UK and global evidence on the emergency remote education of schoolchildren during covid-19. IPPO. https://covidandsociety.com/whathave-we-learned-about-online-learning-summary-evidence-emergency-remote-education-schoolchildrenduring-covid-19/

Bond, M., Bedenlier, S., Marín, V. I., \& Händel, M. (2021). Emergency remote teaching in higher education: mapping the first global online semester. International Journal of Educational Technology in Higher Education, 18(1), 1-24. https://doi.org/10.1186/s41239-021-00282-x

Bond, M., Buntins, K., Bedenlier, S., Zawacki-Richter, O., \& Kerres, M. (2020). Mapping research in student engagement and educational technology in higher education: a systematic evidence map. International Journal of Educational Technology in Higher Education, 17(1), 1-30. https://doi.org/10.1186/s41239-019-0176-8

Bower, M. (2016). Deriving a typology of web 2.0 learning technologies. British Journal of Educational Technology, 47(4), 763-777. https://doi.org/10.1111/bjet.12344

Budianto, L. \& Arifani, Y. (2021). Utilizing whatsapp-driven learning during covid-19 outbreak: EFL users' perceptions and practices. CALL-EJ, 22(1), 264-281. http://repository.uin-malang.ac.id/8021/1/8021.pdf

Bruin, L. R. (2020). Instrumental Music Educators in a COVID Landscape: A Reassertion of Relationality and Connection in Teaching Practice. Frontiers in Psychology, 11. https://doi.org/10.3389/fpsyg.2020.624717

Chen, C. (2020). A glimpse of the first eight months of the covid-19 literature on Microsoft Academic Graph: Themes, citation contexts, and uncertainties. Frontiers in Research Metrics and Analytics, 5, 607286.

https://doi.org/10.3389/frma.2020.607286

Cheung, A. (2021). Language Teaching during a Pandemic: A Case Study of Zoom Use by a Secondary ESL Teacher in Hong Kong. RELC Journal. https://doi.org/10.1177/0033688220981784

Chirinda, B., Ndlovu, M. \& Spangenberg, E. (2021). Teaching Mathematics during the COVID-19 Lockdown in a Context of Historical Disadvantage. Education Sciences, 11(4), 177. https://doi.org/10.3390/educsci11040177

Chiu, T. K. F. (2021). Student engagement in k-12 online learning amid covid-19: A qualitative approach from a self-determination theory perspective. Interactive Learning Environments, 1-14.

https://doi.org/10.1080/10494820.2021.1926289

Clausen, J., Bunte, B. \& Robertson, E. (2020). Professional Development to Improve Communication and Reduce the Homework Gap in Grades 7-12 During COVID-19 Transition to Remote Learning. Journal of Technology \& Teacher Education, 28(2), 443-451. https://www.learntechlib.org/p/216289/

Code, J., Ralph, R., \& Forde, K. (2020). Pandemic designs for the future: perspectives of technology education teachers during COVID-19. Information and Learning Sciences. 121(5-6), 409-421. https://doi.org/10.1108/ILS04-2020-0112

Cohen, J. (1960). A Coefficient of Agreement for Nominal Scales. Education and Psychological Measurement, 20(1), 37-46.

Daley, S., Hu, Y., Harrington, K., Green, O., Stevens, K. \& Wilkins, S. (2020). Goldilocks in the Pandemic: What's "just right" with technology for K-12 teachers in Emergency Remote Teaching? In Proceedings of EdMedia + Innovate Learning (pp. 26-30). Online, The Netherlands: Association for the Advancement of Computing in Education (AACE). https://www.learntechlib.org/primary/p/217452/ 
Dalgarno, B. (2014). Polysynchronous learning: a model for student interaction and engagement Background to the case studies. Rhetoric and Reality: Critical Perspectives on Educational Technology, 673-677. http://www.blackboard.com/platforms/collaborate/overview.aspx

Dema, Y., Chogyel, N., \& Wangdi, N. (2021). Online learning amid COVID-19 pandemic: Perspectives of Bhutanese students. International Journal of Didactical Studies, 2(1), 101456. https://doi.org/10.33902/IJODS.2021167818

Dietrich, H., Patzina, A. \& Lerche, A. (2020). Social inequality in the homeschooling efforts of German high school students during a school closing period. European Societies, 1-22.

https://doi.org/10.1080/14616696.2020.1826556

Digital Solution Foundry, \& EPPI-Centre. (2020). EPPI-Mapper (Version 1.2.5) [Computer software]. UCL Social Research Institute, University College London. http://eppimapper.digitalsolutionfoundry.co.za/\#/

Dorji, T. (2021). Problem and Challenges Faced by Students, Parents, and Teachers in Google Classes \& Television Lessons. International Journal of Asian Education, 2(1), 88-97. https://doi.org/10.46966/ijae.v2i1.98

Easterly, R. G., Humphrey, K. \& Roberts, T. G. (2021). The Impacts of COVID-19 on school-based agricultural education teachers in the U.S. Advancements in Agricultural Development, 2(1). https://doi.org/10.37433/aad.v2i1.79

Education Endowment Foundation. (2019). How Can Schools Support Parents' Engagement in their Children's Learning? Evidence from Research and Practice. https://educationendowmentfoundation.org.uk/evidencesummaries/evidence-reviews/parental-engagement/

Education Endowment Foundation. (2020). Remote learning: rapid evidence assessment. https://educationendowmentfoundation.org.uk/public/files/Publications/Covid19 Resources/Remote learning evidence review/Remote Learning Rapid Evidence Assessment.pdf

Education Scotland. (2021). National overview of practice in remote learning. https://education.gov.scot/media/d5acnogk/national-overview-of-practice-in-remote-learning-12-assessinglearning-and-providing-feedback-to-learners-on-progress-within-secondary-schools.pdfT4

Ferraro, F. V., Ambra, F. I., Aruta, L., \& lavarone, M. L. (2020). Distance Learning in the COVID-19 Era: Perceptions in Southern Italy. Education Sciences, 10(12), 355. https://doi.org/10.3390/educsci10120355

Fiialka, S. (2020). School Media Education During the COVID-19 Pandemic: Limitations and New Opportunities. Media Education (Mediaobrazovanie), 60(3). https://doi.org/10.13187/me.2020.3.367

Gordy, X. Z., Sparkmon, W., Imeri, H., Notebaert, A., Barnard, M., Compretta, C., Dehon, E., Taylor, J., Stray, S., Sullivan, D. \& Rockhold, R. W. (2021). Science Teaching Excites Medical Interest: A Qualitative Inquiry of Science Education during the 2020 COVID-19 Pandemic. Education Sciences, 11.

https://doi.org/10.3390/EDUCSCI11040148

Gough, D., Oliver, S., \& Thomas, J. (Eds.). (2012). An introduction to systematic reviews. Sage.

Gusenbauer, M., \& Haddaway, N. R. (2020). Which academic search systems are suitable for systematic reviews or meta-analyses? Evaluating retrieval qualities of Google scholar, pubmed and 26 other resources. Research Synthesis Methods, 11(2), 181-217. https://doi.org/10.1002/jrsm.1378 
Henrie, C. R. (2016). Measuring Student Engagement in Technology-Mediated Learning Environments (Doctoral Dissertation) [Brigham Young University]. In ProQuest Dissertations and Theses (Issue May). https://scholarsarchive.byu.edu/etd

Hira, A. \& Anderson, E. (2021). Motivating Online Learning through Project-Based Learning During the 2020 COVID-19 Pandemic. IAFOR Journal of Education, 9(2), 93-110. https://doi.org/10.22492/ije.9.2.06

Hodgen, J. Taylor, B., Jacques, L., Tereshchenko, A., Kwok, R. \& Cockerill, M. (2021). Remote mathematics teaching during COVID-19: intentions, practices and equity. UCL Institute of Education: London, UK. https://discovery.ucl.ac.uk/id/eprint/10110311/

Hu, H., \& Huang, F. (2021). Application of universal design for learning into remote english education in australia amid covid-19 pandemic. International Journal on Studies in Education, 4(1), 55-69.

https://doi.org/10.46328/ijonse.59

Hunter, J., Hunter, R., Tupouniua, J. \& Leach, G. (2020). Bringing the home into school: Learning and connecting during the time of the pandemic. https://poutamapounamu.org.nz/assets/resources/site/ESMSpecial-Issue-submission.pdf

Jayathirtha, G., Fields, D., Kafai, Y. B. \& Chipps, J. (2020). Supporting making online: the role of artifact, teacher and peer interactions in crafting electronic textiles. Information and Learning Sciences, 121(5 /6), 381-390. https://doi.org/10.1108/ILS-04-2020-0111

Jelińska, M., \& Paradowski, M.B. (2021). Teachers' engagement in and coping with emergency remote instruction during COVID-19-induced school closures: A multinational contextual perspective. Online Learning Journal, 25(1), 303-328. https://doi.org/10.24059/olj.v25i1.2492

Jeong, H.-C., \& So, W.-Y. (2020). Difficulties of online physical education classes in middle and high school and an efficient operation plan to address them. International Journal of Environmental Research \& Public Health [Electronic Resource], 17(19). https://doi.org/10.3390/ijerph17197279

Kaden, U. (2020). COVID-19 School Closure-Related Changes to the Professional Life of a K-12 Teacher. Education Sciences, 10(6). https://doi.org/10.3390/educsci10060165

Kelley, E. W. (2020). Reflections on Three Different High School Chemistry Lab Formats during COVID-19 Remote Learning. Journal of Chemical Education, 97(9), 2606-2616.

https://doi.org/10.1021/acs.jchemed.0c00814

Kim, L. E. \& Asbury, K. (2020). 'Like a rug had been pulled from under you': The impact of COVID-19 on teachers in England during the first six weeks of the UK lockdown. British Journal of Educational Psychology, 25. DOI: https://dx.doi.org/10.1111/bjep.12381

Kittle, P., \& Hicks, T. (2009). Transforming the group paper with collaborative online writing. Pedagogy: Critical Approaches to Teaching Literature, Language, Composition, and Culture, 9(3), 525-538. https://doi.org/10.1215/15314200-2009-012

Kochan, I. (2021). Distance learning in Polish secondary schools: Students' opinions during the COVID-19 pandemic. Sodobna Pedagogika, 72(138), 342-353. https://www.sodobna-pedagogika.net/en/articles/012021 distance-learning-in-polish-secondary-schools-students-opinions-during-the-covid-19-pandemic/M4 Korzycka, M., Bojjo, M., Radiukiewicz, K., Dzielska, A., Nalecz, H., Kleszczewska, D., Malkowska-Szutnik, A. \& Fijalkowska, A. (2021). Demographic analysis of difficulties related to remote education in Poland from the 
perspective of adolescents during the COVID-19 pandemic. Annals of Agricultural and Environmental Medicine, 28(1), 149-157). https://doi.org/10.26444/aaem/133100

Lansangan, R. V. (2020). Teaching Junior High School Chemistry During the COVID-19 Community Quarantine Season: Lessons, Challenges, And Opportunities. KIMIKA, 31(1), 20-

37. https://doi.org/10.26534/kimika.v31i1.20-37

Larcher, V., Dittborn, M., Linthicum, J., Sutton, A., Brierley, J., Payne, C. \& Hardy, H. (2020). Young people's views on their role in the COVID-19 pandemic and society's recovery from it. Archives of Disease in Childhood, 31, https://doi.org/10.1136/archdischild-2020-320040

Lawrence, K. \& Fakuade, O. (2021). Parental involvement, learning participation and online learning commitment of adolescent learners during the COVID-19 lockdown. Research in Learning Technology, 29. https://doi.org/10.25304/rlt.v29.2544

Lepp, L., Aaviku, T., Leijen, A., Pedaste, M. \& Saks, K. (2021). Teaching during COVID-19: The Decisions Made in Teaching. Education Sciences, 11(2). https://doi.org/10.3390/educsci11020047

Li, C. \& Lalani, F. (2020). The Covid-19 pandemic has changed education forever. This is how. World Economic Forum. https://www.weforum.org/agenda/2020/04/coronavirus-education-global-covid19-online-digitallearning/

Lo, C. K., Hew, K. F., \& Chen, G. (2017). Toward a set of design principles for mathematics flipped classrooms: A synthesis of research in mathematics education. Educational Research Review, 22, 50-73.

https://doi.org/10.1016/i.edurev.2017.08.002

Lundin, M., Bergviken Rensfeldt, A., Hillman, T., Lantz-Andersson, A., \& Peterson, L. (2018). Higher education dominance and siloed knowledge: A systematic review of flipped classroom research. International Journal of Educational Technology in Higher Education, 15(1), 1. https://doi.org/10.1186/s41239-018-0101-6

Mælan, E. N., Gustavsen, A. M., Stranger-Johannessen, E., \& Nordahl, T. (2021). Norwegian students' experiences of homeschooling during the COVID-19 pandemic. European Journal of Special Needs Education, 1-15. https://doi.org/10.1080/08856257.2021.1872843

Moss, G., Bradbury, A., Harmey, S., Mansfield, R., Candy, B., France, R., \& Vigurs, C. (2021). Mitigating impacts of the COVID-19 pandemic on primary and lower secondary children during school closures: a rapid evidence review. London: EPPI Centre, UCL Social Research Institute, University College London.

Nawawi, N., Sukardi, S. \& Handayani Isra, I. (2021). Biological learning adaptation during the COVID-19 pandemic period in Ponorogo 1 Public High School. Acitya: Journal of Teaching and Education, 3(1), 95-103. https://doi.org/10.30650/AJTE.V3I1.2139

Niemi, H. M. \& Kousa, P. (2020). A case study of students' and teachers' perceptions in a Finnish high school during the COVID pandemic. International Journal of Technology in Education and Science, 4(4), 352-369. https://helda.helsinki.fi/bitstream/handle/10138/319017/167 4671 PB.pdf?sequence=1\&isAllowed=yM4

Nugraha Ryan Agustian, Nurlestari Syifa Dwi, \& Maryam Salma Siti (2021). EFL learning challenges in the midst of covid-19 pandemic: A case of senior high school students. International Conference on Education of Suryakancana (Iconnects Proceedings). https://jurnal.unsur.ac.id/cp/article/view/1321

Nurliani, R., Sinaga, P., \& Rusdiana, D. (Eds.) (2021). Problems of online learning and the use of information and communication technology (ICT) in physics learning at Sumedang, West Java. : Vol. 1806. IOP Publishing Ltd. https://iopscience.iop.org/article/10.1088/1742-6596/1806/1/012043 
Nusser, L. (2021). Learning at home during COVID-19 school closures - How do German students with and without special educational needs manage? European Journal of Special Needs Education. https://doi.org/10.1080/08856257.2021.1872845

OECD. (2020a). Education and COVID-19: Focusing on the long-term impact of school closures.

https://read.oecd-ilibrary.org/view/?ref=135 135187-1piyg9kc7w\&title=Education-and-COVID-19-Focusingon-the-long-term-impact-of-school-closures\& ga=2.62634668.1411069064.1627572200-

1309661371.1627572200

OECD (2020b). COVID-19 crisis accentuating the need to bridge digital divide

https://www.oecd.org/digital/covid-19-crisis-accentuating-the-need-to-bridge-digital-divides.htm

Ofsted. (2021). What's working well in remote education.

https://www.gov.uk/government/publications/whats-working-well-in-remote-education/whats-working-wellin-remote-education

Okebukola, P. A., Suwadu, B., Oladejo, A., Nyandwi, R., Ademola, I., Okorie, H. \& Awaah, F. (2020). Delivering High School Chemistry During COVID-19 Lockdown: Voices from Africa. Journal of Chemical Education, 97(9), 3285-3289. https://doi.org/10.1021/acs.jchemed.0c00725

ONS. (2019). Exploring the UK's digital divide.

https://www.ons.gov.uk/peoplepopulationandcommunity/householdcharacteristics/homeinternetandsocialm ediausage/articles/exploringtheuksdigitaldivide/2019-03-04\#what-are-the-barriers-to-digital-inclusion

Onyema, E. M., Eucheria, N. C., Obafemi, F. A., Sen, S., Atonye, F. G., Sharma, A., \& Alsayed, A. O. (2020). Impact of Coronavirus pandemic on education. Journal of Education and Practice, 11(13), 108-121.

Oraif, I \& Elyas, T. (2021). The Impact of COVID-19 on Learning: Investigating EFL Learners' Engagement in Online Courses in Saudi Arabia. Education Sciences, 11(3). https://doi.org/10.3390/educsci11030099

Page, M. J., McKenzie, J. E., Bossuyt, P. M., Boutron, I., Hoffmann, T. C., Mulrow, C. D., Shamseer, L., Tetzlaff, J. M., Akl, E. A., Brennan, S. E., Chou, R., Glanville, J., Grimshaw, J. M., Hróbjartsson, A., Lalu, M. M., Li, T., Loder, E. W., Mayo-Wilson, E., McDonald, S., . . Moher, D. (2021). The prisma 2020 statement: An updated guideline for reporting systematic reviews. BMJ (Clinical Research Ed.), 372, n71. https://doi.org/10.1136/bmj.n71

Pelikan, E. R., Lüftenegger, M., Holzer, J., Korlat, S., Spiel, C., \& Schober, B. (2021). Learning during COVID-19: the role of self-regulated learning, motivation, and procrastination for perceived competence. Zeitschrift Für Erziehungswissenschaft 2021 24:2, 24(2), 393-418. https://doi.org/10.1007/S11618-021-01002-X

Petticrew, M., \& Roberts, H. (2006). Systematic Reviews in the Social Sciences. Blackwell Publishing.

Pirrone C, Varrasi S, Platania G A, \& Castellano S (Eds.) (2021). Face-to-face and online learning: The role of technology in students' metacognition. : Vol. 2817. CEUR-WS.

Poláková, P., \& Klímová, B. (2021). The Perception of Slovak Students on Distance Online Learning in the Time of Coronavirus-A Preliminary Study. Education Sciences, 11(2). https://doi.org/10.3390/educsci11020081

POST. (2021). Distance Learning. https://post.parliament.uk/research-briefings/post-pn-0639/

Primdahl, N. L., Borsch, A. S. V., Jervelund, S. S., Derluyn, I. \& Skovdal, M. (2020). 'It's difficult to help when I am not sitting next to them': How COVID-19 school closures interrupted teachers' care for newly arrived 
migrant and refugee learners in Denmark. Vulnerable Children and Youth Studies, 1-11.

https://doi.org/10.1080/17450128.2020.1829228

QAA. (2020). Building a Taxonomy for Digital Learning. https://www.qaa.ac.uk/docs/qaa/guidance/building-ataxonomy-for-digital-learning.pdf

Rahayu, R. P. \& Wirza, Y. (2020). Teachers' Perception of Online Learning During Pandemic COVID-19. Jurnal Penelitian Pendidikan, 20, 392-406. https://doi.org/10.17509/JPP.V2013.29226

Rap, S., Feldman-Maggor, Y., Aviran, E., Shvarts-Serebro, I., Easa, E., Yonai, E., Waldman, R. \& Blonder, R. (2020). An Applied Research-Based Approach to Support Chemistry Teachers during the COVID-19 Pandemic. Journal of chemical education, 97(9), 3278-3284. https://doi.org/10.1021/acs.jchemed.0c00687

Rienzo, T., \& Han, B. (2009). Teaching Tip: Microsoft or Google Web 2.0 Tools for Course Management. Journal of Information Systems Education, 20(2), 123-245. http://jise.org/Volume20/n2/JISEv20n2p123.html

Riwai-Couch, M., Bull, A., Ellis, B., Hall, J., Nicholls, J., Taleni, T. \& Watkinson, R. (2020). School-led learning at home: Voices of the parents of Māori and Pasifika students. http://www.evaluate.co.nz/key-readings/schoolled-learning-voices-of-parents-of-maori-and-pasifika-students/\#topY3

Rhine, S., \& Bailey, M. (2008, June). Collaborative Software and a Parallel Universe: Technology Facilitated Changes in Teacher-Student Dynamics in Classrooms. In EdMedia+ Innovate Learning (pp. 4375-4381). Association for the Advancement of Computing in Education (AACE). https://www.learntechlib.org/p/28992/

Rusmansyah, Hayati N, Winarti A, \& Rahmi (Eds.) (2021). Train students' science process skills and self-efficacy in online learning using the Scientific Critical Thinking (SCT) model assisted by google classroom and google meet. : Vol. 1760. IOP Publishing Ltd. https://iopscience.iop.org/article/10.1088/1742-6596/1760/1/012034

Russell, B.S., Hutchison, M., Tambling, R., Tomkunas, A.J. \& Horton, A.L. (2020). Initial Challenges of Caregiving During COVID-19: Caregiver Burden, Mental Health, and the Parent-Child Relationship. Child Psychiatry Human Development, 51, 671-682. https://doi.org/10.1007/s10578-020-01037-x

Schaefer, M. B., Abrams, S. S., Kurpis, M., Abrams, M. \& Abrams, C. (2020). "Making the Unusual Usual:" Students' Perspectives and Experiences of Learning at Home during the COVID-19 Pandemic. Middle Grades Review, 6(2). https://scholarworks.uvm.edu/mgreview/vol6/iss2/8

Schwartz, H. L., Grant, D., Diliberti, M. K., Hunter, G. P., \& Setodji, C. M. (2020). Remote Learning Is Here to Stay: Results from the First American School District Panel Survey. Santa Monica, CA: RAND Corporation. https://www.rand.org/pubs/research reports/RRA956-1.html.

Shemilt I, Gough D, Thomas J, Stansfield C, Bangpan M, Brunton J, Dickson K, Graziosi S, Hull P, Kneale D, Muraki S, Ramadani F, Vigurs C (2021). Living map of systematic reviews of social sciences research evidence on COVID-19. London: EPPI Centre, UCL Social Research Institute, University College London.)

Shidiq, A. S., Permanasari, A., Hernani, \& Hendayana, S. (2021). Chemistry teacher responses to learning in the covid-19 outbreak: Challenges and opportunities to create innovative lab-work activities. Journal of Physics: Conference Series, 1806(1), 12195. https://doi.org/10.1088/1742-6596/1806/1/012195

Sibanda, L. \& Mathwasa, J. (2021). Perceptions of teachers and learners on the impact of COVID-19 pandemic lockdown on rural secondary school female learners in Matobo District, Zimbabwe. European Journal of Social Sciences Studies, 6(3), 14-34. 
Simanjuntak, U. S., Silalahi, D. E., Sihombing, P. S. R., \& Purba, L. (2021). Students' perceptions of using YouTube as English online learning media during COVID-19 pandemic. Journal of Languages and Language Teaching, 9(2), 150-159. https://doi.org/10.33394/JOLLT.V9I2.3567

Singh, V. \& Thurman, A. (2019). How Many Ways Can We Define Online Learning? A Systematic Literature Review of Definitions of Online Learning (1988-2018). American Journal of Distance Education, 33:4, 289-306, https://doi.org/10.1080/08923647.2019.1663082

Stewart, B. E., \& Lyons, E. (2021). When the classroom becomes datafied: A baseline for building data ethics policy and data literacies across higher education. Italian Journal of Educational Technology, 29(2), 54-68.

Suliani, M., Juniati, D., \& Ulfah, F. (2021). Learning mathematics in madrasah aliyah muhammadiyah 2 banjarmasin during the covid-19 pandemic era. Journal of Physics: Conference Series, 1747(1), 12018. https://doi.org/10.1088/1742-6596/1747/1/012018

Thomas, J., Graziosi, S., Brunton, J., Ghouze, Z., O'Driscoll, P., \& Bond, M. (2020). EPPI-Reviewer: advanced software for systematic reviews, maps and evidence synthesis [Computer software]. EPPI-Centre Software. UCL Social Research Institute. London. https://eppi.ioe.ac.uk/cms/Default.aspx?alias=eppi.ioe.ac.uk/cms/er4

Thurab-Nkhosi, D., Maharaj, C. \& Ramadhar, V. (2021). The impact of emergency remote teaching on a blended engineering course: perspectives and implications for the future. SN Social Sciences, 1(159). https://doi.org/10.1007/s43545-021-00172-z

Tong, Q., \& Wang, L. (2020). Exploring junior high school students' online self-regulation during the covid-19 pandemic in china. In H.-J. So, M. Rodrigo, J. Mason, \& A. Mitrovic (Chairs), ICCE Proceedings 2020. https://apsce.net/upfile/icce2020/ICCE2020-Proceedings-Vol2-FinalUpdated.pdf

Tran, T., Ho, M-T., Pham, T-H., Nguyen, M-H., Nguyen, K-LP., Vuong, T-T., Nguyen, T-HT., Nguyen, T-D., Nguyen, T-L., Khuc, Q., La, V-P. \& Vuong, Q-H. (2020). How Digital Natives Learn and Thrive in the Digital Age: Evidence from an Emerging Economy. Sustainability, 12(9), 3819. https://doi.org/10.3390/su12093819

Tricco, A. C., Garritty, C. M., Boulos, L., Lockwood, C., Wilson, M., McGowan, J., McCaul, M., Hutton, B., Clement, F., Mittmann, N., Devane, D., Langlois, E. V., Abou-Setta, A. M., Houghton, C., Glenton, C., Kelly, S. E., Welch, V. A., LeBlanc, A., Wells, G. A., . . Straus, S. E. (2020). Rapid review methods more challenging during covid-19: Commentary with a focus on 8 knowledge synthesis steps. Journal of Clinical Epidemiology, 126, 177-183. https://doi.org/10.1016/j.jclinepi.2020.06.029

Trung, T., Hoang, A. D., Nguyen, T. T., Dinh, V. H. \& Nguyen, Y. C. (2020). Dataset of Vietnamese student's learning habits during COVID-19. Data in Brief, 30. https://doi.org/10.1016/j.dib.2020.105682

Turchi, L. B., Bondar, N. A. \& Aguilar, L. L. (2020). What Really Changed? Environments, Instruction, and 21st Century Tools in Emergency Online English Language Arts Teaching in United States Schools During the First Pandemic Response. Frontiers in Education, 5. https://doi.org/10.3389/feduc.2020.583963

Velichová, L., Orbánová, D. \& Kúbeková, A. (2020). The COVID-19 Pandemic: Unique Opportunity to Develop Online Learning, TEM Journal, 1633-1639. https://doi.org/10.18421/TEM94-40

Weinhandl, R., Lavicza, Z., Houghton, T. \& Hohenwarter, M. (2021). A look over students' shoulders when learning mathematics in home-schooling. International Journal of Mathematical Education in Science \& Technology. https://doi.org/10.1080/0020739X.2021.1912423 
Willermark, S. (2021). Who's There? Characterizing Interaction in Virtual Classrooms. Journal of Educational Computing Research. https://doi.org/10.1177/0735633120988530

Yan, S. (2021). Covid-19 and technology use by teenagers: A case study. Human Behavior and Emerging Technologies, 3(1), 185-193. https://doi.org/10.1002/hbe2.236

Yates, A., Starkey, L., Egerton, B. \& Flueggen, F. (2020). High school students' experience of online learning during Covid-19: the influence of technology and pedagogy. Technology, Pedagogy \& Education. https://doi.org/10.1080/1475939X.2020.1854337

Zakso, A. \& Agung, I. (2021). Impact of Student Learning at Home Prevent Pandemic Covid-19 in Indonesia. Academic Journal of Interdisciplinary Studies, 10(2). https://doi.org/10.36941/ajis-2021-0053

Zawacki-Richter, O., Kerres, M., Bedenlier, S., Bond, M., \& Buntins, K. (2020). Systematic Reviews in Educational Research. Springer Fachmedien Wiesbaden. https://doi.org/10.1007/978-3-658-27602-7 


\section{Appendix A - Data extraction coding scheme}

- Publication Type

- Journal article (peer reviewed)

- Journal article (teacher magazine)

- Editorial

- Journal article (pre-print, not peer-reviewed)

- Conference paper

- Book chapter

- Report

- Data set

- Website article

- Methodology

- Date of data collection

- Unclear

- Before Jan 2020

- January 2020

- February 2020

- March 2020

- April 2020

- May 2020

- June 2020

- July 2020

- August 2020

- September 2020

- October 2020

- November 2020

- December 2020

- January 2021

○ Method

- Qualitative

- Quantitative

- Mixed Methods

- Data Collection

- Interviews

- Survey

- Focus groups

- Content/Thematic analysis

- Documents

student production (writing, art, digital, e.g., 3D printed robots), artefacts, student programmes, teaching material, written reflections, lesson plans

- Observation/Field notes

- Test (assessment)

- System log data Dashboard or LMS data

Tracking device data (eye tracking, mouse tracking) Sensors

- Respondent diary

- Length of study 

- Unclear
- Less than 1 week
- 1 week
- 2 weeks
- 3 weeks
- 1 month
- 5 weeks
- 6 weeks
- 7 weeks
- 2 months
- 3 months
- 4 months
- 6 months
- 7 months
- 9 months

- Setting/Context

- Participant Country

- Country not indicated

- Argentina

- Australia

- Austria

- Belgium

- Bhutan

- Bosnia Herzegovina

- Brazil

- Burundi

- Canada

- Central African Republic

- Chile

- China

- Colombia

- Costa Rica

- Croatia

- Czech Republic

- Denmark

- Dominican Republic

- Ecuador

- Egypt

- Estonia

- Finland

- France

- Georgia

- Germany

- Ghana

- Greece

- Hong Kong

- Hungary

- Iceland

- India

- Indonesia

- Iran 
- Ireland

- Israel

- Italy

- Jamaica

- Japan

- Jordan

- Kazakhstan

- Kenya

- Latvia

- Lithuania

- Macedonia

- Madagascar

- Malaysia

- Malta

- Mexico

- Morocco

- Nepal

- New Zealand

- Nigeria

- Norway

- Pakistan

- Peru

- Philippines

- Poland

- Portugal

- Republic of Korea

- Romania

- Russia

- Saudi Arabia

- Senegal

- Slovak Republic

- Slovenia

- South Africa

- South Korea

- Spain

- Sweden

- Switzerland

- Tajikistan

- The Netherlands

- Timor-Leste

- Tunisia

- Turkey

- UAE

- Uganda

- UK

- Ukraine

- Uruguay

- USA

- Vietnam

- Zambia

- Zimbabwe 


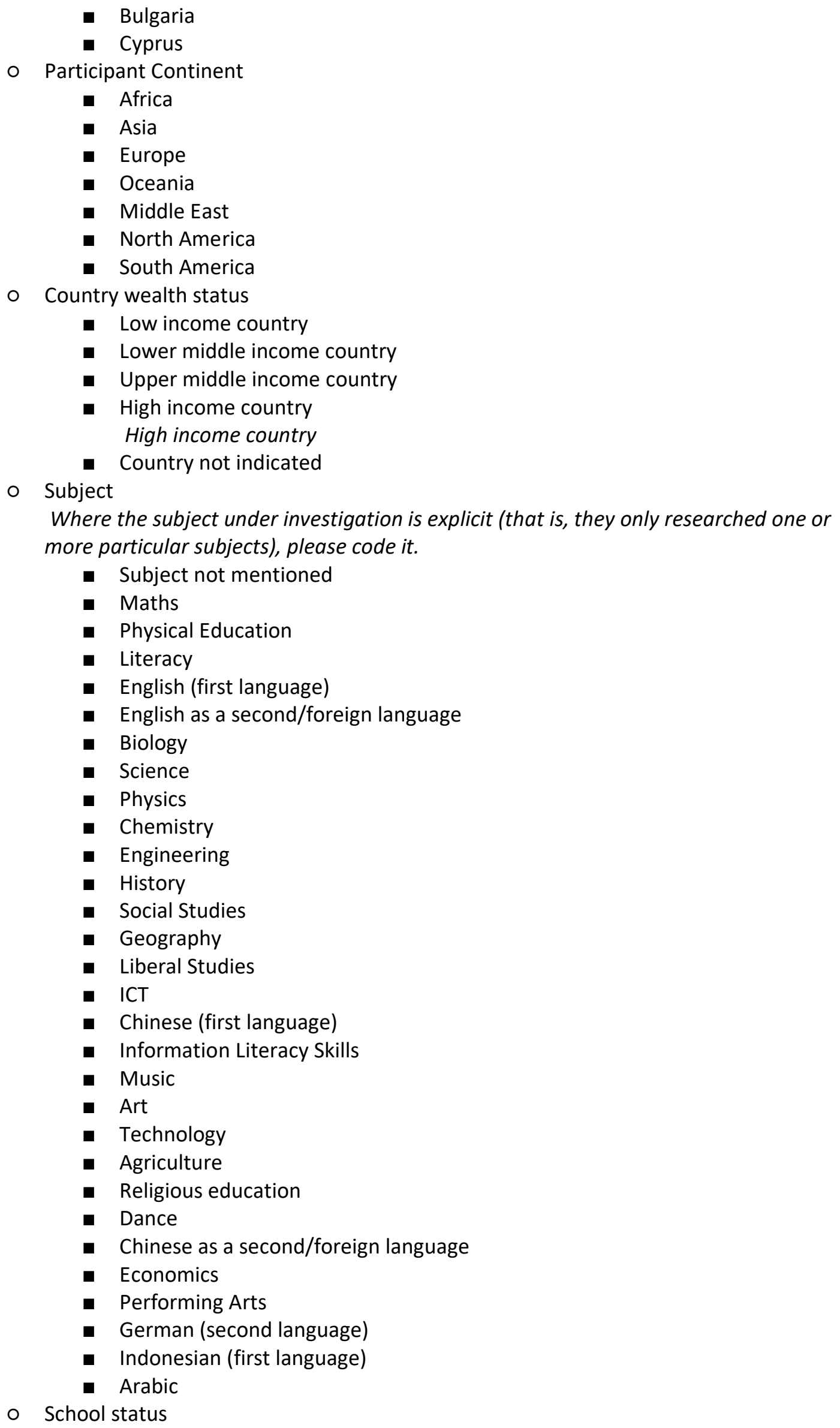

- Low income country

- Lower middle income country

- Upper middle income country

- High income country High income country

- Country not indicated

- Subject

Where the subject under investigation is explicit (that is, they only researched one or more particular subjects), please code it.

- Subject not mentioned

- Maths

- Physical Education

- Literacy

- English (first language)

- English as a second/foreign language

- Biology

- Science

- Physics

- Chemistry

- Engineering

- History

- Social Studies

- Geography

- Liberal Studies

- ICT

- Chinese (first language)

- Information Literacy Skills

- Music

- Art

- Technology

- Agriculture

- Religious education

- Dance

- Chinese as a second/foreign language

- Economics

- Performing Arts

- German (second language)

- Indonesian (first language)

- Arabic

- School status 
- Government school

- Private/independent school

- Not stated

- Unclear

- Population

- Number of participants

Choose appropriate checkbox and type exact number into INFO box.

- 1-25

- 26-50

- 51-99

- 100-299

- 300-499

- 500-749

- 750-999

- $1000+$

- Not stated

- Participant Focus

In observations, who is the focus?

In surveys, who is answering?

- Teachers

- Students

- Parents

- School Leaders

- District administrators

- Learning designers

- Government officials

- Year Level

Year level of students where mentioned.

Choose as many as appropriate. Choose â $€^{\sim}$ Unclear/Secondary' where specific year levels not mentioned.

- Unclear/Secondary

- Year 7

- Year 8

- Year 9

- Year 10

- Year 11

- Year 12

- Year 13

- Student variables

- SEND students

Special educational needs and disabilities

- Migrants/Refugees

- Low-income background

Where the information is given explicitly that lower-income students are included, please indicate this and feel free to code text that provides further information about them here.

- Low attainment

○ Gender

- Males

- Females

- Other or not disclosed 
- Our research questions

- RQ1. Student motivation/engagement

In what ways did emergency remote education affect motivation and engagement in secondary students?

- RQ2. Online assessment

How did research report on emerging online assessment practices in secondary schooling during the pandemic?

- RQ3. Peer collaboration

Are new approaches to peer collaboration emerging and what does this suggest?

- RQ4. Parent engagement

How does online learning in secondary schools support parent engagement?

- Intervention

- Technology Types Used

- Synchronous collaboration tools

Audio-Video conferencing (e.g., Zoom)

Collaborative writing tools (e.g., Google Docs)

- Video conferencing (unknown)

- Zoom

- Teams

- Webex

- Skype

- Google Meet

- Google Docs

- Tencent Meeting

- Explain Everything

- Jitsi

- Google Workspace for Education

Google Workspace for Education Fundamentals (Formerly known as $G$ Suite for Education) Â.

- Any video conferencing

- Multimodal production tools

Animations

Tutorials Recorded lectures Videos Podcast/Vodcast Screencast Authoring tools Voice recorder

- Videos (teacher made)

- Videos (made by others)

- Videos (uncertain origin)

- Khan Academy

- YouTube

- Oak Academy

- BBC Bitesize

- Twinkl

- Movie Maker

- Edpuzzle

- Podcasts

- Scratch

- Zmaker

- Autodesk SketchBook

- FastStone Capture

- TEDEd

- Gleerups 
- URPlay

- Screencastify

- Flipgrid

- PowToon

- Alcody

- Sonometer app

- Macromedia Flash

- Studio (Canvas)

- Oak Academy

- Knowledge organisation \& sharing

LMS (e.g., Google Classroom)

Cloud storage Bookmarking Diary tool in Moodle

- Other LMS

- Google Classroom

- Edmodo

- Class Dojo

- Moodle

- Blackboard

- Daymap

- Schoology

- Aula

- Cloud storage (e.g., Google Drive)

- Dropbox

- Google Drive

- SLearning platform

- PlayPosit

- Seesaw

- Microsoft 365

- Bingel

- Gsuite

- Showbie

- WebAssign

- Padlet

- MeisterTask

- Compass

- EduPage

- ItsLearning

- Canvas

- OneNote

- Text-based tools

Discussion forums

Readings Newsletter Text RSS Interactive textbook Annotation tools Email Chat Instant messaging Wikis

- Discussion forums

- Email

- Chat/Messaging (unknown)

- WhatsApp

- DingTalk (Alibaba)

- WeChat

- CCTalk

- Chaoxing 
- Google Slide Deck

- PowerPoint

- School website

- Interactive eBook

- iBooks

- International Children's Digital Library

- Word

- Excel

- Telegram

- Jabber

- GroupMe

- Social networking tools

Social platforms (e.g., Facebook)

Microblogging (e.g., Twitter)

- Facebook

- Twitter

- Social media

- Social networks

- DingDing

- Instagram

- Snapchat

- Assessment tools

eAssessment

Quizzes ARS Open badges Online exams

- Self-assessment quizzes

- Socrative

- Kahoot

- Google Forms

- Formative

- Microsoft Forms

- In-built tests and assignments (within LMS)

- Learning games

- Computer games

- Paragraph Punch https://paragraphpunch.com/

- Video games

- Sumdog https://pages.sumdog.com/

- Spelling City https://www.spellingcity.com/

- Codecombat

- TT Rockstars

- Education Perfect

- Hegarty Maths

- Non-tech printed materials

- MOOCs

- Textbooks and printed materials

- MOOCs

- Website creation tools

Blogs

ePortfolios 


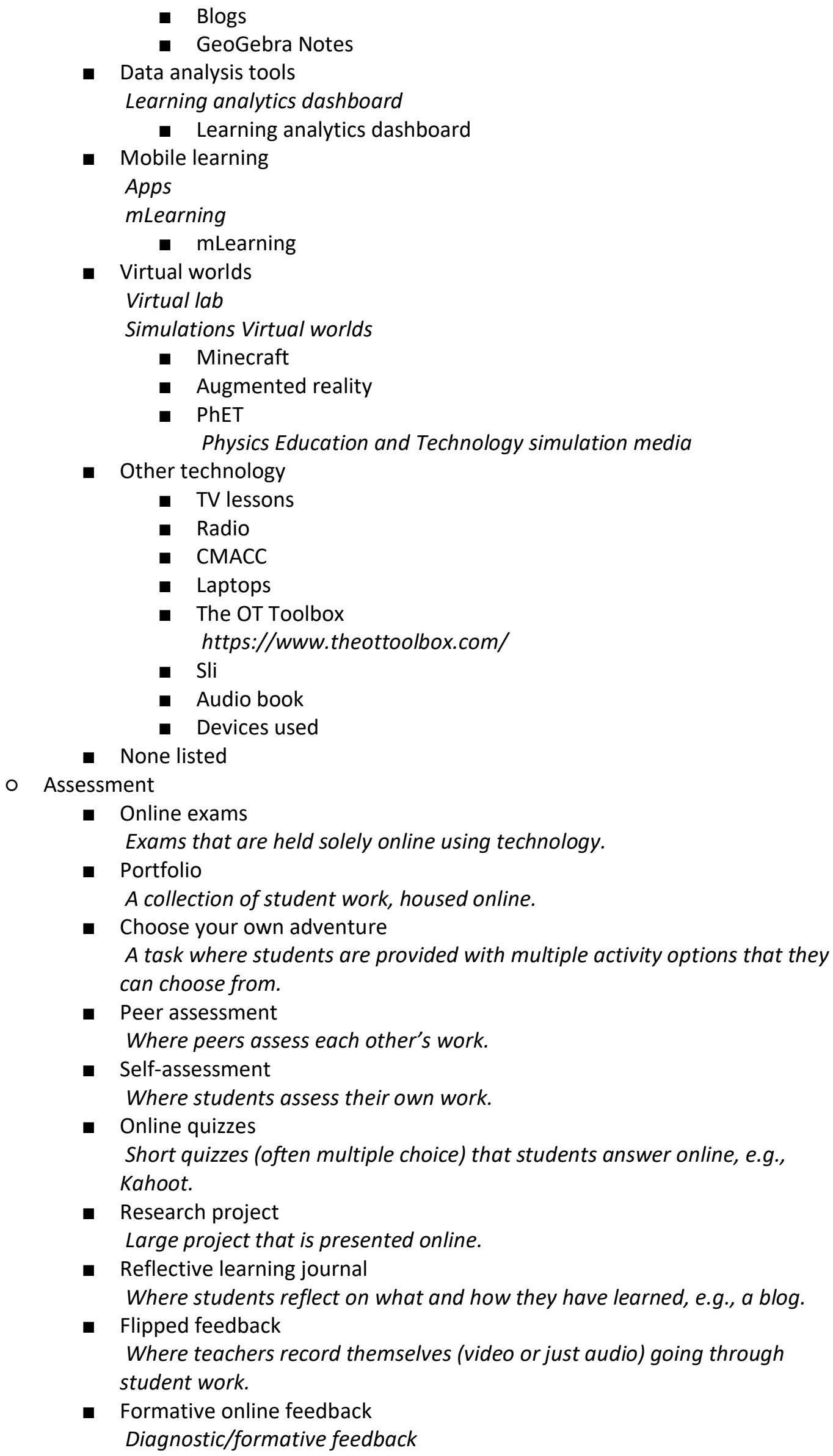

- None listed

○ Assessment

- Online exams

Exams that are held solely online using technology.

- Portfolio

A collection of student work, housed online.

- Choose your own adventure

A task where students are provided with multiple activity options that they can choose from.

- Peer assessment

Where peers assess each other's work.

- Self-assessment

Where students assess their own work.

- Online quizzes

Short quizzes (often multiple choice) that students answer online, e.g., Kahoot.

- Research project Large project that is presented online.

- Reflective learning journal Where students reflect on what and how they have learned, e.g., a blog.

- Flipped feedback Where teachers record themselves (video or just audio) going through student work.

- Formative online feedback Diagnostic/formative feedback 
- Assessment submission

How students are submitting work

- No assessment allowed

- Worksheets

- Conversations/Speaking assessment

- Video project makers

- Images

Students send a photo of their work

- Project-based (not research)

- Checklists

- General challenges with conducting assessment

- Online debate

- Providing exemplars of student work

- Videos

- Live marking

- Differentiation

- At home experiments

- Pedagogical approaches

- Flipped learning

Where students learn through watching videos (either teacher made or made by other educators) in their own time, and then apply concepts learned in the group space.

An example is the Weinhandl (2021) study in this review.

- Collaborative learning

Where students undertake learning activities in pairs or in groups, in order to achieve learning outcomes.

- Self-directed learning

Independent learning. Students take responsibility for what to learn, when and how. It could include selection of topic, resources, mode of assessment. An example would be where students have to undertake a research project, where the topic and design of the task, as well as pacing of work undertaken, is completely up to them. Creating ePortfolios are often examples of selfdirected/self-regulated learning (see Weinhandl 2021).

- Inquiry-based learning

- Teacher professional development Not a pedagogical approach per se, but related

- Outcomes

○ Student

- Positive/Increased Motivation

Evidence of students being motivated, e.g., "94.4\% considered that Alcody motivated them to learn how to program even during the COVID-19 pandemic when they were at home using Alcody online"

- Negative motivation/demotivation

Evidence of students being demotivated, e.g., e.g., some parents were concerned that their children seemed to lack motivation and were easily distracted .[...]Not putting in effort as they think no one else is. Not taking learning at home seriously. [...]They don't want to. It's such a struggle.

- Positive overall engagement

Where a study has measured engagement generically, without specifying exactly what aspect of engagement they're focused on, e.g., "Online learning is more engaging, $M=4.0^{\prime \prime}$ 
- Disengagement

Where a study has measured disengagement generically, without specifying exactly what aspect of disengagement they're focused on (which should be coded underneath the individual domains, e.g., Cognitive Disengagement)

- Learning gains

Where students have increased the amount of learning, e.g., "It is clear that students learned a lot about preventive health care and SARS-CoV-2, with more than $70 \%$ of students responding e.g., agree and e.g., strongly agree. The number for sustainable development knowledge was around $50 \%$.

- Learning loss

Where a study has indicated less learning somehow, or where learning loss has been measured in absolute terms, e.g., "e.g., They learned, but less than they would have in school $51.11 \%$ according to teachers"

"These barriers resulted in 7 out of 10 students indicating that grades in their classes dropped during online learning in the spring."

- Better for males

- Better for females

- Worse for males

- Worse for females

- No significant differences found based on gender

○ Parent engagement

- Parental involvement \& engagement with learning Examples of parents being involved or engaged with their child's learning. Can also be examples of difficulties in parents engaging.

- Relationships Evidence of relationship building with the school community (parents, teachers etc), or difficulties in relationship building.

- Communication Home-school communication, preferably about how schools communicate with parents using specific technology.

- Attitude towards learning Evidence of parent attitudes towards learning or activities.

- Self-efficacy (as educator) Evidence of parent opinions about themselves as an educator (as a direct result of online/blended learning).

- ICT skills \& knowledge Evidence around parent ICT skills \& knowledge.

○ Peers

- Collaborating with peers

Evidence of importance of peer interaction, or how collaboration was facilitated through technology.

- Co-creating learning materials

Specific collaboration between students to create something together, e.g., lesson notes, revision guide, presentation.

○ Learning environment \& technology

- Access to technology Impact of internet or device access on students' learning, engagement or motivation.

- Usability How the ability to use technology affected learning, e.g., accessibility, design. 
- Internet connection

- Design

How the design/pacing of activities affected learning and/or engagement.

- Content length

Impact of

- Video length - Activity length

- Feedback

- What students thought of how feedback was given.

- How did specific types of online feedback affect learning and/or student/parent engagement?

o Cognitive engagement

- Critical thinking

The process of actively conceptualising, applying, analysing, synthesising, and/or evaluating information.

- Setting learning goals Students setting learning goals for themselves/working to achieve a certain level.

- Understanding Students develop greater understanding of learning material, or of how to perform certain tasks.

- Reflection Student reflection on their own learning/knowledge, learning processes or skills.

- Focus/concentration Improved/enhanced ability to focus or concentrate.

- Deep learning Students learn concepts to a deeper level (not just surface level understanding) and retain the information.

- Learning from peers Students learn from other students.

- Follow through/care/thoroughness Students show particular care in their work, or ensure completion to a high standard. They finish what they start.

- Preference for challenging tasks Students choose to complete work of a higher level, or challenge themselves to work to a higher standard.

- Teaching self and peers Students take initiative to teach themselves and/or other students new concepts.

- Positive perceptions of teacher support Students find teacher feedback, teaching, and/or support good.

- Self-regulation Students manage aspects of their own learning, without being asked to do so. Students monitor their own thinking and make their own decisions as they're engaged in learning activities.

- Positive self perceptions/self-efficacy

Students acknowledge their skills or knowledge have improved, or see that they have accomplished something.

o Affective engagement 
- Enthusiasm

Students show enthusiasm about something (intense and eager enjoyment, interest or approval)" code this if the word enthusiastic or enthusiasm is used.

- Satisfaction

Students are satisfied with something to do with their learning (activities/assignments, teaching, online learning, technology etc).

- Curiosity

Evidence of a desire to know or learn something.

- Sense of connectedness

Students feel connected to or at home among their classmates.

- Positive attitude towards learning

Students display a positive approach towards learning.

- Sees relevance

Students can relate what they learn to real life/to their own lives, or they see the reason for learning something in a particular way.

- Feeling appreciated

Students feel appreciated for the work they do or the role they have played in the class.

- Pride

Students feel proud of their skills or knowledge, or of any other aspect relating to their learning.

- Excitement

Students are excited about their learning.

- Enjoyment

Students enjoy an aspect of their learning (e.g., the teaching method used, the activities)

- Positive interactions with peers

Working well with other students.

- Positive interactions with teachers

Positive communication, interaction and/or connection between students and their teacher/s.

- Interest

Students show interest in their learning/activities/teaching method etc.

- Sense of wellbeing

Students feel comfortable and happy with their learning and/or within their learning environment.

○ Behavioural engagement

- Effort

Students expend effort in their learning, e.g., doing extra work, watching videos multiple times.

- Study habits

Students talk positively about studying/doing homework.

- Attending live lessons

Positive attendance to live lessons (any synchronous activities - conference calls, collaborative writing etc).

- Increased interaction with peers Increased interaction and collaboration with fellow students.

- Increased interaction with teachers Increased interaction with teachers through activities, feedback, online lessons and so on. 
- Homework completion

Students complete set homework/activities, e.g., watching videos.

- Positive conduct

Students behave and do the right thing (e.g., in online lessons).

- Participation/involvement

Students participate or get more involved in their learning somehow.

- Asking teacher or peers for help

Students ask the teacher or peers for help.

e.g., For example, they were more willing to ask for help and contribute key mathematical ideas rather than wait for these to be provided during a homework review.

- Assuming responsibility

Students take responsibility for their learning and/or behaviour.

e.g., Many students explained that the flipped classroom required that they assume more responsibility for their own learning, especially outside of the classroom. Lucas talked about this external classroom experience: You actually have to be an adult. You have to self-teach yourself. You have to watch stuff at home. You have to do your work. You need to stay on top to make sure you continuously grow as a student.

- Confidence Students display increased confidence in an aspect of their learning, e.g., asking questions, undertaking/completing activities.

- Amount of time studying/Time on task Increased time on task (when completing activities).

- Unwilling

Students resist or are unwilling to complete tasks or participate in live lessons for example.

e.g., Interview of the students who participated in the flipped classroom approach indicates that the biggest issue that was found related to students acceptance of the format. Students were resistant at first to the concept of having to watch videos and do work at home which were new to them.

- Apathy

Students are apathetic towards learning activities and-or online learning in general. Lack of interest, enthusiasm, or concern.

- Helpless

Students feel unable to act without help.

e.g., Can it be more complicated to control my avatar? Someone please give me a hand

- Opposition/rejection

Students flat out refuse to do something or are completely against online learning, for example.

- Avoidance

Students avoid completing activities and/or doing things that might be difficult.

- Pressured/stressed Students feel stressed or pressured as a result of their learning/technology etc.

- Unfocused/inattentive Students cannot concentrate on activities or in live lessons. 
e.g., students reported that staying focused when watching videos was a challenge. "I cannot focus on watching videos, not even 2 minutes"

- Distracted

Students are distracted by things other than their learning.

"Sometimes when I am doing the pre-learning on my mobile phone, there are messages popping up frequently at the top of the screen and I have to reply"

- Confusion

- Affective disengagement

- Boredom

Students express boredom around some aspect of their learning.

Student A (Traditional): e.g., Sometimes the PowerPoint presentations were boring and unclear.

- Anger

Students are angry about some aspect of their learning and/or the technology they have to use.

- Dislike

Students dislike an aspect of their learning, e.g., the activities, the technology used, online learning in general.

- Disinterest

Students have lost interest in their learning.

- Dissatisfaction

Students are dissatisfied about some aspect of their learning.

e.g., a minority of students expressed strong opinions that they did not enjoy working as a pair and some of these reported that their partners did not equitably contribute to the workload

- Disappointment

Students are disappointed about an aspect of their learning, e.g., grades, interaction.

e.g., ... miss out on discussions and explanations on certain topics. ...

- Frustration

Students are frustrated about an aspect of their learning.

e.g., Students shared it was frustrating when there was no one around to answer questions.

- Worry/anxiety

Students are worried or anxious about an aspect of their learning.

e.g., Taking control of their learning was an attribute that caused anxiety amongst the student-participants. The fear of not being able to immediately ask questions and having to delve into the content in order to gain understanding was evident in the journals compiled by the participantresearcher for the first couple of days.

- Overwhelmed Students are overwhelmed by an aspect of their learning, e.g., using different technology, the amount of work to complete.

- Lack of confidence Students are not confident about an aspect of their learning, e.g., talking in online lessons.

- Negative or no interaction with teachers

- Procrastination

Students put off doing work or procrastinate in some way. 
e.g., At first, if I had a lot of homework, I would put off the videos thinking I would just get the information in class then next day

- Half-hearted

Doing tasks in a half-hearted manner, not doing them to the best of a student's ability.

e.g., Many students identified that a lack of personal effort was the root of a stagnant learning.

- Absent

Students do not attend scheduled classes.

e.g., In a survey completed by $81 \%$ of students registered for the manufacturing processes course, 35\% reported not attending all the lectures. However, only $10 \%$ suggested that this was due to the podcast availability.

- Giving up

Students give up, e.g., on completing homework/activities, or watching videos.

- Burned out/exhausted

Students are exhausted as a result of their learning.

- Poor conduct

Students misbehaving.

e.g., Higher instances of off-task behaviour were observed in the flipped classroom. Discussion with the teacher and class observations revealed instances of students listening to music on YouTube when the expectation was to be working.

- Unprepared Not being prepared for learning (e.g., live lesson) or assessment (e.g., exam).

e.g., in the first few days of the first week, there were several students unprepared for the class time and had difficulty in joining the group discussion and activities in class.

- Task incompletion Not completing work set by the teacher. e.g., One of the biggest problems we have encountered is students not watching the video at home.

○ Social disengagement

- Social isolation Isolated due to covid restrictions, lockdown, school closure

- Decreased teacher-student interaction 
Appendix B - Studies included in the review

\begin{tabular}{|c|c|c|c|c|c|c|c|c|}
\hline Author & Year & Continent & Country & Subject & $\begin{array}{l}\text { Participant } \\
\text { focus }\end{array}$ & Participant \# & Year levels & Technology types used \\
\hline Agustin et al. & 2020 & Asia & Indonesia & - & $S$ & 33 & 10 & TBT \\
\hline Al Salman et al. & 2021 & Middle East & Jordan & - & $S$ & 720 & - & - \\
\hline Aldossry & 2021 & Middle East & Saudi Arabia & - & $\mathrm{T}$ & 3 & - & SCT,MPT, KOS, AT \\
\hline Almarashdi \& Jarrah & 2021 & Middle East & UAE & Maths & $S$ & 580 & $9-12$ & KOS \\
\hline Álvarez-Guerrero et al. & 2021 & Europe & Spain & Literacy & $S, T$ & 5 & - & SCT, Other \\
\hline Amelia et al. & 2020 & Asia & Indonesia & Maths & $S, T$ & 10 & 7 & SCT, KOS, TBT, AT \\
\hline Ang \& Wu & 2021 & Asia & China & - & $S, T$ & 411 & - & SCT, MPT, TBT \\
\hline Asanov et al. & 2021 & South America & Ecuador & - & $S$ & 1500 & $10-12$ & SCT, MPT, KOS, TBT, print \\
\hline Asvial et al. & 2021 & Asia & Indonesia & - & $S$ & 50 & - & - \\
\hline Atmojo \& Nugroho & 2020 & Asia & Indonesia & ESL/EFL & $\mathrm{T}$ & 16 & - & SCT, MPT, KOS, TBT, AT \\
\hline Azhari \& Fajri & 2021 & Asia & Indonesia & - & $\mathrm{T}$ & 353 & - & $\mathrm{SCT}, \mathrm{MPT}, \mathrm{KOS}, \mathrm{TBT}$, Other \\
\hline
\end{tabular}




\begin{tabular}{|c|c|c|c|c|c|c|c|c|}
\hline Author & Year & Continent & Country & Subject & $\begin{array}{l}\text { Participant } \\
\text { focus }\end{array}$ & Participant \# & Year levels & Technology types used \\
\hline Babincakova \& Bernard & 2020 & Europe & Slovakia & Chemistry & $S, T$ & 95 & - & SCT, MPT \\
\hline Balkist \& Agustiani & 2020 & Asia & Indonesia & Maths & $\mathrm{s}$ & 3 & 10 & SCT \\
\hline Baptista et al. & 2020 & Europe & Portugal & $\begin{array}{l}\text { Engineering, } \\
\text { Science, Maths, } \\
\text { ICT, Physics }\end{array}$ & $\mathrm{T}$ & 4 & 8 & SCT, MPT, KOS, TBT, SNT \\
\hline Becker et al. & 2020 & North America & USA & - & $S, P$ & 238 & $9-11$ & SCT, MPT, print \\
\hline Bhattarai & 2020 & Asia & Nepal & ESL/EFL & $\mathrm{T}$ & 2 & - & SCT \\
\hline Bhaumik \& Priyadarshini & 2020 & Asia & India & - & $\mathrm{s}$ & 74 & 11,12 & \\
\hline Bruin & 2020 & Oceania & Australia & Music & $\mathrm{T}$ & 15 & - & SCT \\
\hline Budianto \& Arifani & 2021 & Asia & Indonesia & ESL/EFL & $\mathrm{S}, \mathrm{T}$ & 317 & - & TBT \\
\hline Cheung & 2021 & Asia & Hong Kong & ESL/EFL & $\mathrm{T}$ & 1 & - & $S C T, T B T, A T$ \\
\hline Chirinda et al. & 2021 & Africa & South Africa & Maths & $\mathrm{T}$ & 23 & 12 & SCT, MPT, KOS, TBT, SNT \\
\hline Chiu & 2021 & Asia & Hong Kong & - & $\mathrm{s}$ & 1201 & 8,9 & SCT \\
\hline Chiu & 2021 & Asia & Hong Kong & - & $\mathrm{S}, \mathrm{T}$ & 54 & - & \\
\hline
\end{tabular}




\begin{tabular}{|c|c|c|c|c|c|c|c|c|}
\hline Author & Year & Continent & Country & Subject & $\begin{array}{l}\text { Participant } \\
\text { focus }\end{array}$ & Participant \# & Year levels & Technology types used \\
\hline Clausen et al. & 2020 & North America & USA & - & $\mathrm{T}$ & 44 & $7-12$ & SCT, MPT, KOS, Other \\
\hline Code et al. & 2020 & North America & Canada & Technology & $\mathrm{T}$ & 42 & - & - \\
\hline Dema et al. & 2021 & Asia & Bhutan & - & $\mathrm{s}$ & 200 & - & - \\
\hline Dietrich et al. & 2020 & Europe & Germany & - & $\mathrm{s}$ & 1735 & - & - \\
\hline Dorii & 2021 & Asia & Bhutan & - & $S, T, P$ & 40 & 9,11 & KOS \\
\hline Easterly et al. & 2021 & North America & USA & Agriculture & $\mathrm{T}$ & 4 & - & SCT, KOS, TBT, print \\
\hline Education Scotland & 2021 & Europe & UK (Scotland) & - & $S, T, P, S L$ & - & - & SCT, MPT, KOS, TBT, AT, DAT \\
\hline El lq Bali \& Mursrifah & 2020 & Asia & Indonesia & $\mathrm{RE}$ & $\mathrm{T}$ & 1 & 11 & TBT \\
\hline Ferraro et al. & 2020 & Europe & Italy & - & $\mathrm{s}$ & 83 & - & SCT \\
\hline Gordy et al. & 2021 & North America & USA & Science & $\mathrm{T}$ & 11 & - & SCT, MPT, KOS, print \\
\hline Hira \& Anderson & 2021 & North America & USA & - & $\mathrm{T}$ & 11 & - & - \\
\hline Hodgen et al. & 2020 & Europe & UK & Maths & SL & 49 & 7,8 & SCT, MPT, KOS, TBT, LG \\
\hline
\end{tabular}




\begin{tabular}{|c|c|c|c|c|c|c|c|c|}
\hline Author & Year & Continent & Country & Subject & $\begin{array}{l}\text { Participant } \\
\text { focus }\end{array}$ & Participant \# & Year levels & Technology types used \\
\hline Hu \& Huang & 2021 & Oceania & Australia & ESL/EFL & $\mathrm{s}$ & 30 & 10 & SCT, AT \\
\hline Jayathirtha et al. & 2020 & North America & USA & ICT & $\mathrm{S}, \mathrm{T}$ & 38 & - & SCT, MPT, TBT \\
\hline Jeong \& So & 2020 & Asia & South Korea & $\mathrm{PE}$ & $\mathrm{T}$ & 6 & - & SCT, MPT, TBT \\
\hline Kaden & 2020 & North America & USA & Maths, Science & $\mathrm{T}$ & 1 & - & SCT, MPT, KOS, AT, print \\
\hline Kelley & 2020 & North America & USA & Chemistry & S & 59 & - & SCT, KOS, AT, print \\
\hline Kochan & 2021 & Europe & Poland & - & $\mathrm{s}$ & 114 & - & SCT, TBT \\
\hline Korzycka et al. & 2021 & Europe & Poland & - & $\mathrm{s}$ & 2408 & - & - \\
\hline Lansangan & 2020 & Asia & Philippines & Chemistry & $\mathrm{T}$ & 1 & 9 & MPT, KOS, SNT \\
\hline Lawrence \& Fakuade & 2021 & Africa & Nigeria & - & $\mathrm{s}$ & 1407 & - & MPT, KOS, TBT, SNT \\
\hline Lepp et al. & 2021 & Europe & Estonia & $\begin{array}{c}\text { Biology, Science, } \\
\text { Chemistry, } \\
\text { Physics, } \\
\text { Geography }\end{array}$ & $\mathrm{T}$ & 16 & - & SCT, MPT, KOS \\
\hline Mælan et al. & 2021 & Europe & Norway & - & $\mathrm{s}$ & 1755 & $8-10$ & \\
\hline
\end{tabular}




\begin{tabular}{|c|c|c|c|c|c|c|c|c|}
\hline Author & Year & Continent & Country & Subject & $\begin{array}{l}\text { Participant } \\
\text { focus }\end{array}$ & Participant \# & Year levels & Technology types used \\
\hline Makamure \& Tsakeni & 2020 & Africa & Zimbabwe & $\begin{array}{c}\text { Maths, Biology, } \\
\text { Physics, } \\
\text { Chemistry }\end{array}$ & $\mathrm{T}$ & 5 & 10,11 & SCT, KOS, TBT \\
\hline Nawawi et al. & 2021 & Asia & Indonesia & Biology & $\mathrm{s}$ & 361 & $10-12$ & SCT, MPT, KOS, TBT, AT \\
\hline Niemi \& Kousa & 2020 & Europe & Finland & - & $S, T, S L$ & 309 & - & SCT, KOS, TBT, AT \\
\hline Nugraha et al. & 2021 & Asia & Indonesia & ESL/EFL & $\mathrm{s}$ & 23 & - & SCT, MPT, KOS, TBT \\
\hline Nurliani et al. & 2021 & Asia & Indonesia & Physics & $S, T$ & 71 & - & KOS, TBT, SNT \\
\hline Nusser & 2021 & Europe & Germany & - & $S, P$ & 1452 & - & \\
\hline Okebukola et al. & 2020 & Africa & $\begin{array}{c}\text { Nigeria, Ghana, } \\
\text { Senegal, } \\
\text { Burundi, } \\
\text { Morocco }\end{array}$ & Chemistry & $\mathrm{T}$ & - & 12 & SCT, MPT, KOS, TBT, SNT, Other \\
\hline Oraif \& Elyas & 2021 & Middle East & Saudi Arabia & ESL/EFL & $\mathrm{s}$ & 379 & $10-12$ & KOS \\
\hline Pelikan et al. & 2021 & Europe & Austria & - & $\mathrm{s}$ & 2652 & - & - \\
\hline Pirrone et al. & 2021 & Europe & Italy & - & $\mathrm{s}$ & 324 & $\begin{array}{c}14-19 \text { years } \\
\text { old }\end{array}$ & \\
\hline
\end{tabular}




\begin{tabular}{|c|c|c|c|c|c|c|c|c|}
\hline Author & Year & Continent & Country & Subject & $\begin{array}{l}\text { Participant } \\
\text { focus }\end{array}$ & Participant \# & Year levels & Technology types used \\
\hline Poláková \& Klímová & 2021 & Europe & Slovakia & - & S & 72 & $\begin{array}{l}15 \text { - } 19 \text { year } \\
\text { old }\end{array}$ & SCT, KOS \\
\hline Primdahl et al. & 2020 & Europe & Denmark & - & $\mathrm{T}$ & 8 & - & SCT, KOS, TBT, SNT \\
\hline Rahayu \& Wirza & 2020 & Asia & Indonesia & ESL/EFL & $\mathrm{T}$ & 102 & - & SCT, KOS, TBT, AT \\
\hline Rap et al. & 2020 & Middle East & Israel & Chemistry & $\mathrm{T}$ & 193 & - & SCT, MPT, KOS, TBT \\
\hline Rosayanti \& Hardiana & 2021 & Asia & Indonesia & ESL/EFL & $S, T$ & 66 & - & - \\
\hline Rusmansyah et al. & 2021 & Asia & Indonesia & Maths, Science & S & - & 11 & SCT, KOS \\
\hline Schaefer et al. & 2020 & North America & USA & - & $S, P$ & 5 & $7,9,11$ & SCT, KOS, TBT \\
\hline Shidiq et al. & 2021 & Asia & Indonesia & Chemistry & $\mathrm{T}$ & 55 & - & SCT, MPT, KOS, TBT, VW \\
\hline Sibanda \& Mathwasa & 2021 & Africa & Zimbabwe & - & $S, T$ & 24 & - & TBT \\
\hline Simanjuntak et al. & 2021 & Asia & Indonesia & ESL/EFL & $\mathrm{s}$ & 72 & 11 & MPT \\
\hline Suliani et al. & 2021 & Asia & Indonesia & Maths & $S, T$ & 18 & 10 & AT \\
\hline
\end{tabular}




\begin{tabular}{|c|c|c|c|c|c|c|c|c|}
\hline Author & Year & Continent & Country & Subject & $\begin{array}{l}\text { Participant } \\
\text { focus }\end{array}$ & Participant \# & Year levels & Technology types used \\
\hline$\underline{\text { Suryana et al. }}$ & 2021 & Asia & Indonesia & $\begin{array}{l}\text { ESL/EFL, German, } \\
\text { Indonesian, } \\
\text { Arabic }\end{array}$ & $\mathrm{T}$ & 4 & $10-12$ & TBT \\
\hline Tong \& Wang & 2020 & Asia & China & ESL/EFL & $\mathrm{s}$ & 229 & $\begin{array}{c}14-15 \text { years } \\
\text { old }\end{array}$ & MPT \\
\hline Tran et al. & 2020 & Asia & Vietnam & - & $\mathrm{s}$ & 420 & - & - \\
\hline Trung et al. & 2020 & Asia & Vietnam & - & $\mathrm{s}$ & 460 & $7-12$ & - \\
\hline Turchi et al. & 2020 & North America & USA & English & $\mathrm{T}$ & 3 & $9-12$ & SCT, MPT, KOS, TBT \\
\hline Velichová et al. & 2020 & Europe & Slovakia & - & $\mathrm{s}$ & 2824 & $10-13$ & SCT, KOS, AT, Other \\
\hline Weinhandl et al. & 2021 & Europe & Austria & Maths & $S, T$ & 42 & 10,11 & SCT, MPT, WCT \\
\hline Willermark & 2021 & Europe & Sweden & - & $\mathrm{T}, \mathrm{SL}$ & 331 & - & SCT \\
\hline Yan et al. & 2020 & Asia & China & ESL/EFL & $\mathrm{s}$ & 287 & - & - \\
\hline Yan & 2021 & North America & USA & $\begin{array}{c}\text { History, PE, } \\
\text { Dance, Chinese }\end{array}$ & $\mathrm{s}$ & 1 & - & SCT, MPT, KOS, TBT, AT \\
\hline Yang et al. & 2020 & Asia & China & ESL/EFL & $\mathrm{s}$ & 287 & - & - \\
\hline
\end{tabular}




\begin{tabular}{|l|c|c|c|c|c|c|c|c|}
\hline \multicolumn{1}{|c|}{ Author } & Year & Continent & Country & Subject & $\begin{array}{c}\text { Participant } \\
\text { focus }\end{array}$ & Participant \# & Year levels & Technology types used \\
\hline Yates et al. & 2020 & Oceania & New Zealand & - & $\mathrm{S}$ & 1975 & 12,13 & SCT, MPT, KOS, TBT, SNT, AT, LG \\
\hline Zasko \& Agung & 2021 & Asia & Indonesia & - & $\mathrm{S}$ & 558 & - & TBT, print \\
\hline Zorčič & 2020 & Europe & Austria & - & $\mathrm{T}$ & 43 & - & MPT, print \\
\hline
\end{tabular}


Appendix C - Educational technology tool typology (based on Bower, 2016)

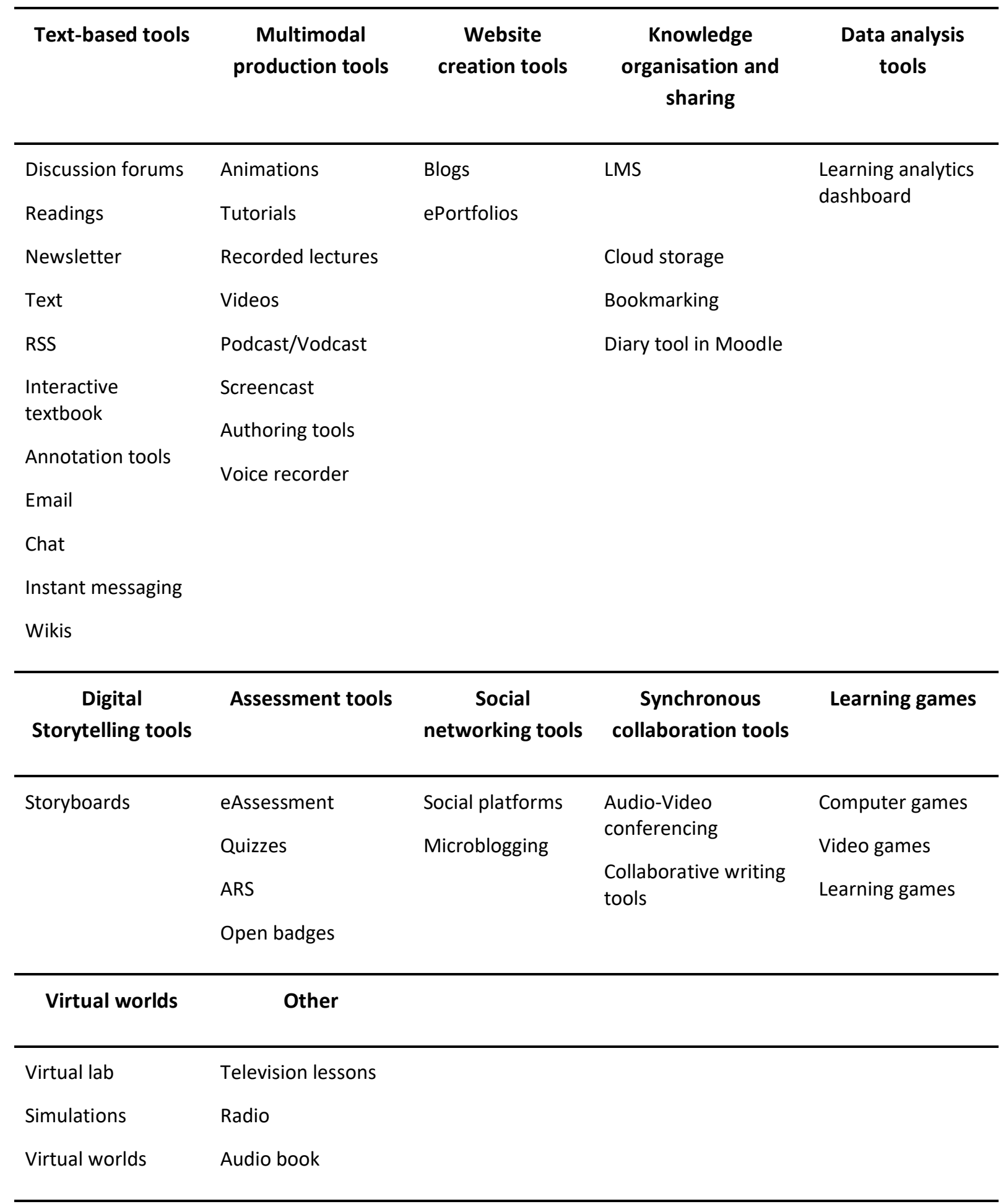




\section{Appendix D - Quality assessment tool}

This tool is designed as a checklist to indicate whether there are any reasons why the evidence claim is not relevant or trustworthy and so not to be relied upon in your synthesis of research evidence. The aim is to record those concerns and to provide a judgment for each of the 2 questions below. It is not necessary to score items for where there is no concern about the basis of the evidence claim and its use in your synthesis.

- Does this study answer our research questions?

Think about topic, method etc.
○ Yes
o No
- Partly
- Unclear

- Is the evidence trustworthy, given the method that was used?

Please write concerns in the INFO box. Do the authors make claims that are relevant to us?
o Yes
o No
- Partly
o Unclear 
Appendix E - Items by source

\begin{tabular}{|c|c|c|c|c|}
\hline Date of search & Database & Number of Items & Duplicates & Total for screening \\
\hline 5 May 2021 & Web of Science & 782 & 157 & 625 \\
\hline 5 May 2021 & ERIC & 2379 & 21 & 2358 \\
\hline 5 May 2021 & Scopus & 1697 & 584 & 1113 \\
\hline Previous reviews & Bond (2020b) & 78 & 0 & 78 \\
\hline Previous reviews & Bond (2021) & 325 & 0 & 325 \\
\hline 13 May 2021 & Web of Science & 6 & 2 & 4 \\
\hline 16 May 2021 & MAG & 1000 & 24 & 976 \\
\hline May-June 2021 & Grey literature & 4 & 0 & 4 \\
\hline May-June 2021 & ResearchGate & 2 & 0 & 2 \\
\hline
\end{tabular}


Appendix F - Countries where research was undertaken

\begin{tabular}{|c|c|c|c|}
\hline Country & Wealth Status & Number * & Percentage of studies \\
\hline Indonesia & LMIC & 19 & $24 \%$ \\
\hline USA & HIC & 11 & $14 \%$ \\
\hline China & UMIC & 4 & $5 \%$ \\
\hline Slovakia & HIC & 3 & $4 \%$ \\
\hline Austria & HIC & 3 & $4 \%$ \\
\hline Hong Kong & HIC & 3 & $4 \%$ \\
\hline Australia & HIC & 2 & $3 \%$ \\
\hline Germany & HIC & 2 & $3 \%$ \\
\hline Italy & HIC & 2 & $3 \%$ \\
\hline Nigeria & LMIC & 2 & $3 \%$ \\
\hline Poland & HIC & 2 & $3 \%$ \\
\hline Saudi Arabia & $\mathrm{HIC}$ & 2 & $3 \%$ \\
\hline UK & HIC & 2 & $3 \%$ \\
\hline Vietnam & LMIC & 2 & $3 \%$ \\
\hline Zimbabwe & LIC & 2 & $3 \%$ \\
\hline Bhutan & LMIC & 2 & $3 \%$ \\
\hline Burundi & LMIC & 1 & $1 \%$ \\
\hline Canada & $\mathrm{HIC}$ & 1 & $1 \%$ \\
\hline Denmark & $\mathrm{HIC}$ & 1 & $1 \%$ \\
\hline Ecuador & UMIC & 1 & $1 \%$ \\
\hline Finland & HIC & 1 & $1 \%$ \\
\hline Ghana & LMIC & 1 & $1 \%$ \\
\hline India & LMIC & 1 & $1 \%$ \\
\hline Israel & HIC & 1 & $1 \%$ \\
\hline Jordan & UMIC & 1 & $1 \%$ \\
\hline Morocco & LMIC & 1 & $1 \%$ \\
\hline Nepal & LMIC & 1 & $1 \%$ \\
\hline New Zealand & HIC & 1 & $1 \%$ \\
\hline Norway & HIC & 1 & $1 \%$ \\
\hline
\end{tabular}




\begin{tabular}{|l|l|l|l|}
\hline Philippines & LMIC & 1 & $1 \%$ \\
\hline Portugal & HIC & 1 & $1 \%$ \\
\hline Senegal & UMIC & 1 & $1 \%$ \\
\hline South Africa & UMIC & 1 & $1 \%$ \\
\hline South Korea & HIC & 1 & $1 \%$ \\
\hline Spain & HIC & 1 & $1 \%$ \\
\hline Sweden & HIC & 1 & $1 \%$ \\
\hline UAE & HIC & 1 & $1 \%$ \\
\hline
\end{tabular}

* Some studies were conducted in more than one country. 


\section{Appendix G - Participant focus}

\begin{tabular}{|c|c|c|}
\hline Participant Focus & N Studies & N Studies [\%] \\
\hline Students only & 34 & $42 \%$ \\
\hline Teachers only & 27 & $33 \%$ \\
\hline Parents only & 0 & $0 \%$ \\
\hline School leaders only & 1 & $1 \%$ \\
\hline Students + teachers & 12 & $15 \%$ \\
\hline Students + parents & 3 & $4 \%$ \\
\hline Teachers + parents & 0 & $0 \%$ \\
\hline Parents + school leaders & 0 & $0 \%$ \\
\hline School leaders + teachers & 1 & $1 \%$ \\
\hline School leaders + students & 0 & $0 \%$ \\
\hline Students, teachers + school leaders & 1 & $1 \%$ \\
\hline Students, teachers + parents & 1 & $1 \%$ \\
\hline Students, teachers, parents + school leaders & 1 & $1 \%$ \\
\hline
\end{tabular}


Appendix $\mathrm{H}$ - Subjects

\begin{tabular}{|c|c|c|}
\hline Subject & N Studies & N Studies [\%] \\
\hline English as a Second/Foreign language & 14 & $17 \%$ \\
\hline Maths & 11 & $14 \%$ \\
\hline Chemistry & 8 & $10 \%$ \\
\hline Science & 5 & $6 \%$ \\
\hline Physics & 4 & $5 \%$ \\
\hline Biology & 3 & $4 \%$ \\
\hline ICT & 2 & $2 \%$ \\
\hline Physical Education & 2 & $2 \%$ \\
\hline English (first language) & 1 & $1 \%$ \\
\hline Engineering & 1 & $1 \%$ \\
\hline History & 1 & $1 \%$ \\
\hline Music & 1 & $1 \%$ \\
\hline Religious Education & 1 & $1 \%$ \\
\hline Dance & 1 & $1 \%$ \\
\hline Chinese as a second/foreign language & 1 & $1 \%$ \\
\hline German (second language) & 1 & $1 \%$ \\
\hline Indonesian (first language) & 1 & $1 \%$ \\
\hline Arabic & 1 & $1 \%$ \\
\hline Literacy & 1 & $1 \%$ \\
\hline
\end{tabular}


Technology

1

$1 \%$ 
Appendix I - Number of participants per study

\begin{tabular}{lcc}
\hline Number of participants & N studies & N studies [\%] \\
\hline $1-25$ & 27 & $33 \%$ \\
$26-50$ & $11 \%$ & $14 \%$ \\
$51-99$ & 8 & $10 \%$ \\
$100-299$ & 10 & $12 \%$ \\
$300-499$ & 3 & $4 \%$ \\
$500-749$ & 10 & $12 \%$ \\
$1000+$ & 3 & $4 \%$ \\
\hline
\end{tabular}


Appendix J - Data collection methods

Data Collection

(Online) survey

Interviews

Observation/Field notes

Documents

Focus group

Test (assessment)

Respondent diary
N Studies

53

33

10

10

6

3

3
N Studies [\%]

$65 \%$

$41 \%$

$12 \%$

$12 \%$

$7 \%$

$4 \%$

$4 \%$ 
Appendix K - Technology used

\begin{tabular}{|l|c|c|}
\hline Technology Type & N studies & \% \\
\hline Synchronous collaboration tools & 47 & $46 \%$ \\
\hline Knowledge organisation \& sharing & 37 & $43 \%$ \\
\hline Text-based tools & 35 & $38 \%$ \\
\hline Multimodal production tools & 31 & $19 \%$ \\
\hline Assessment tools & 15 & $10 \%$ \\
\hline Social networking tools & 8 & $6 \%$ \\
\hline Other technology & 5 & $2 \%$ \\
\hline Learning games & 2 & $1 \%$ \\
\hline Website creation tools & 1 & $1 \%$ \\
\hline Data analysis tools & 1 & $1 \%$ \\
\hline Virtual worlds & 1 & \\
\hline
\end{tabular}


International Public Policy Observatory (IPPO)

IPPO is an ESRC funded initiative to provide decision-makers in government at all levels with access to the best available global evidence on the social impacts of the COVID-19 pandemic, and the effectiveness of policy responses. IPPO is a collaboration between the Department of Science, Technology, Engineering and Public Policy (STEaPP) and the EPPI Centre at UCL; Cardiff University; Queen's University Belfast; the University of Auckland and the University of Oxford, together with think tanks including the International Network for Government Science (INGSA) and academic news publisher The Conversation.

\section{EPPI Centre}

Founded in 1996, the EPPI Centre is a specialist centre in the UCL Social Research Institute. It develops methods: (i) for the systematic reviewing and synthesis of research evidence; and (ii) for the study of the use research. As well as being directly involved in the academic study and the practice of research synthesis and research use, the centre provides accredited and short course training programmes in research synthesis and social policy and research.

\section{UCL Social Research Institute (SRI)}

The SRI (formerly the Department of Social Science) is one of the leading centres in the UK for multidisciplinary teaching and research in the social sciences. With more than 180 academic, research and professional staff, it works to advance knowledge and to inform policy in areas including gender, families, education, employment, migration, inequalities, health and child/adult wellbeing.

\section{First produced in 2021 by:}

International Public Policy Observatory

Department of Science, Technology, Engineering and Public Policy (STEaPP)

Shropshire House (4th Floor)

11-20 Capper Street

London WC1E 6JA

https://covidandsociety.com

Twitter: @covidandsociety

ISBN: 978-1-911605-26-3

Design and editorial support by: Lionel Openshaw

This document is available in a range of accessible formats including large print. Please contact the UCL Social Research Institute for assistance. 